\title{
MSTER
}

$x>723$ ORML-5173

\section{A Review of Analysis Methods for Prestressed Concrete Reactor Vessels}

\author{
W. G. Dodge \\ Z. P. Bazant \\ R. H. Gallagher
}

OAK RIDGE NATIONAL LABORATORY 


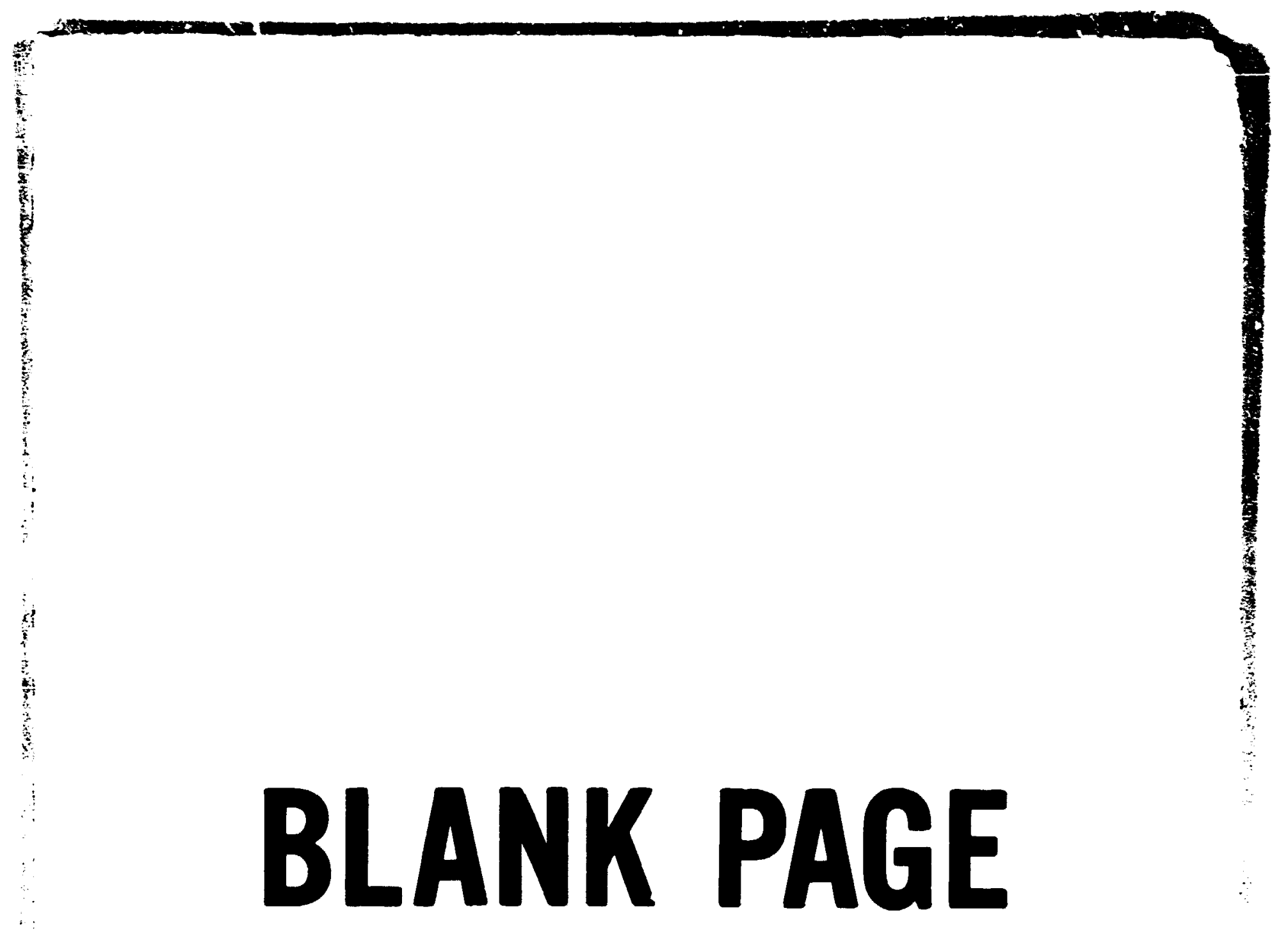

$\therefore$

(i) 
Printed in the Unitud States of America Availeble from National Technical Information Service

U.S. Departument of Commerce

5205 Port Royal Road, Springlield, Virginia 22161

Price. Printed Copy \$5.50. Microtiche \$3.00

Thus report was prepared as an account of wort sponsored by the United Stibes Government. Neither the Unibed Staves nor the Energy Aesearch and Development Adminustrationunived Stewes Nuclear Aeguletory Commission. nor any of thair employens. nor any of meir comrectors. subcontraciors. Or their employees. mates any warrenty. express or implied. or ascumes any legel lisebitity or responsibitity for the eccuracy. completeness or usefulnass oi any inlormation. spparalus, procuct or process disclosed, or represents that its use would not infrings prestety owned rights. 


\author{
oand-5173 \\ Dist - Category Uc:-77 \\ Gas-Cooled Reactor Technology
}

Contract No. U-7405-eng-26

Engineering Technology Division

HTGR BASE TECHEOLOGY PROGRAM

Prestressed Concrete Nuclear Pressure Vessel Development (1992 04003)

PCRV Analytical Studies - Milestone Ib

A REVIEU OF AHLYSIS METHODS FOR PRESTRESSFD CONCRETE REACTOR VESSEIS

H. G. Dodge Z. P. Bazant R. H. Gallagher

Date Published: February 197

Prepared by the

OAK RIDGE MTIONAL LABORATORY

Oak Ridge, Teanessee 37830

operated by

USIOA CARAIDE CORPORATIOA

for the

ENERTY RESEARCH AND DEVRLOPMIANT ADMIRISTRATION

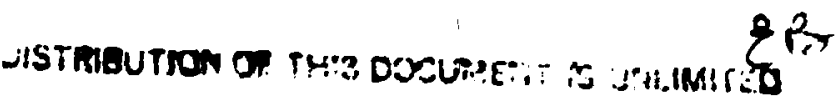


PREFACE .......................... v

sunurt ........................ vti

ABSTRACT ......................... 1

1. Immodction . . . . . . . . . . . . . . 1

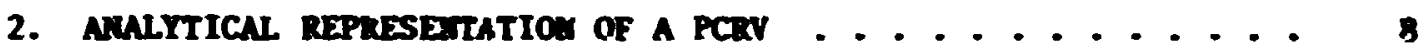

2.1. The Continum Hadel ................ 8

2.2. The Finfte-Eleoent formulation ........... 8

2.3. The Elastic Analysis ................ 12

2.4. Sparsity of the Stiffaess Matrix and Solution

Algorithas. . . . . . . . . . . . . . 14

2.5. Spectal Element Formulations............ 17

2.6. Dewonstrated Results.............. 22

3. TEIE-DEPEDDEAT BEHUIOR Of CONCRETE ............ 24

3.1. Effects of Tine-Dependent Defornations on a PCRV .... 24,

3.2. Lasic Characteristicz of Concrete Crsep ........ 25

3.3. The Superposition Principle ........... 27

3.4. Integral-Type Fornulations ............. 24

3.5. Rate-Type Formulations ............... 30

3.6. The Effect of Temperature Changes . . . . . . . . . 36

3.7. The Effect of Molsture Changes ............. 39

3.8. Effective Modulus Method ............. 42

3 :. Denonstrated Results .............. 42

4. TIE-DEPEIDENT MOALINEAR BEHYVIJR OF CONCRETE . . . . . . 46

4.1. Basic Characteristics . . . . . . . . . . . 46

4.2. Fallure Surfaces for Pla in Concrere ......... 61

4.3. Postfallure Hodels for Tensfle Fallures ........ . 67

4.4. Postfallure Models in the Compressive Regine . . . . . 72

4.5. Monlfnear Stress-Strain Relations .......... 78

4.6. Endochronic Theory ................. 32

4.7. The Effect of Refnforcenent .............. 84

4.8. Glooo: Analyais for Time-Independent Behavio: ..... 87

4.9. Applications to Practice . . . . . . . . . . . 91

5. conclusions ................... 95

RERERECES ........................ 96 
This report was prepared as part of the Oak Ridge Hitional Labotatory Prestressed Concrete Muclear Pressure Veseel Development Progran (iA9a No. 04003). The gasl of the progras is to develop and further iprove prestressed concrete reactor vessels (PCRTs) for high-tenperature sas-cooled reactors in particular and gas-cooled reactors in general.

In ddition to contributing to the establishneat of the overall state of the art of PCRV analysis capabilities, this report is inteated to assist is identifying and interpreting spectfic needs in this particular area. It will therefore provide the basis for future work undertaken to develop insroved xethods of analysis for complex cosacrete structures such as the PCRV. 
The prestressed concrete reactor vessels (PCNs) of the cype curreatly used in large high-remperacure gas-cooled reactors are asesive structures with conples soontric charserteristics that require threedinensional analyctical codels. These structures exhibit tine-dependent quasi-scatic response under nornal operating condicions. Thefr response to accideatal overpreasurization requires a wonlsear constitutive odel to describe meterial behavior, and the brittle node of fallure exhibited by concrete introduces localized violation of the comptibility requirenents of contimun wechanics.

The finfte-elenet ethod is the only werical procedure currently available that is capablo of providios a realistic odel for a structure having the geometric complext:y of a wodern FCXV. Even with this wethod, difficulties arist in the structure of the systen of algebraic equations that define the unlowown paraneters, and judicious utilization of the wast advanced discretization techatques and solution algorithes is required If computation costs are to renan reasosable. Tis is particularly true for Inctenercal tive-dependent and noalinear analyses that requite repeated resslution of the systen of equations.

The tine-depeadent reoponce of the veasel metial under isothernal operatios conditions and wornal levels of stress seems to be adequately represented by the linear viscoelastic constitutive nodel. It is not clear that conpletely satisfactory analytical nodels have been identified for the cases of thernal traneients and changes in wisture, although some satisfactory results hove been achieved in the former case utilizing the time-tcaperature shift principle of therwo-rheologically simple naterials. The inplenentation of the linear viscoelastic codel within the frawework of the finite-eleweat nethod is understood; however, the required compucational effort is strongly affected by the analytical representation of the creep or relaxation functions. When an exponential series representation corresponding to Masuell or Relvin rheological chain nodels is used, it is poceible to develop recursive relations for computing the stress and strain increants occurring during a tine increaent and avoid the normal requirenent of utilizing the cotal stress-strain history in 


\section{BLANK PAGE}


this conputation. The resulting saving in computational effort is somewhet offset by increased difficulty in obtaining an accurate odel for the actual wetertal response using these representations.

The nonlinear response of a PCRV to moderate overpressurization is the result of two separate phenonena: nonlinearity in the concrete stressstrain relations and the propagation of cracks within che concrete as the faflure lints of concrete are exceeded. As the ultinate pressure is approached, the response is primarily deternined by the plastic response of the steel reluforcing and prestressing memers.

Two aterial wodels are comonly used to simulate concrete nonlinear stress-strain response: plastictity and upperelasticity. There are two fundamental difficulties associated with the use of the plasticity codel. The first is the apparent difficulty in achieving an adequate representation for the yield function and hardening law to reproduce the proper stress-strain response under multiaxial loadings. The second, and possibly related, difficulty is that the use of this model implies isotropic eaterial damage, while the microcracking that accomanies the nonlinear response of concrete is known to exhibit directional preference depending cn the state of stress.

Two fundanental difficulties are also associated with the use of the hyperelastic codel. The first is the inability of the model to account for irteversibility upon unloeding, and the second is the apparent difficulty in achieving functional relations for the coefficients that properly account for the stress-induced anisotropy accompanying the nonlinear stress-strain response. At this tise, there does not appear to be a conpletely satisfactory constitutive wodel for representing the nonlinear response of concrete, although recent work on utflizing the "endochronic theory" developed for wrik-hardening metals shows significant promise.

Because the trial functions used in finte-element-ecthod analyses are continuous functions, the treatient of the displacenent discontinuities associated with cracking poses serious difficulties. The wodeling of concrete cracking has proceeded along two distinct lines. Some practitioners sodel the cracks as actual discontinuties in the displacenent field by utilizing techniques of wew redefinition, while others retain continuity in the displacenent field but modify the material constitutive 
relations in ap attempt to achieve proper force-displacenent relations for the postcrack condition. Neither of the techniques is completely satisfactory. In the former cace, the aigorithes wist be developed for each specific case and, consequencly, are applicable oaly for acadeatc studies, while the algorithes used in the latter case do not, in general, yield the proper force-displecenent relatioas. At this tine, a completely satisfactory technique for wodeline concrete cracking in a PCA does not exist. 


\section{A REVIad OF AWLYSIS MITIODS FOR PRESTRESSED CONCUETE RENCTOR VESSELS}

U. G. Dodze 2. P. Dazant R. H. Gallagher

\section{ANSTICT}

Theoretical and practical aspects of analytical codels and merical precedure for detalled annlysis of prestressed concrete reactor veasels are reviewed. Constitutive nodels and wuerical algorith for tine-dependent and nonlinear response of concrete and various ethods fur modeling crack propagation are discused. Published comparisons beturen experinental and theoretical results are used to assess the accuracy of these anniytical wethods.

\section{Intropucticu}

The prestressed concrete reactor ressel (PCRV) is extensively used in reactor designs having a gas as the reat-transfer mediun for the priary lcop. Because of the characteristics of this coolat.t, a large volune is required for the reactor core. A current $1160-\mathrm{mw}(\mathrm{e})$ comercial reactor ressel ${ }^{1}$ has a core cavity height and dianeter of $14.4=(47.3 \mathrm{ft})$ and 9.97 a (32.7 ft), respectively, and an extermal height and dianeter of 27.8 a $(91.2 \mathrm{ft})$ and $29.3 \mathrm{a}(96.0 \mathrm{ft})$. Because it is fabrirated by on-site casting tachniques utflizing readily avallable matertals, the PCRV offers distinct advantages in the construction of these large vessels.

The nature of the PCRV design aleo offers unique safety advantages. Due to the low tensile strength of concrete, steel prestressing tendons are used to derelop compressive stresses in the concrete during normal operating conditions. These tendons represent the primary load-bearing eleaents in the vessel and are installed in such a anner that they may be inspected and/or replaced at any time duriag the life of the vessel. Insulation and cooling coils are attached to the steel liner at the Inside vessel wall to protect the concrete from exposure to excessive temperatures, and, consequently, the steel load-bearing portions of the vessel are not 3ubjected to the plastic theranl cyclfng or creep that occurs in high-temperature steel reactor pressure vessels. Reinforcing steel is ised to control any localized cracking of the concrete. Also, since the 
concrete provides radiation shieldins, the steel liner on the inside vessel wall is the oaly structural component of the vessel that is exposed to significant radiation. The high degree of redundancy in the prestressing and reinforcing alewents and the protection afforded then by the concrete results in an extremely : $w$ probability of undetected extensive failure leading to vessel collapse.

Fron the atandpoint of public safety, the most significant aspect of the PCRV is that the complete prinary loop (consisting of reactor core, coolant circulators, and stean generators) is contained within a vessel that can exhibit a gradual wode of faflure as its ultimate pressure is apprcached. This response has been demonstrated in macrous nodel cescs of various vessel configurations. ${ }^{2}, 3$ In the early reactor designs (nid1960s), the complete primary loop was contained within a single central cavity of the vessel. The predoninant vessel shape was cylinirical with two distinct intermal configurations depending upon the location of the stean generators.

In the Britiso Oldbury" and Dungeness $B^{5}$ reactors, the stean generators are located around the periphery of the core (see Fig. 1). Ultinateload tests of scale models, 7 Indicated cracking and associated nonlinear behavior at 1.5 to 2 tines the operating pressure and an ultinate-load capability in excess of 3 tines the operating pressure. The stean generators in the French St. Laurent II and Bugey I ractors" are located directly below and in line with che reactor core (see Pig. 2). An ultimateload test of a cne-fifth-scale nodel of the Bugey I vessel' Indicated cracking at 2.5 to 3 tines the operating pressure and an ultinate-load capability in excess of 4 times operating pressure. As in the case of the British dezign, the fallure was gradual and was the result of excessive leakage due to liner fallure. The configuration of the American Fort St. Vrain vessel $1^{10-12}$ is sintlar to the French designs discussed above (see Fig. 3). The performance of the vessel was verified by a sequence of tests using a one-fourth-scale mode $1^{13}$ that stulated various operating conditions including overpressurizution to twice the operating pressure. 


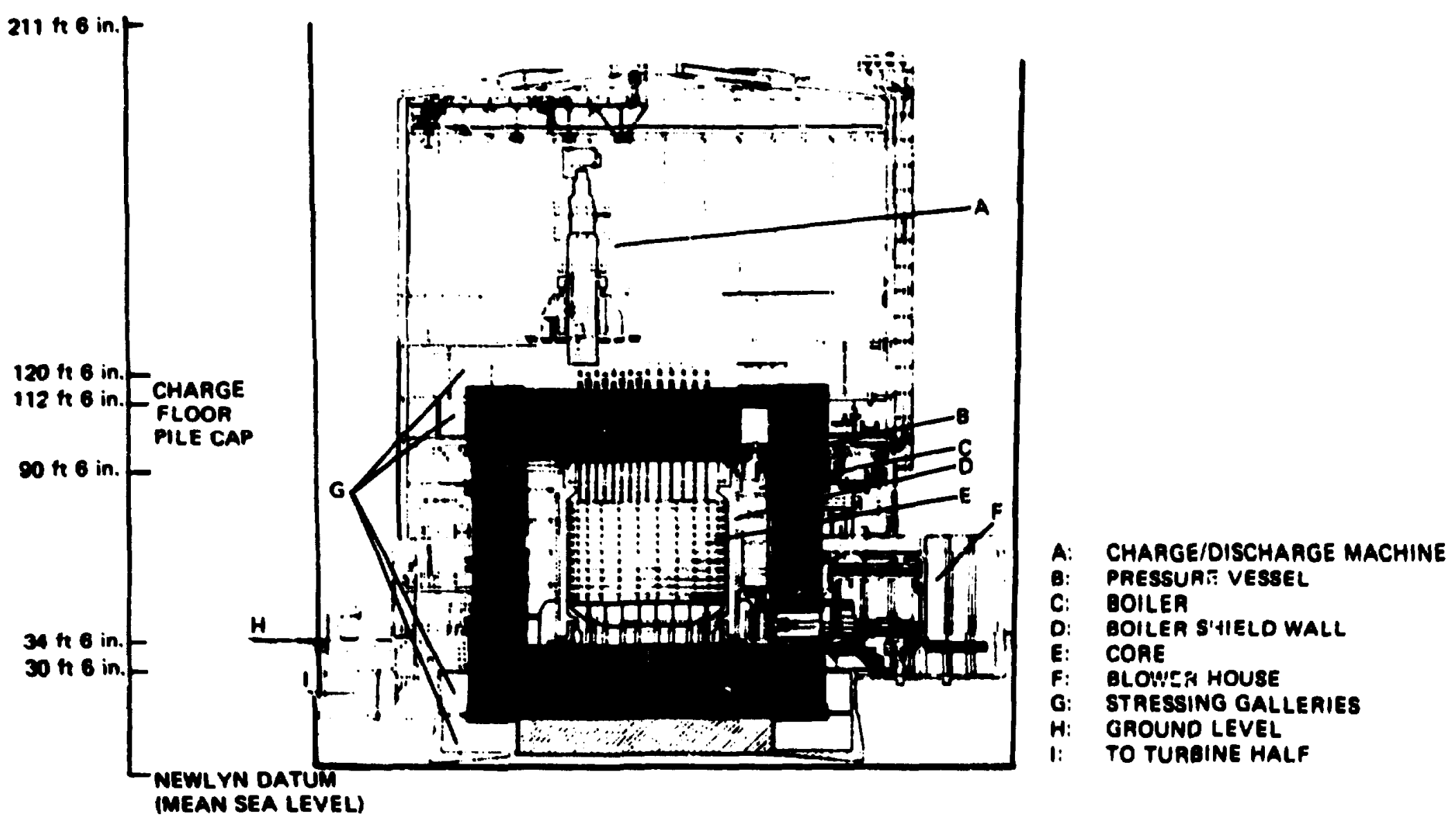

F1g. 1. Transverse elevation of one of the reactora for Oldbury power station thowing the prestressed concrete preasure vessel (Ref. 4 ). (1 ft $=0.305 \mathrm{~m})$ 


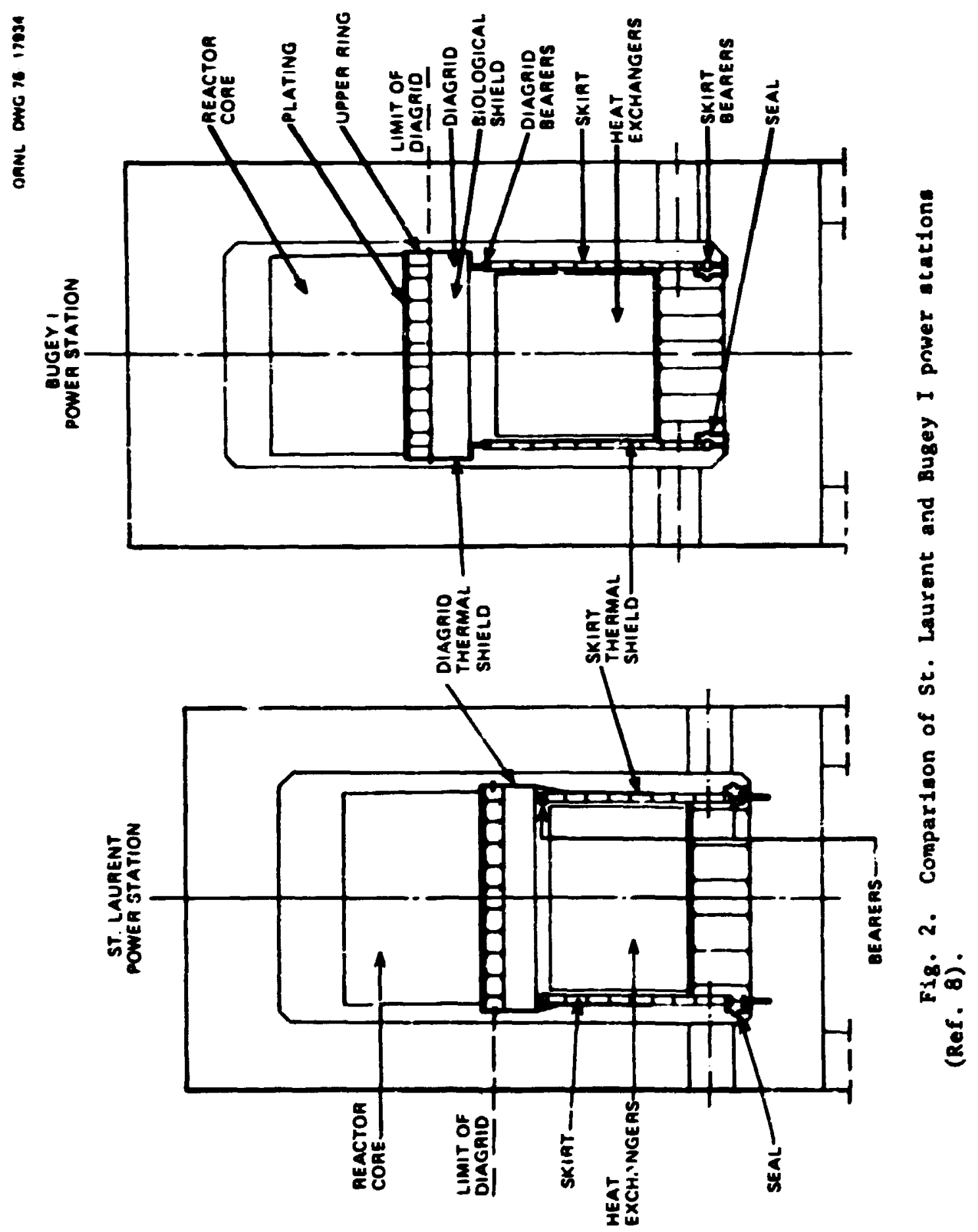




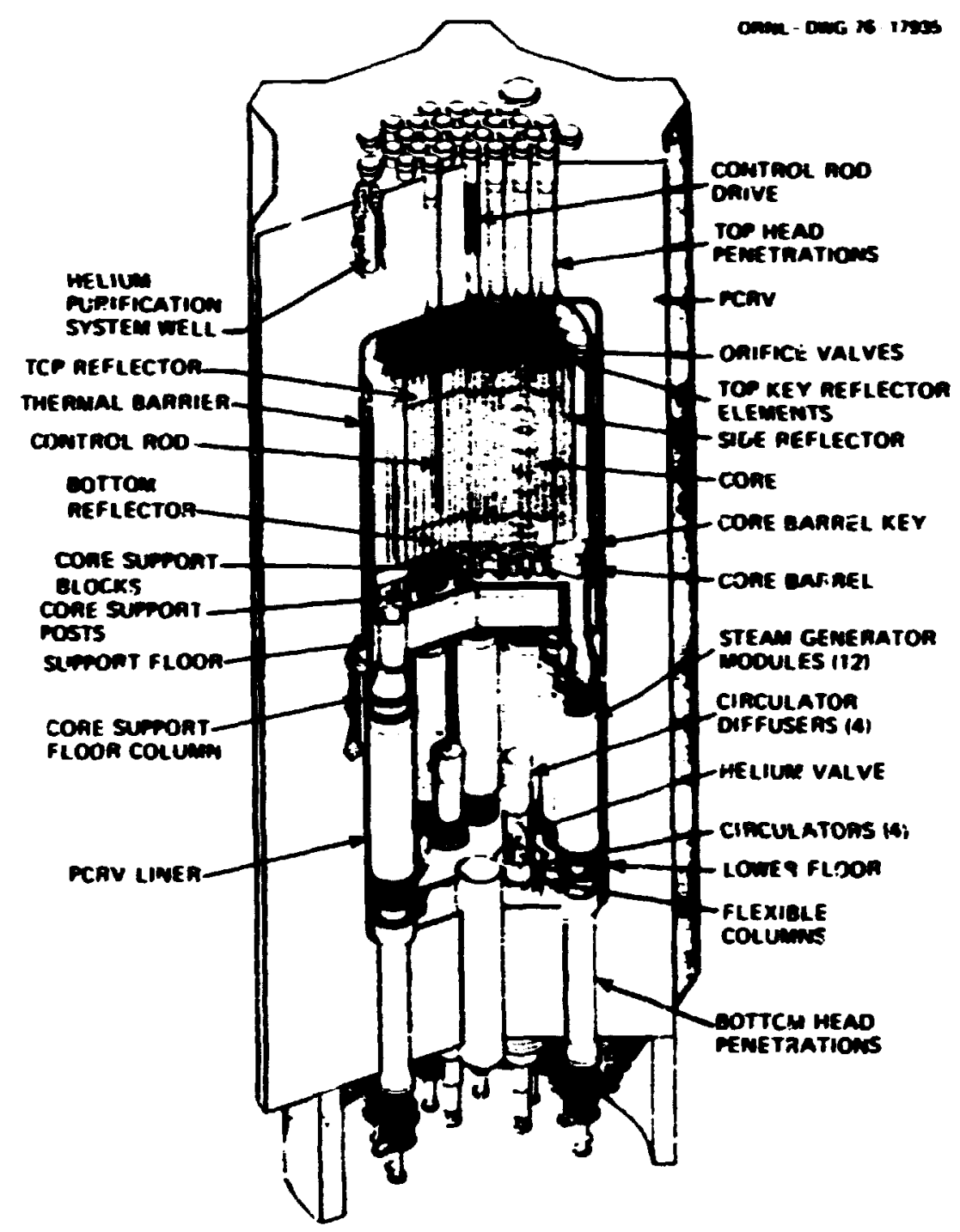

Fig. 3. General arrangement of the primary reactor components (Ref. 11).

A hough the performance of the early PCRV designs discussed above was satisfactory, there are certain difficulties associated with these configurations. The large unsupported span across the head regions in the British design is not desirable, while the French configuration leads to a more complex path for coolant flow. In both designs, the stean-generator systeas wust be assembled within the vessel cavity, and thus a closely integrated schedule of delivery and ingtallation is required. Access for repair work on these systens after installation is by manhole only. These 
problens are awoided in the nodern high-tenperature gas-cooled reactor (HTCR) vesse ${ }^{14}$ by placing the stean generators and circulators in vertical cylindrical cavities within the vessel wall (see Fig. 4). Dy using removable closure plugs, it is possible to design the circulator-stera generator systen so that it can be shop fabricated and tested before installation and renoved for repair if necessary. The British Hartlepool

$0000-00-1700$

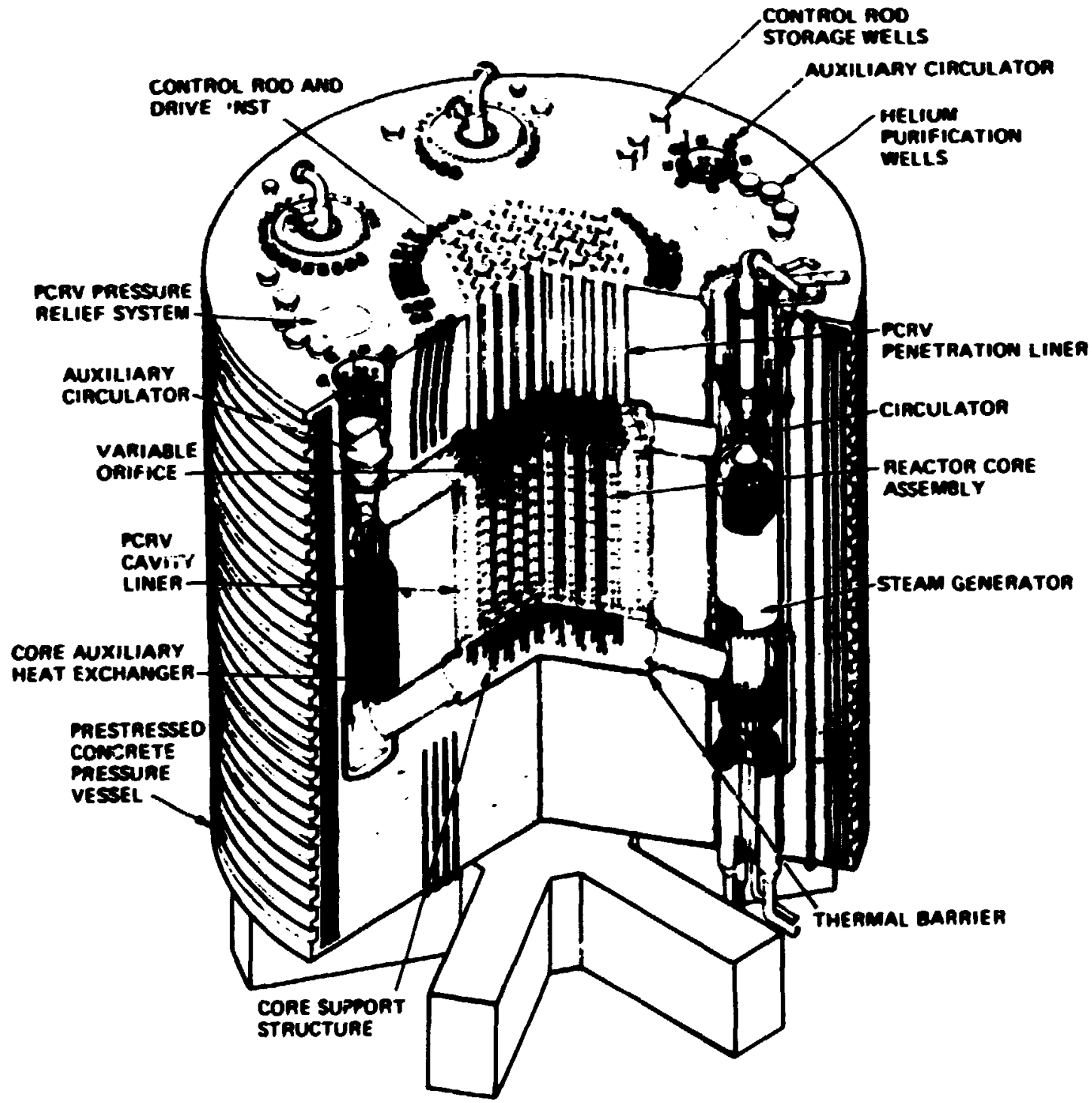

Fig. 4. The mafor components, system, and fuel enclosed in the HTGR PCRV for the Sumlt plant (Ref. 1). 
reactor $^{15}$ was the first reactor to utilize this witicavity vessel coucept. A test of one-tenth-scale wodel of this vessel 16 denonstrated a gradual wode of fallure for this configuration sintlar to that of the previcus single-cavity designs.

The model cests have demonstrated the gradual and predictable response of the PCRV co Increasing pressure. At the loner pressure levels, the response is linearly elastic with oaly highly -ocalized woalineerity or cracking. As pressure is increased, significant nonlinear response develops. This nonlinearity is due to two sources: nonlinearity in the stress-strain relation of concrete and the development of significant zones of concrete cracking. The latter effect beconss wore pronounced as the pressure is increased, and as the ultimate pressure is approsched, the vessel is reduced to a state that can be characterized as discrete blocks of concrete held together by steel reinforcing and prestressing nebers. The deformations in the latter phase are due priarily to plastic deformation of the steel webers. Fallure is generally che result of excesstve leakage due to rupture of the liner. Because of the distinctly different meclanise imolvet, it is comventent to group the discussion of PCRV analysis inco linear elastic analysis, nonifnear analysis, and tine-dependent effects of shrinkage and creep in the concrete.

Although prevfous expertence has dewonstrated that safe and reliable prestressed concrete vessels can be designed and constructed, it should be recognized that (1) the PCRV is a wore complex structure than a corresponding steel vessel, (2) the behavior of concrete is complex and subject to any factors such as changes in tepperature and wotsture content, and (3) the totality of destgn experience for prestresed concrete vessels extends for only two decades. The parfornance of the veseels discussed above was the result of careful destga based upon extensive use of anslytical and experfencel reaules. The purpoes of this report is to reviest the analytical wethods ovallable to the destgner of eodern PCiN configurations and to assess their capability. 


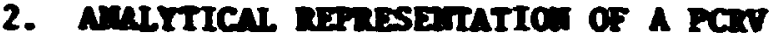

\subsection{The Continare rodel}

At the macroscopic level, a PGRV is a quasi-honogeneous structure composed of wrtar, angrezate, and steel. At a more refined level of gradation, the wortar ay be viewed as a porous solid franework with wolds coataining gas and liquid. The 3 fruts is held within the pores of the solid by intermolecular fories. Obviously, this level of codeling is inpractical, and the first step in siplification is to view the PCRr as a three-dinenstonal continum appoed of two components - concrete and steel. The equilibriu configuration of a continum is uniquely defined by three conditions: (1) the deformetions wat be continwous and single valued (conpatibility coodition), (2) the state of stress oust satisfy conditions of equilibriu, and (3) the stresses and strains aust satisfy appropriate constitutive relations for the aterial." The comatibility of deforations and equilibriu conditions are physical relations, while meterial behavior is described by the constitutive relations.

In a sodern finite-elenent code, the three requirenents of compatibility, equilibriun, and constitutive relations are considered in functionally independent portions of the progren. This wodular structure, combined with the ability to hadle probleas having complex geometry, has led to the wide acceptance of the netrod and has gtibulated a capid evolution in engineering analysis capabilities. It is anticipated that the wethod will play the dominant role in future PCRV analysis; consequently, it is pertinent to discuss such amalyses in this context.

\subsection{The Pinite-Elenent Formulation}

The finite-element sethod is a procedure within the broad class of numerical cechniques called methods of trial functions. 1 . A functional forn of the solution is assuned that contains unknown paraneters - usually constants - wich are deternined 20 as to achieve an approximaze solution so the governing equations. The unique feature of the finite-elenent nethod is that the trial functions are defined only for finite subregions, 
or eleseats, of the domin. The princigal cestictions placed on the selection of trial fuctions are asoociated with the coatinuity requirenents of the aninization principle. Twere are a nober of general certs on the finite-elemeat wethod, two of which are thefs. 19 and 20.

The donath is abdivided into discrete elenents by epecifyine spatial points called wedes that define the bonary sarface of each elenent (see F18- 5). In the wore conon inleneatation, che trial foctions are coor cinowe displaceneat fields within each elrsent. Thes, If the functional form is soch that conpatibility of deformetions is wot rolated alonedjecect eleneat boublariee, the conpatibllity relations of the coatinue ste autonatically satisfied. Comectivity is accomplisbed by specifying

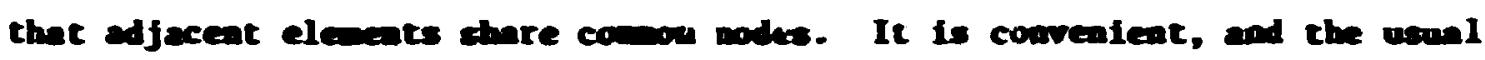
practice, to wase the velue of the copponats of the displacentent vector at the modal points as the uborm paraneters in the trial foxctoms associated with each eleneat. These walues are referted to as the degrees of freedon of the structural sadel. Thas, the trial functions have the for

$$
\left.\delta_{i} x, y, x\right)=\sum_{i=1}^{n}\left(x_{i}(x, y, z)\right\}^{T}\left\{\delta_{i}\right\}
$$

where $a$ is the ouber of nodal polats aseociaced with the eleneat, $f(x$,

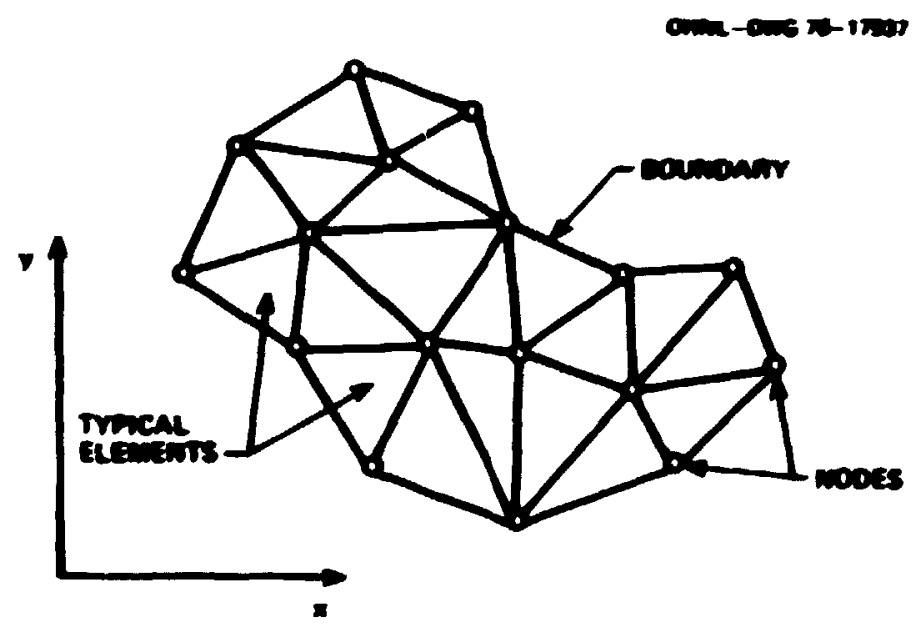

P18. 5. Subdivision of the region into finite elements. 
Y. 2) Is the displacenent vector, $\delta_{i}$ is the value of displacenent field at the ith wode point, and $x_{1}(x, y, z)$ is a functior that is waity at the ith wole and zero at all ocher podes (see Fis. 6). The functions $\mathrm{H}_{1}$ are the interpolating functions for the displacenent field and are known collectively as the shape function for the elenent. Wote that $\left(\mathrm{f}^{\mathrm{T}}\right.$ indicates the metrix transpese and is a vector ibose componeats are the values of the displecenest in the coordinate directions (1.e., $6_{x}, \delta_{y}$. and $\delta_{2}$.
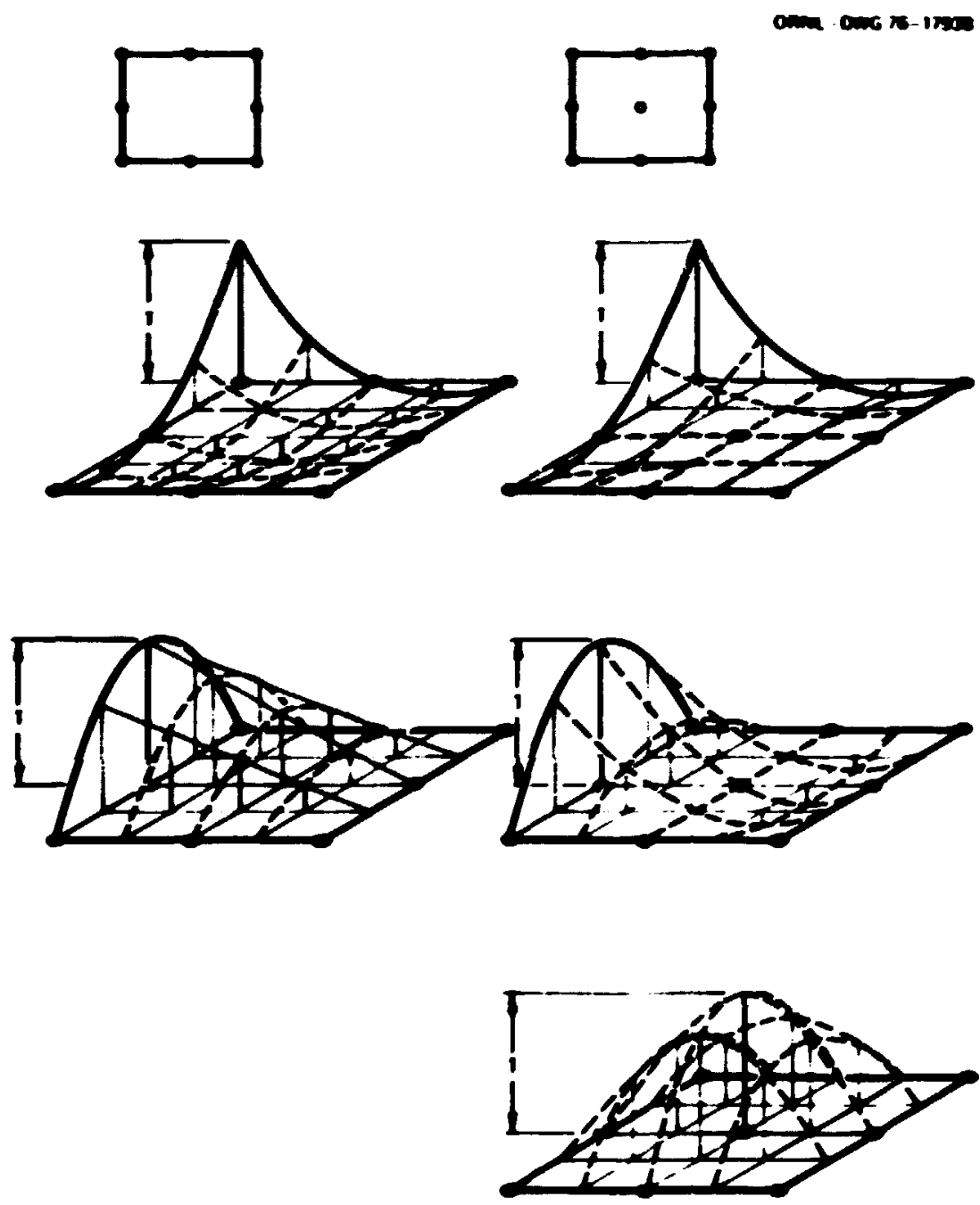

18. 6. Shape functions for quadratic elements of "Serendipity" and "Lagrange" functions (Ref. 19). 
Fanilies of element formulations beve been developed for specific proble classes (see Fig. 7). Three-dinenofonal tetrabedron and hexahedron elewents are ued for solld bodtes with rewerally three degrees of freedon per wode. In planar situntions (plane streas, plane strain, or axisymetric probles), triangular and quadrilateral elenents are used with two degrees of fredoe per node. Shell and plate-bending probles utilize special form for the shape functions and rotational degrees of freedon to betcer approximte the deformetions assoctated vith these structures. The important point is that the eleseat formulations provide displacesent trial functions that satisfy the compatibility requirenents for the continum and contain the nodal displaceneats as unionow parameters. The wolution to the problen is obtained by deternining the unknow parmeters so as to satisfy an appropriate afninization criteria.

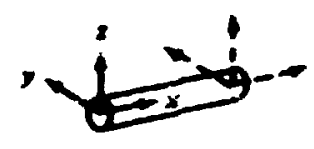

IS F RANEWOMK ME MUER

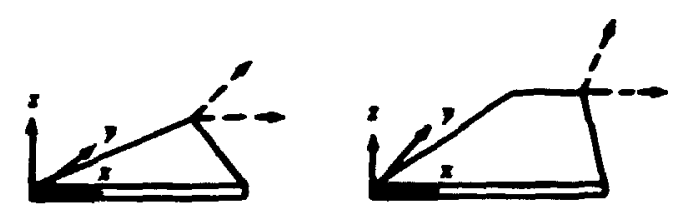

bi Mane staess

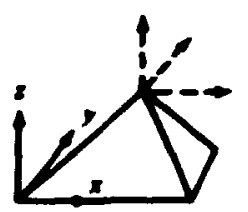

ir' SOL 10 ELENENTS
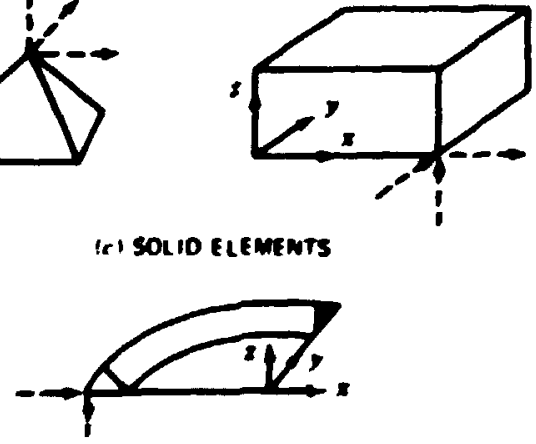$$
1
$$
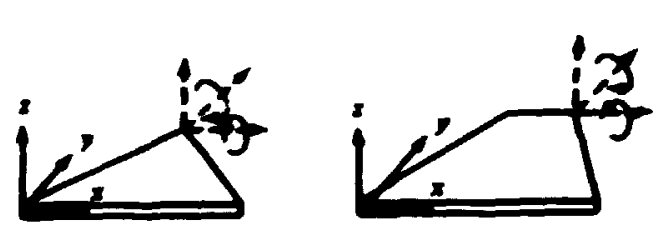

lei flat Rate oenoing

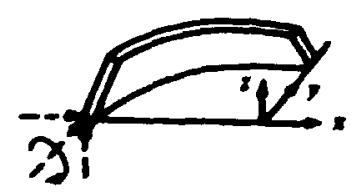

if axisrumet taic twin sutcl
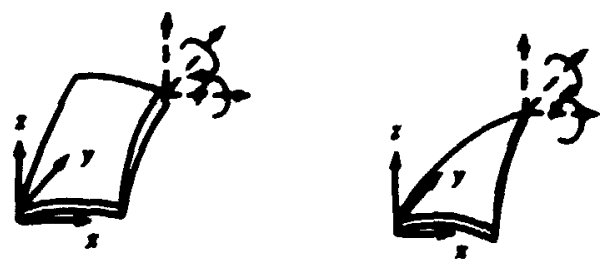

(g) CUnVED thIN senels

P1g. 7. Types of finite elements (Ref. 20). 


\subsection{The Elastic Analysis}

Host structural aterials behove elastically within a certain stress range, and for the mjority of these miterials, the relation between the stresses and sfretns can be approximated with sufficient accuracy by a linear relationship, that is,

$$
[\sigma\}-\left\{\sigma_{0}\right\}=[D]\left(\{\varepsilon\}-\left\{\varepsilon_{0}\right\}\right)
$$

where $\{\sigma\}$ is a vector containing the componerts of stress and $\{\varepsilon\}$ is the vector of the components of strain. The metrix [D] is called the material matrix and depends, in the case of homeneous isotropic aterials, on the modulus of elasticity $E$ and Poisson's ratio $\mu$ of the material. The vectors $\left\{\sigma_{0}\right\}$ and $\left(\varepsilon_{0}\right\}$ are the infital componeats of stress and strain, respectively. The high-strength concrete typlcally used in PCRV construction responds elastically to applied nechanical loads at stress levels up to approxinately 602 of the ultinate strength. ${ }^{21}$ Within the elastic range, the inftial strains are recoverable on unloading, and the structural response realos unchanged under repeated application of the load. Hence, it is standard practice to design the PCRV to reain elastic under credible combinations of operating, accident, and enviromental loads. ${ }^{22}$ Some highly localized regions of inelastic stresses may be tolerated if adequate reinforcement is used to control cracking. The effect of these inelastic stresses on an elastic analysis is negligible, except in the inediate neighborhood of the region involved. Thus, the elastic analysis serves as the primary analysis of the PCRV for credible design-base conditions.

The principle of stationary potential energy ${ }^{23}$ provides a variational statement for deternining the unknown parameters of the trial functions in the analysis of a linearly elastic atructure. This principle states that equilibriun corresponds to the position at which the total potential energy has a stationary value. Consider an element having $n$ degrees of freedom that is in equilibriue under the action of forces $\left\{F_{i}\right\}$ applifed at the norles. Let $\left\{\delta_{1}\right\}$ be the equilibriun displacements of the nodes and $\{\sigma\}$ be the corresponding stresses. The necessary condition for stationary 
potential energy is

$$
\int(\Delta \varepsilon)^{T}\{\sigma) d v-\sum_{i=1}^{n}\left\{\Delta \delta_{1}\right\}^{T}\left\{F_{i}\right\}=0
$$

where $\left\{\Delta \delta_{i}\right\}$ is an arbitrary inf initesiand displacenent from the equilibrium position, $\{\Delta \varepsilon\}$ is the corresposding increnent in the strains, and the integration is over the element volume. The strains are related to the displacenents by

$$
\{\varepsilon\}=\sum_{i=1}^{n}\left[s_{i}\right]\left[\delta_{1}\right\}
$$

where the atrix $\left[B_{i}\right]$ is obcained from differential operations on the element shape functions $N_{i}$. Utilizing the stress-strain relations given by Eq. (2) and the strain-displacement relation above, Eq. (3) becomes

$$
\left\{F_{i}\right\}=\sum_{j=1}^{n}\left\{k_{i j}\right]\left\{\delta_{i}\right\}+\int\left[B_{i}\right]^{T}\left\{\sigma_{0}\right\} d v-\int\left[B_{i}\right]^{T}[D]\left\{\varepsilon_{0}\right\} d v,
$$

where

$$
\left[k_{1 j}\right]=\int\left[B_{1}\right]^{T}[D]\left[B_{j}\right] d v
$$

is called the element stiffness matrix and the integration is over the volume of the element. This equation states the relationship between the equilibriw values of the degrees of freedon and the corresponding nodal forces for the element.

Requiring that the external forces at each node equai the resultant of the forces exerted by the node on adjace, $t$ elenents yields a systen of N linear algebraic equations

$$
[K]\{\delta\}=\{R\} \text {, }
$$


where $N$ is the total number of degrees of freedon in the complete structural model, [K] is an $N \times N$ atrix called the global stiffness matrix, and $\{R$ \} is the nodal force vector. The nodal force vector $\{R$ \} is the sum of the external forces $\left(F_{i}\right\}_{\text {ex }}$ and the pseudonodal forces due to the initial strains $\left\{F_{i}\right\}_{\varepsilon_{0}}$ and the initial stresses $\left.i F_{i}\right\}_{\sigma_{0}}$, where

$$
\left\{F_{i}\right\}_{\varepsilon_{0}}=\int\left[B_{i}\right]^{T}[D]\left\{\varepsilon_{0}\right\} d v
$$

and

$$
\left\{F_{i}\right\}_{\sigma_{0}}=-\int\left[B_{i}\right]^{T}\left\{\sigma_{0}\right\} d v
$$

The integration in the above equations extends over all elewents containing the $i$ th degree of freedon.

\subsection{Sparsity of the Stiffness Matrix and Solution Algorithws}

Suppose the equilibrium values of the degrees of freedon of the scructure are

$$
\delta_{\ell}=\left\{\begin{array}{l}
0 \text { if } \ell \neq j \\
1 \text { if } \ell=j
\end{array}\right.
$$

then

$$
R_{i}=\sum_{\ell=1}^{n} k_{i \ell} \delta_{\ell}
$$

is the value of the ith generalized nodal force required to maintain equilibriun for a unity value of the $j$ th degree of freedom, all other degrees of freedom being zero. Only those elements that contain the $j$ th degree of freedon will be deformed by this displacesent, and thus the force $R_{1}$ will be zero if the $i$ th and $i$ th degrees of freedon do not share common element. Consequently, all $k_{i j}$ terms for which the $i$ th and $j$ th degrees of freedon do 
not share a comoo element will be sern. It follows that the global stiffness matrix contains relatively fev monzers term, and by a suitable winbering of the degrees of freedon, these cerms can be restricted to a nartow band containias the min diagonal, as shour in Fig. 8.

The fact that the matrix is sparae and banded is the tey to developing efficieat algorithe that mate it possible to obtain a solution to the large nuber of algebraic equations imolved in a typical finite-elenent analysis. The maxima banduidth in a particular problen is ceternined by the maxim difference of the subscripts assigned to the degrees of freedon within any of the eleneats of the structure.

The early single-cavity PGov coafigurations could be adeled to a reasonable degree of accuracy as axisynetric structures and bence required only a two-dineasional analysis. For such an analysis, the bonduldth of the global stiffuess metix is related to tulce the puber of nodes along a line through the structure. The alticavity PCaV is a troly three-dineasional. structure of relatively complex geonetry. For this type of problem, the banduidth is relased to three times the mber of nodes on a plane

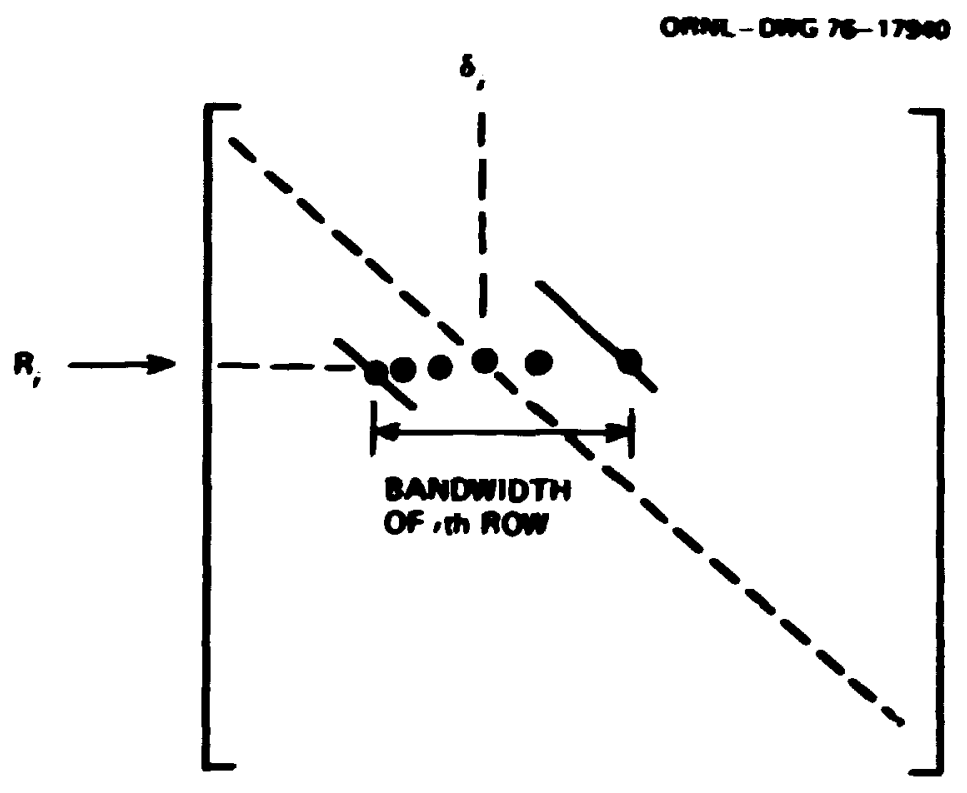

Fig. 8. Banded global stiffness merix achieved by suitible numberIng of degrees of freedom. 
through the structure. Thus, in addition to the difficulty of hasdling the yarger nuber of equations involved in a three-dinensional analysis, there is the proplea that the bandudth is considerably larger. The solution algorithms in virtualiy all existing finite-element prograns uiilize a direct wethod for which the nuber of operations required is proportional to the product of the number of equations and the square of the bandwidth. Thus, analyses of three-dinensional structures with the geonetric characteristics of the multicavity PCRV are several orders of agnitude nore expensive than analyses of plane or axisymetric structures of equiralent Jetail.

The bandwidth problen can be avoided completely by utilizing an itera:ive-solution procedure based on the Gauss-Seidel method. 24,25 since the procedure requires only successive matrix multiplications and does not alter the original stiffness matrix, it is possible to design the algorith such that only the nonzero elements of the stiffness watrix need bp stored or maipulated. Unfortunately, slow convergence is of ten characteristic of the iterative-solution sethod, and known procedures for accelerating the convergence are not uniforaly effective and ay produce divergence. Until better acceleration techniques are developed for the fterative-solution algorithas, the most efficient solusion procedures will be based on direct methods. ${ }^{26}$

The wethod for the direct solution of banded equations comenly implemented in early codes is based upon the "block diagonalization" wethod develnped by Clough and Hilson. ${ }^{27}$ In this method, the diagonal hand is partitioned into $N$ square submatrices lying along the diagonal and triangular off-diagonal submatrices. By a procedure involving inversion of the diagonal submatrices and multiplication by the off-diagonal matrices. N groups of equations are formed for which the unknowns in the last group are obtained directly and the rewaining unknowns are obtained by backsuistitution. If $w$ is the bandwidth, the process requires $N$ inversions of $(m \times m)$ matrices and in-cote storage of the equivalent of two ( $m \times m$ ) matrices.

More efficient algorithms based on triangular decomposition? have been implemented in recent codes. 29 In the later algorithms, the matrix 
Is decomposed into an upper and lower triangular form by a process equivalent to Gaussisn elfinintion, and the solution is obtained by back-substitution, thus avoiding the merix imversions required in the block diagonalization method. A techaique called skylfaing is used to take partial advantage of sparsity within the bantuldth and can be inplenented in such a manaer as to provide a better balance between input and output. The latcer coment is par:icularly true for the frontal-solution technique developed by Irons. ${ }^{30}$ A more detalled survey and discussion of the various solution cechniques is given in Refs. 31 and 32.

\subsection{Special Element Formulations}

Because of ti.e strongly adverse effect that the mat=ix banduidth has on soluzion cost, it becones critical to utilize an efficient discretization for modeling three-dinensional problems. To achieve an adequate ndel for the structure with a ninimum muber of degrees of fricedon and bandwidth, two characteristics are necessary: (1) the elewents wust have sufficient flexibility in their geonetric configurations so that the geometry of the structure can be wodeled with relatively few nodal points, and (2) the eleaent shape functions aust be of sufficiently high order to wodel the existing strein gradients. The isoparametric elenent formulation provides a relatively sinpie means of achieving these requirements by utilizing a normalized-basis coordinate syste to express the functionai representation of the shape functions, that is,

$$
\delta(\xi, n, \zeta)=\sum_{i=1}^{m}\left\{x_{1}(\xi, n, \zeta)\right\}^{T}\left\{\delta_{1}\right\}
$$

where $\xi, n, \zeta$ are variables with a range of -1 to +1 (see Fig. 9); $\delta_{1}$ is the value of the displacenent vector $\delta$ at node 1 ; and $m$ is the nuber of noojas associated with the elenent. These shape functions are also used to describe the element geonetry in the global coordinate system in cerms 


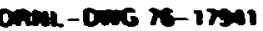
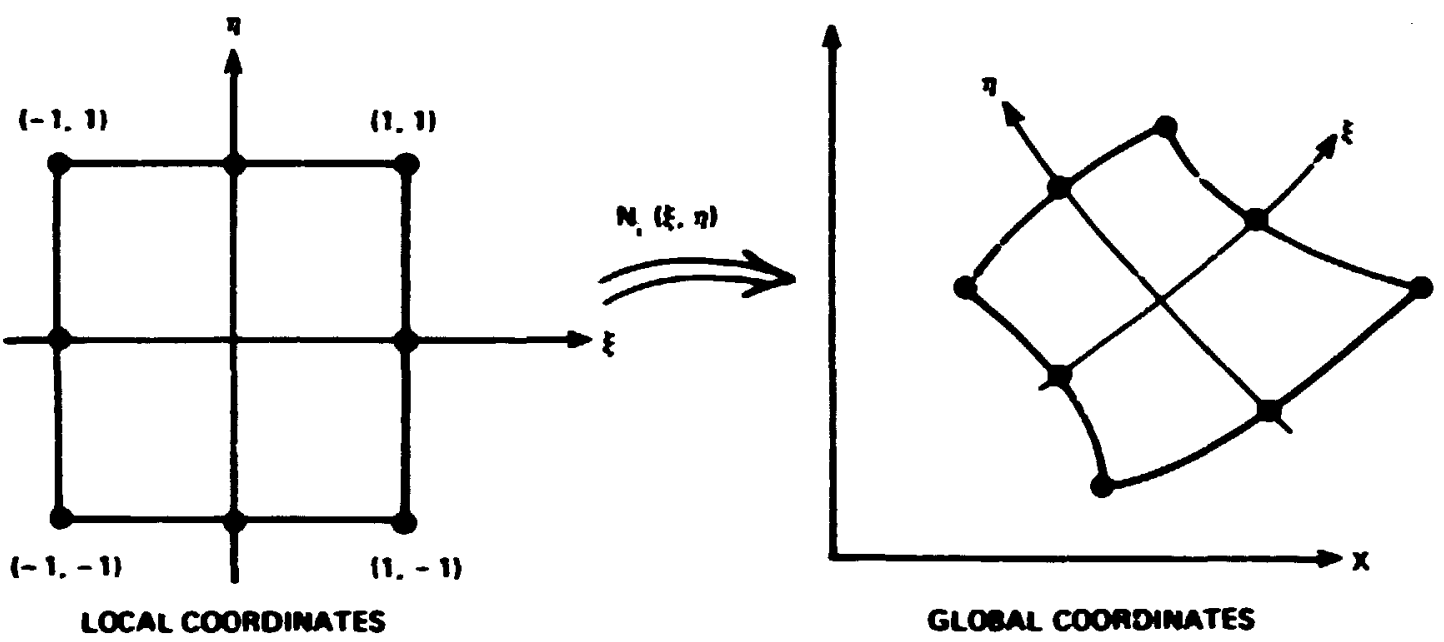

F18. 9. The 1soparanetic apping.

of the coordinates or the node points of the elenent, that is,

$$
\overrightarrow{\mathrm{P}}(\xi, n, \zeta)=\sum_{i=1}^{m}\left\{\mathrm{n}_{1}(\xi, n, \zeta)\right\}^{\mathrm{T}}\left\{\overrightarrow{\mathrm{P}}_{1}\right\}
$$

were $\vec{P}$ is the position vector of a point in the clobal system and $\vec{F}_{t}$ is the position vector of the ith node of the element. If bilinear interpoiation is used in the definition of the shape functions, curved coniours of second degree are produced in describing the element geometry. Thus, the isoparanetric representation provides a systematic procedure for developing appropriate high-order displacenent trial functions for elements having complex geonetry. Most nodern codes contain elenents that are based on this formulation.

The use of the high-order isoparanetric elenent provides a means of representing the geonetrical outline of the PCRV and simultaneously modelIng the strain gradients with relatively few elesents; however, because of the high cost of formulating the element stif 1 nesses and the large number of degrees of freedon sssociated with these elenents, it is desirable co utilize them efficiently. Thus, it is neceseary to have avallable the special elements required to make transitions in the element mesh. These 
eleneats are of two types: hierarchical and desenerate. The hierarchical elesents are those for which the muber of nodes and associated order of the shape functions $m$ be differeat alone different sides of the elenent (sce Fig. 10). With the use of these elements, additional degrees of freedon ay be introduced where higher-order strain gradients are expected. The degenerate el saents are those for which two adjacent corner podes are coalesced, as show in Fig. 10. These elements are required at the centerline apex of three-dinensional cylindrical models and at certain regions of mesh transition. The use of both hierarchical and degenerate elenents for a typical alticavity PCav wodel is discussed in Ref. 33, and an exanple is shown in Fis. 11. Some of the special cousiderations necessary In the formulation of the stiffnesses for such elenents are discussed in Ref. 34.

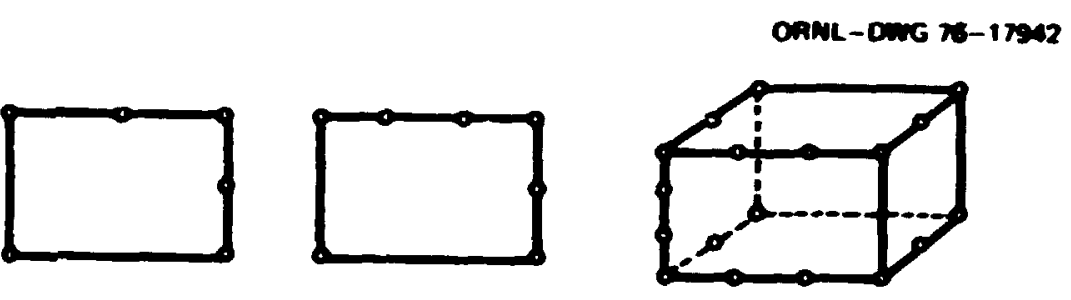

(a)
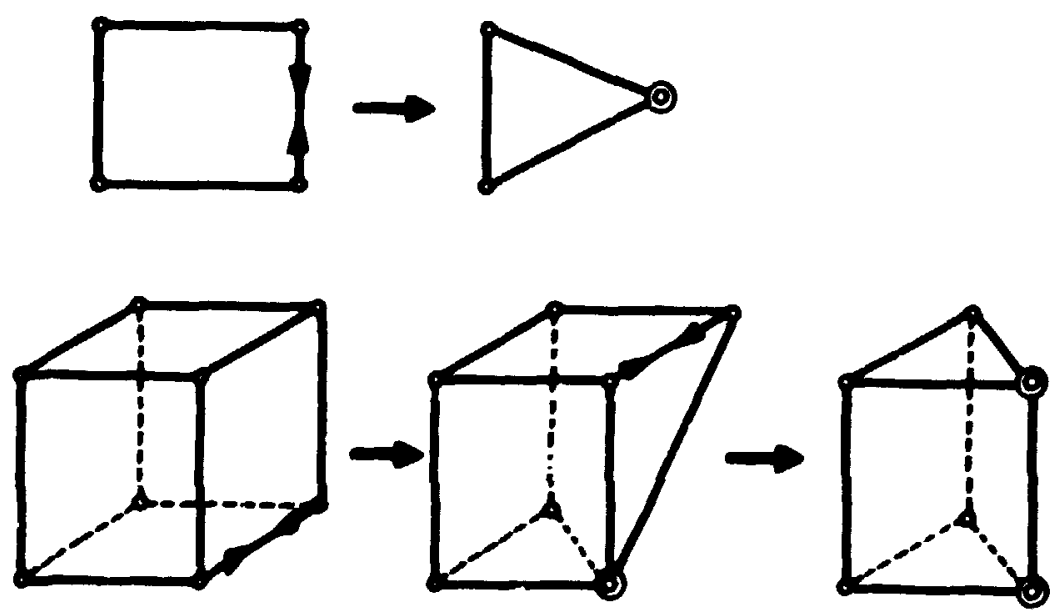

(b)

Fis. 10. Typicel elements: (Ref. 33).

(a) hierarchtcal, (b) "degenerate" 

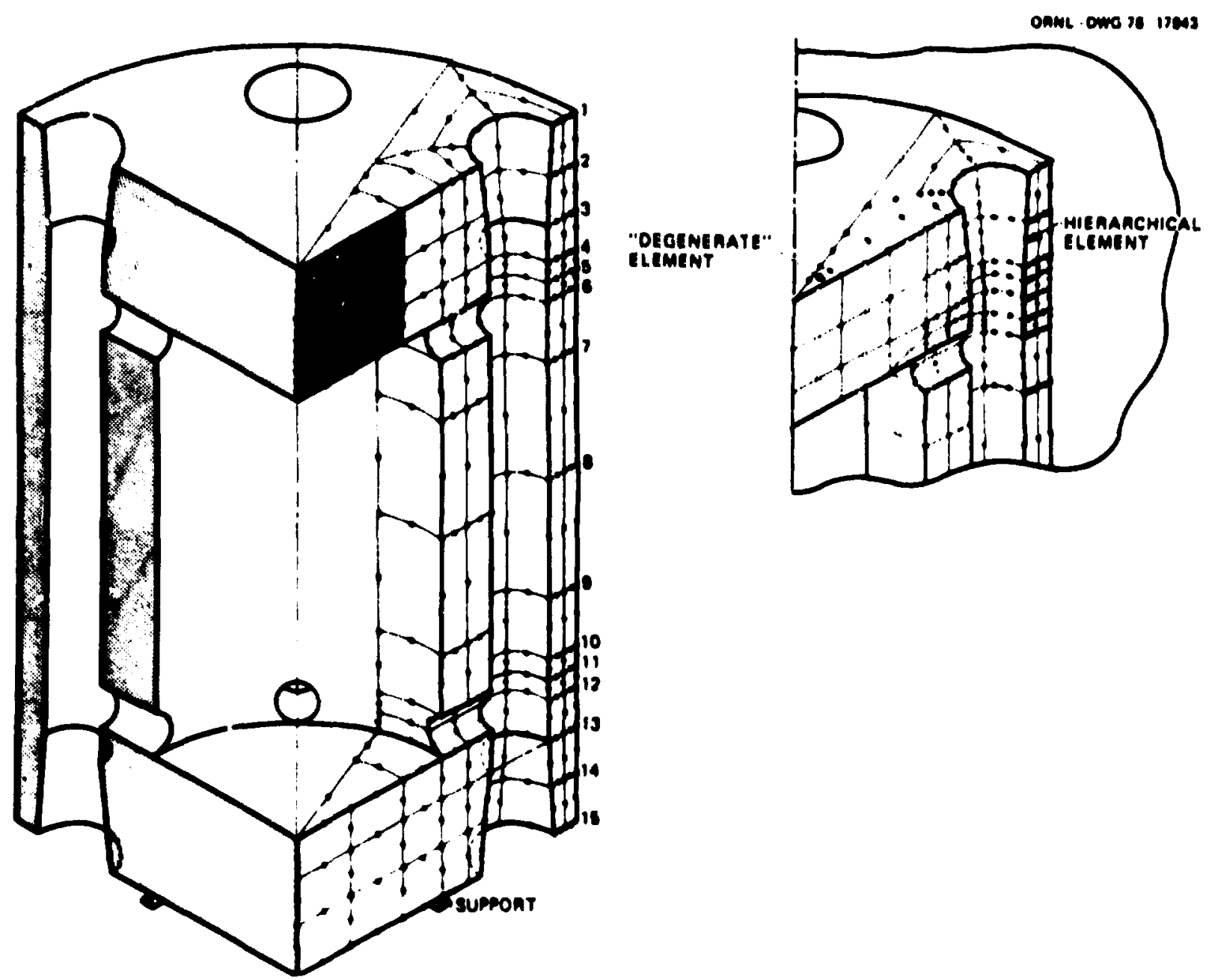

F18. 11. Three-dimensional analyeis of a preseure veesel Indicating advantares in Idealtacion provided by hierarchical and "degenerate" elemente (Ref, 33). 
Because only relatively fer high-order elenents are needed in an analysis, the ideailization of the reinforcing bars and cobrane liners requires special treatnent. Liniting these elements to colncide with boundaries of the solid elenents places an intolerable restriction on the weah layout. A less restricted formulation is presented in Ref. 33 in which the bar and cebrane elenents are enbedded within the solid elenents but restricted to lines of constant $\xi, n$, or $\xi$ in the basis-coordinate systen (see Fig - 12). By assuning displaceneat copptibility between the solfd elements and the enbedded nebbers, one can obtain the conbined stiffness contributions. The ajor problea assexiated with this formalation is that, in general, a bax or enbrase elewent is located by its position in the global coordinate systen, and the corresponding position in the basis coordinate syste an no: colncide with positions of conscant $\xi$, $n$, or $\zeta$. This probles could be overcome by a suicable generalization.

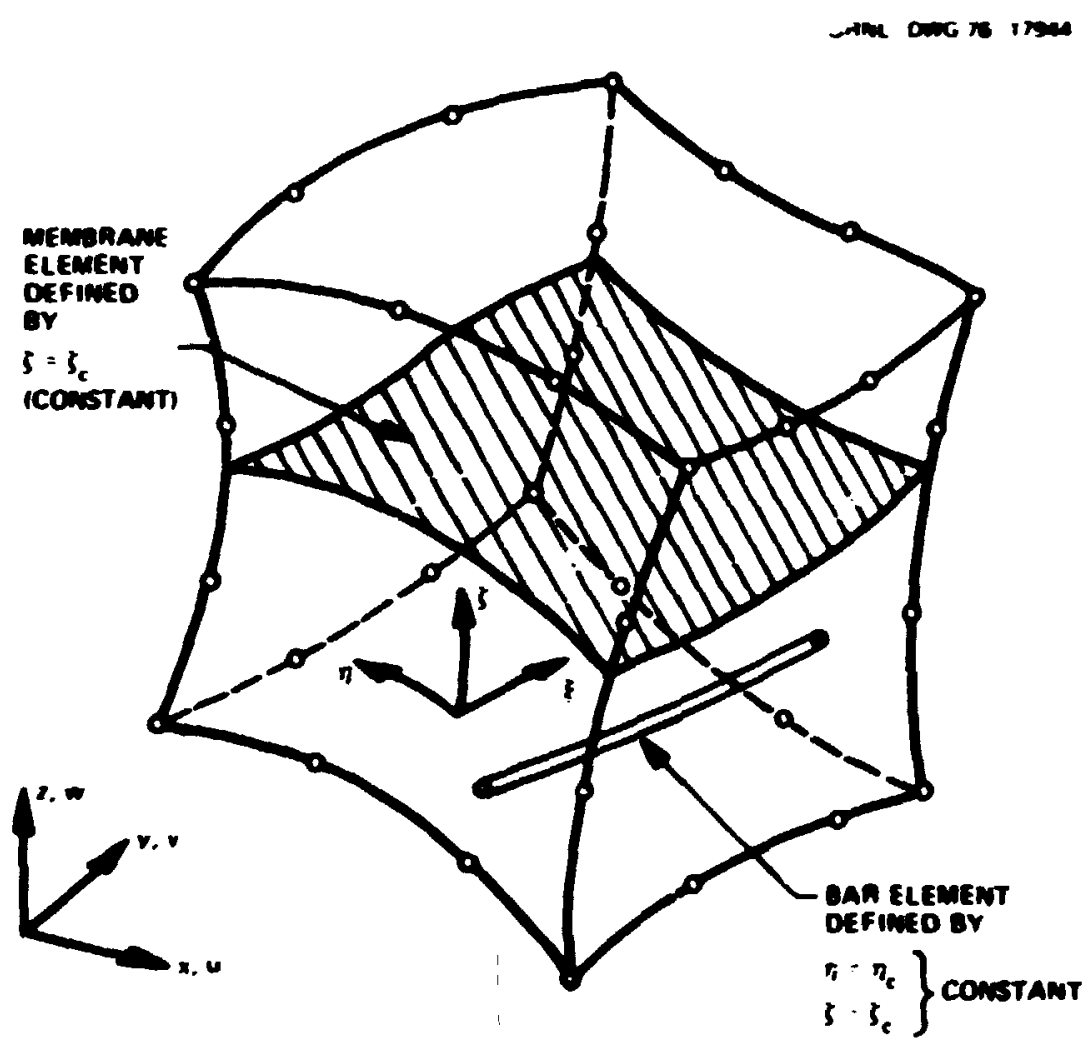

Pig. 12. Trpical ber and netbrane elenents in curvilinear directlons within a solid element (Ref! 33). 


\subsection{Deponstraced Resulcs}

The theoretical results for coe of the earliest published comparisons of analjtical and experinental strain distributions in a complex threedinensional body ${ }^{35}$ vere obtained with a conputer code ${ }^{36}$ that utilizes an iterative-solution wethod and the constant-strain tetrabedral solid elemeat. A $30^{\circ}$ symetry extor of the top half of a concrete pressure vessel was modeled using 12,231 tetrabedral elenents, as stown in Fig. 13. The solution of the 8034 algebraic equations by iteration required several hours of In $360 / 75$ computer tine; hovever, the use of a direct nethod for this systen of equations, whose banduidth was approxinately 500 , would have been virtually inpossible. The larga muber of elenents were required in the codel because the constant-strain tetrahedron is rather inefficient in codeling strain distributions. Of the 12 degrees of freedon avallable in this element, 6 mat be used to account for rigid-body wotion

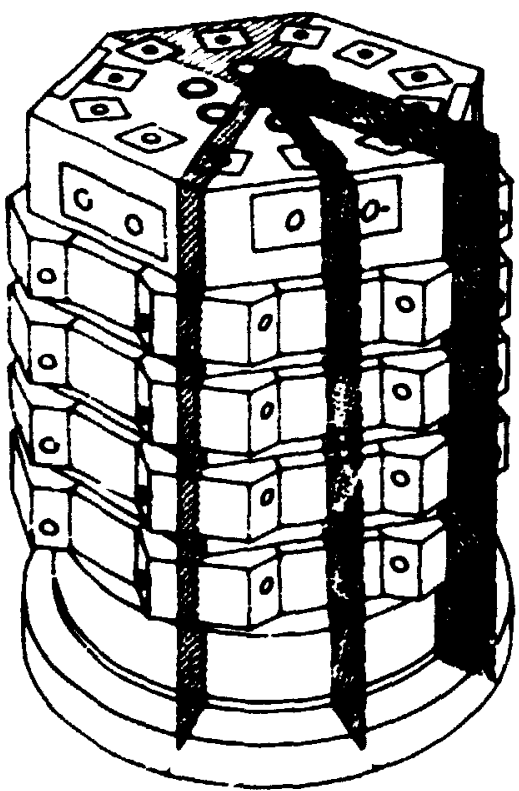

(a) MCTUAL STAUCTUME

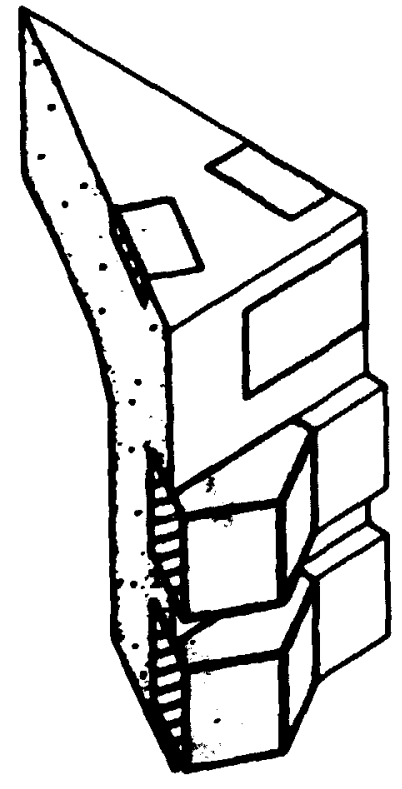
(0) OCTANT Of ACTUAL

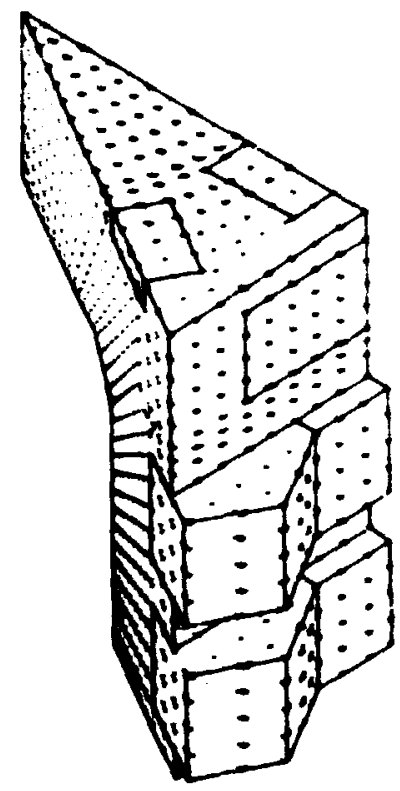

(c) FINITE ELEMENT

IOEALIZATION iTEThameononal ELEMENTSI

P18. 13. P1nite-element analysis of prestressed concrete reactor vessel (Ref. 35). 
of the elenest; thos, only balf are avallable for approximeting the strain distribution. The excessive conpating tine wa the reoult of the slow convergence of the solution for saccessive iterations. Alshom this study demontrated that relatively accurate results can be obtained using the constant-strain cetrahedral elesent and an icerative-solution algorith, the effort imolved uns coesiderable.

With the high-order isogarmetric eleneats and wre efficieat directsolution algoriths, it becane possible to develop reasosably realistic odels of complex three-dinensional bodies that are sinultaweously within tre capability of these alporfitws. This was damostrated by a comarison betwee analytical and experinental revalts for a one-teatb-scale nodel of the Bartlepool reactor. ${ }^{37}$ Althoun the geonetry of this vessel was wore conplex then that of the veseel previousiy discusced, satisfactory eccuracy was obtained usios a wolel conposed of 41 elenents and 978 defrees of freedon (see Fig- 14). The frostal-solution techaique was used, and

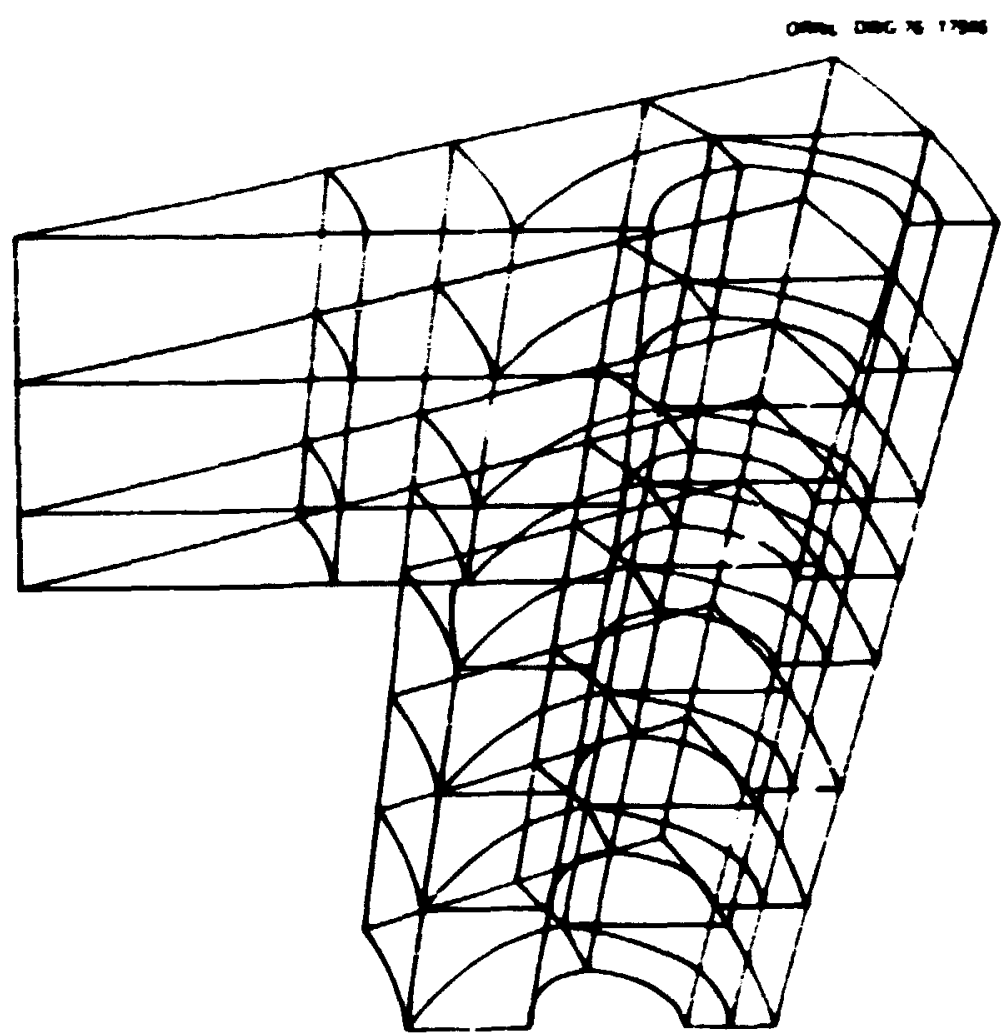

Fis- 14. Finite- clement wech (Ref. 37). 
the solution was obtained with oaly 10 ain conputing the on the $1 \mathrm{~m}$ 360/75. A core complex codel having 177 elements and 3519 degrees of freedon was also used and required 55 an computing tine. The differences between the two solutions were not significant, and both agreed relatively well with the experinental values obtained from the test. A histogran indicates that the afor portion of the variations between experimental and analytical results cere within -30 and $+40 \mathrm{w} / \mathrm{m}$ ( $\mathrm{kin.} / \mathrm{in}$.$) of strain. The standard$

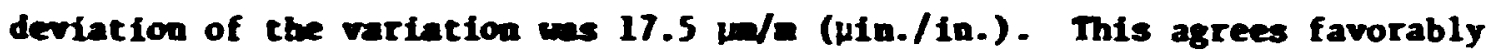
with the 25-ma/n ( $\mu$ in./fn.) standard deviation for sfallar results obtained from a test of the U/fa prestreased concrete pressure vessel ${ }^{30}$ and with the results given by Brener. ${ }^{39}$ Thus, it appears that agreenent within this order of agnitude is as $800 d$ as can be expected for currently avadlable experinental instrunentation. A rather detafled discussion of the problems associated with the assessment of experinental results for PCRV nodels given in Ref. 40 cends to confirn this conclusion.

\section{THE-DEPDDOET BEAVIOR OF CONCRETE}

\subsection{Effects of Tine-Dependent Deformations on a PCRV}

The tine-depeodent deformtions (creep) of the concrete in a PCRV under normal operating cooditions are significant from a design consideration. The anount of deformation ay be several thes the instantaneous elastic deformations and mut be cons'dered to ensure proper equipment alignment and the maintenance of minim tolerances and prestressing forces. They also produce increases in the compressive stress in the vessel liner that my result in liner buckling. Horeover, differences In the creep properties actoss the vessel wall, caused by differences in temperature, hydration, colsture atgration, etc., say lead to significant redistribution of the stresces. If a vessel is subjected in extended periods of prestress wthout internal pressure, the st: $s$ relaxation ay result in censile cracking of concrete along the insite vessel wall upon subsequent pressurizetion, thus jeoperdizing the inte;rity of the iner anchor studs. For these reasons, it is pertinent to consider the 
nature of the tine-dependent response of concrete and the analytical nethods avallable for evaluating this effect.

\subsection{Dasic Characteristics of Concrete Creep}

Hardened portland cement paste is the binder for the concrete aggregate, and the properties of the paste and its bond with the aggregate deternine: (1) the namer in which the concrete responds to changes in temperature and misture, (2) the characteristics of its nonlinear response, and (3) che nature of its fallure. The interior structure of the agsregate has little effect on these properties, provided sound aggregates are used. The paste is an ultrafipe gel-type structure consisting principally of calciu silicate hydrate forned by hydration of the cenent. This iydration process is rapid during the first few days and continues at a decreasing rate thereafter, but remins significant throughout the vessel 1ife. The gradual change in the properties of concrete that occurs during hydration is called aging, and aging introduces one of the ajor complicacions into the analysis of concrete structures.

The hardened cenent paste is a strongly hydrophilic, porous aterial with a typical porosity of 0.40 to 0.55 and normally contains a substantial anount of evaporable water. 41,42 much of the evaporable water is held within pores several wolecules thick by strong surface forces (see Fig. 15). The Internal surface of the pores is enornous - roughly 500 $\mathrm{a}^{2} / \mathrm{ca}^{3}\left(12.7 \times 10^{6} \mathrm{in}^{2} / \mathrm{in} .^{3}\right)$ of cenent paste. Concrete has a relatively low degree of chentical stability, and its nicrostructure reacts to any changes in temperature, weter consent, or stress. The principal wechanis. responsible for the tine-dependent deformation (creep) of concrete is thought to be the migration of molecules or tons of the solid particles of cement paste (perhaps ca fons) from the loaded areas to the unloaded areas, as shown in Fig. 16. The presence of misture facilitates this migration, especially when the water within the pores of the microstructure is soving as a result of differences in relative huidity or tesperature. The loss of cvaporable water within the pores also produces substantial capillary tensions and surface tensions on the walls of the pores, resulting in volunetric shrinkage. 
OAm-0ng $x-17997$

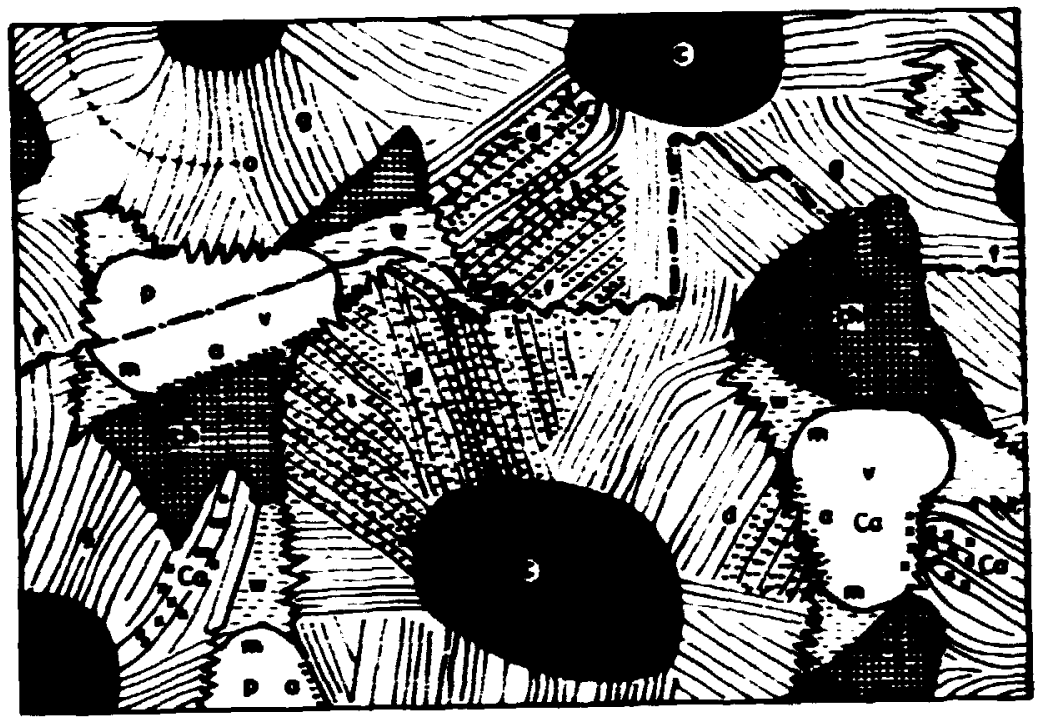

Fig. 15. Idealized schenatsc of alcrostructure of hardened portland cenent paste; a = free adsorbed water wlecules, ca = calctú fons (crosses), c = renaining anhydrous ceneat, ch = calciu hydroxide, d = hindered adsorbed weter mlecules, $f=$ fracture surface, $s$ = ceneat gel (1 ines represent sheets of calciu silicate hydrates), 1 - interlayer water, - capillary miniscus, 0 - original surface of anhydrous cenent grains, $p=$ capillary pore, $v=$ unter vapor and air, $v=$ captllary water (1iquid). Water wlecules and calciu fons are not shown everywere they exist. Width of picture $t_{30} \mathrm{u}(1180 \mathrm{uin.})$. Spacing of sheets $(\sim 30$ X) relistive to lengch of sheets is magnified about 100 tines.

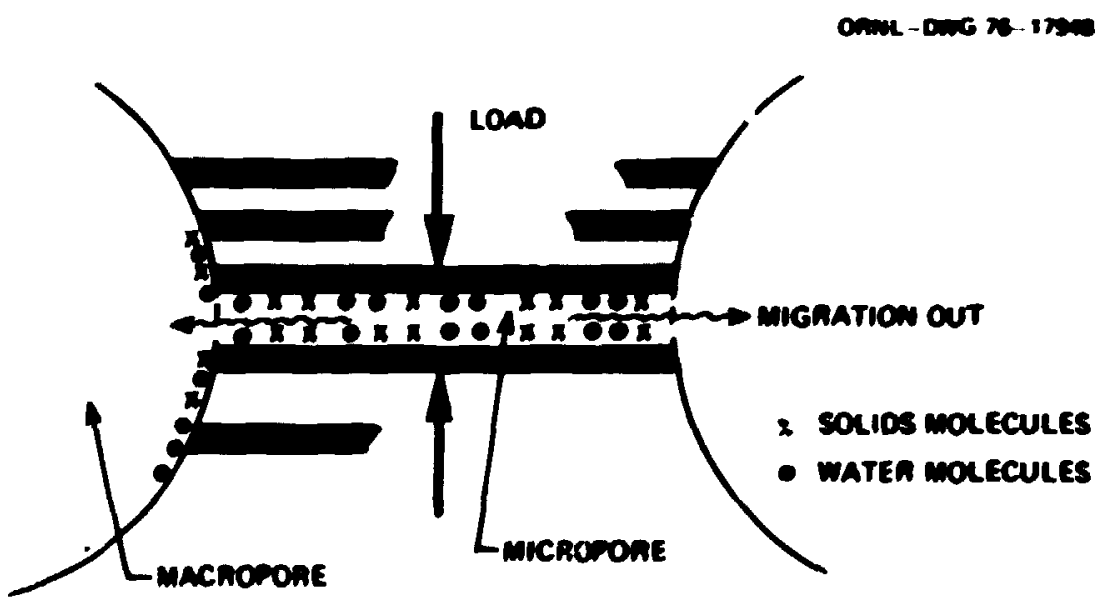

P1g. 16. Idealized drowlog of the creep mechanise in cenent paste. 


\subsection{The Superposition Principle}

Atte-pts to relate creep to processes at the aicrostructural level are plagued by the any and complex interactions; consequent1y, the earliest and wost widely used ecthods for creep analysis are based upon a phesonesological apprasch. In this approsch, the creep response is of tained by perforning tests on concrete saples under representative environental coaditions. To linte the nuber of tests, it is important to seek relations between the various variables and other simplifications. An important simplifying assuption comonly eployed is that the creep response due to an increnent of stress is independent of any previous stress increnents and say be superimpoced linearly on the response due to the previous incresents. This assuption is called the principle of superposition, an without such an assumption, it would be necessary to conduct tests for each streas history of every element in a finiteelenent analysis. If the velidity of this principle ts - -pted, the creep law takes the for

$$
E(t)=J\left(t, t^{\prime}\right) \sigma
$$

where $E$ is the strain caused by the streas $\sigma$ and $J\left(t, t^{\prime}\right)$ is the function (called the creep compliaxce function) that yields the strain at tise $t$ caused by a constant unt: streas applied at tine $t^{\prime}$ (see Fig. 17), both $t$ and $t^{\prime}$ belng measured from the tine of casting. The fact that concrete undergoes a significant aging effect requires that $J$ depend on two separate variables $\left(t\right.$ and $\left.t^{\prime}\right)$ rather than on the one variable $\left(t-t^{\prime}\right)$, as is nornal in classical linear viscoelasticity. Note that $1 / J(t, t)$ equals the instantaneous elastic nodulus $E(t)$. The generalizetion of ES. (14) to continuously varying stress, according to the principle of superposttion, yields the relation

$$
c(t)=\int_{0}^{t} J\left(t, t^{\prime}\right) d \sigma\left(t^{\prime}\right),
$$

where $d \sigma\left(t^{\prime}\right)$ is an infinitesinal increment in stress occurring at time $t^{\prime}$. 

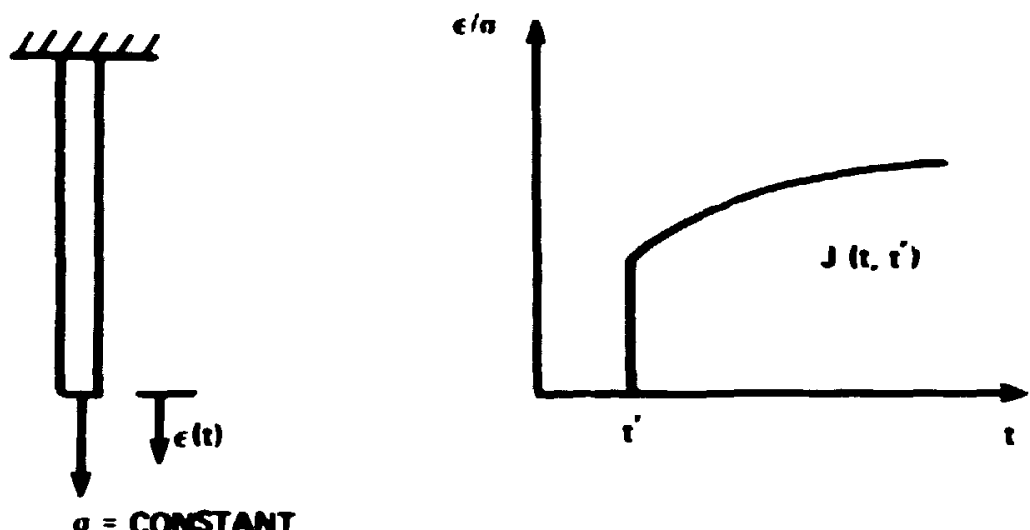

Fig. 17. Creep test and creep compl tance function.

Test results obtained by the U.S. Dureau of Reclantion:3 for mass concrete show fairly close agreenent with those predicted by the principle of superposition. These and later results indicate that under constant temerature and notsture the primciple of superposition yields reasonably accurate results within a stress range approxinately the same as that for which linear elasticity is valid."

With the assumpion that Poisson's ratio is independent of tine, the generalization of the uniaxial creep law to the case of coastant witiaxial stress follows directly and takes the form of the corresponding lav for linear elasticity, "s : hat is,

$$
\begin{aligned}
& \varepsilon_{x}=J\left(t, t^{\prime}\right) \sigma_{x}-w\left(t, t^{\prime}\right)\left[\sigma_{y}+\sigma_{z}\right], \\
& \varepsilon_{y}=J\left(t, t^{\prime}\right) \sigma_{y}-w\left(t, t^{\prime}\right)\left[\sigma_{x}+\sigma_{z}\right], \\
& \varepsilon_{z}=J\left(t, t^{\prime}\right) \sigma_{z}-w\left(t, t^{\prime}\right)\left[\sigma_{x}+\sigma_{y}\right],
\end{aligned}
$$

where

$$
w\left(t, t^{\prime}\right)=\mu J\left(t^{\prime}, t^{\prime}\right)+u_{c}\left[J\left(t, t^{\prime}\right)-J\left(t^{\prime}, t^{\prime}\right)\right]
$$

and $\mu$ and $\mu_{c}$ are the instantaneous and creep F.isson's ratios respectively. The experinental results given in Refs. 45 and 46 indicate that 
the asamption of a constant-creep Poisson"s ratio is reasomable, and the value of this conscant is approximately 0.15 to 0.33 .

\subsection{Interral-Tipe Formilation}

Structural analysis bed on the stress-strain law givea by Eq. (15) wa be performed by the followins zethod. The tocal tine incerval is subdivided at discrete tines $t_{r}(r=1,2, \ldots)$ into tine steps $\Delta t$, and the incegral is approximeted by a fintte son, chat is,

$$
\begin{aligned}
& \varepsilon_{r}=\sum J\left(t_{r}, t_{s-1 ! 2}\right) \Delta \sigma_{s} \\
& \Delta c_{s}=\sigma\left(t_{s}\right)-\sigma\left(t_{s-1}\right) .
\end{aligned}
$$

where subscripts $r$ and s refer rc tiecs $t_{r}$ and $t_{s}$, and $t_{s-1 / 2}$ is an average time within the interval ( $\left.t_{s-1}, t_{s}\right)$. Cosine this approxination, it is possible to formlate the incremental stress-strain las as follows:":

$$
\Delta \varepsilon_{r}=\frac{\Delta \theta_{r}}{E_{r}^{n}}+\Delta \varepsilon_{r}^{\prime \prime}
$$

with

$$
\begin{aligned}
& \frac{1}{E_{T}^{m}}=J\left(t_{T}, t_{T-1 / 2}\right) \\
& \Delta \varepsilon_{T}^{\prime \prime}=\sum_{s=1}^{r-1}\left[J\left(t_{T}, t_{s-1 / 2}\right)-J\left(t_{T-1} \cdot t_{s-1 / 2}\right)\right] \Delta \delta_{S},
\end{aligned}
$$

where $E_{Y}^{\prime \prime}$ is a pseudoelastic odulus and $\Delta \varepsilon_{Y}^{\prime \prime}$ is the inelastic strain increneat due to creep. Obviously, both $E_{r}^{\prime \prime}$ and $\Delta E_{T}^{\prime \prime}$ can be calculated on the basis of previous streas increments prior to calculacing $\Delta \varepsilon_{T}$ and $\Delta \sigma_{T}$. Therefore, the amalysis way be performed as a sequence of elastic amalyses in individual cine sceps $\Delta t$ in which the wodulue of elasticity is $E_{r}^{\prime \prime}$ and the accurulated creep strains $\Delta c_{T}$ are iocorporated as initial strainis using Eq. (9). This procedure is gemerally applicable to any form th the creep function $J\left(t, c^{\circ}\right)$. 
The for of the creep function that enfoys widest international acceptance is

$$
J\left(t, t^{\prime}\right)=\frac{1}{E_{0}}+\phi\left(t^{\prime}\right) F\left(t-t^{\prime}\right)
$$

where $E_{0}$ is a constant representing a typical value of the elastic adulus and $\phi$ and $F$ are continuous, positive, montonic functions of one variable. This form is recomended by the conité Européan de BétonFédération Internationale de la Précontrainte (CEB-FIP)"7 and the Arerican Concrete Institute" . Excellent fits were obtained by Bazant" ${ }^{\text {"D }}$ using a double-power law for the functions $\phi$ and F, that is,

$$
J\left(t, t^{\prime}\right)=\frac{1}{E_{0}}+\frac{\phi_{1}}{E_{0}}\left(t^{\prime}\right)^{-\rightarrow}\left(t-t^{\prime}\right)^{n},
$$

where $\phi_{1}, m$, and $n$ are nondinensional constants. Typically $m$ and $n$ are approximately $1 / 3$ and $1 / 8$, respectively.

Simple, but relatively accurace, approximations are also obtained"s by taking $J\left(t, t^{\prime}\right)$ to be the sum of an age-dependent instantaneous elastic part plus a logarithmic function of time after loading multiplied by a function that accounts for the effect of aging. This form has the advantage that the coefficients in the approximation can be obtained directly from semilog plots of creep strain vs tine.

\subsection{Rate-Type Fornulations}

A difficulty associated with the analysis procedure just discussed Is that at each time step Eq. (19) requires the evaluations of sume over all previous steps for each stress component of every element in the model. This results in extensive storage and computational requirements. The problew can be avolded by approximating the creep function by a series of real exponentials (Dirichlet series), ${ }^{30}$ that is,

$$
J\left(t, t^{\prime}\right)=\frac{1}{E\left(t^{\prime}\right)}+\sum_{i=1}^{n} \frac{1}{\hat{E}_{1}\left(t^{\prime}\right)}\left[1-e^{-\left(t-t^{\prime}\right) / \tau_{1}}\right],
$$


in which $\tau_{1}$ are constants called retardation tines and $\hat{E}_{i}$ are coefficients. Wien this function is introduced into the superposition integral [Eq. (15)]. the integrand degenerates into the product of a function of $t^{-}$and a function of $t$. The latter function does not involve the variable of integration and can be extracted from the integral, leaving only an integra:ion of functions that are indegendeat of $t$. Thus, at each new tine step, it is only necessary to compute the change in value of the integral from the last time step rather than fron the tine of initial loading, as is required in the general case.

A completely stable increaental analysis can be obtafned by numerically approxinating the integral at discrete times $t_{0}, t_{i}, \cdots, t_{N}$ and using the assumption that $d \sigma(t) / d t$ and $\hat{E}_{i}\left(t^{\prime}\right)$ are constant within each time interval. ${ }^{30}$ The increnental stress-strain lav becones

$$
\Delta \varepsilon_{T}=\frac{\Delta \sigma_{r}}{E_{r}^{\prime \prime}}+\Delta \varepsilon_{T}^{\prime \prime},
$$

in which

$$
\frac{1}{E_{r}^{11}}=\frac{1}{E_{r-1 / 2}}+\sum_{i=1}^{n} \frac{1-\left[1-e^{-\Delta t_{r} / \tau_{i}}\right] \tau_{i} / \Delta t}{\left(\hat{E}_{t}\right)_{r-1 / 2}}
$$

and

$$
\Delta \varepsilon_{r}^{\prime \prime}=\sum_{i=1}^{n}\left[1-e^{\Delta t_{r} / \tau_{1}}\right]\left(\varepsilon_{1}^{*}\right)_{r-1}
$$

The effect of prior stress history is contained in the variabla $\varepsilon_{i}^{\star}$, which is defined by the recurrence formula

$$
\left(\varepsilon_{1}^{*}\right)_{r}=\frac{\Delta \sigma_{r}\left[1-e^{-\Delta t / \tau_{1}}\right]_{\tau_{1} / \Delta t_{r}}}{\left(E_{1}\right)_{T-1 / 2}}+\left(\varepsilon_{i}^{*}\right)_{r-1} e^{-\Delta t_{r} / \tau_{1}} .
$$


Thus, the difficulty of conputing sus involving the complete stress hir:tory at each tine step is avoided.

It can be shown ${ }^{59}$ that the Dirichlet series is the solution to the syste of differential equations

$$
\begin{aligned}
& \dot{\varepsilon}=\dot{\sigma} / E+\sum_{i=1}^{n} \dot{\varepsilon}_{i}, \\
& \dot{\varepsilon}_{i}=\sigma_{i} / n_{i}, \\
& \dot{\sigma}=\dot{\sigma}_{i}+\hat{E}_{i} \dot{\varepsilon}_{i},
\end{aligned}
$$

when a unt step stress $\sigma(t)$ is applied at tine $t^{\prime}$. This systen of equations, wich corresponds to the physical system shown in Fig. 18, is called the Kelvin chain model. The response of a typical element of the Kelvin chain in series with the spring elenent to a stress pulse is shown in Fig. 19. Since the formulation defined by Eqs. (27) states the relations between the rates of stress and strain, it is referred to as a rate-type formulation.

Although the rate-type formulation of fers computaticnal advantages, the identffication of the aterial parameters from experfaental data is difficult. This problem was discussed by Bazant in Ref. 50, and an algorith was presented that was successfully used to fit various published data. In a later publication, ${ }^{51}$ an inproved algorith was presented along with its FORTRAs program listing.

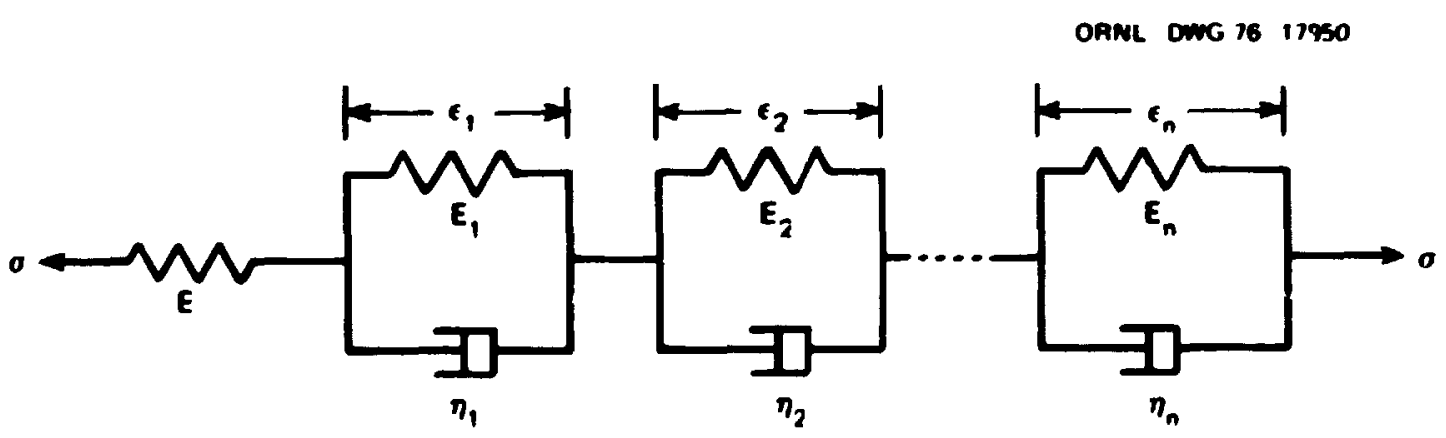

Fig. 18. Kelvin chain model. 

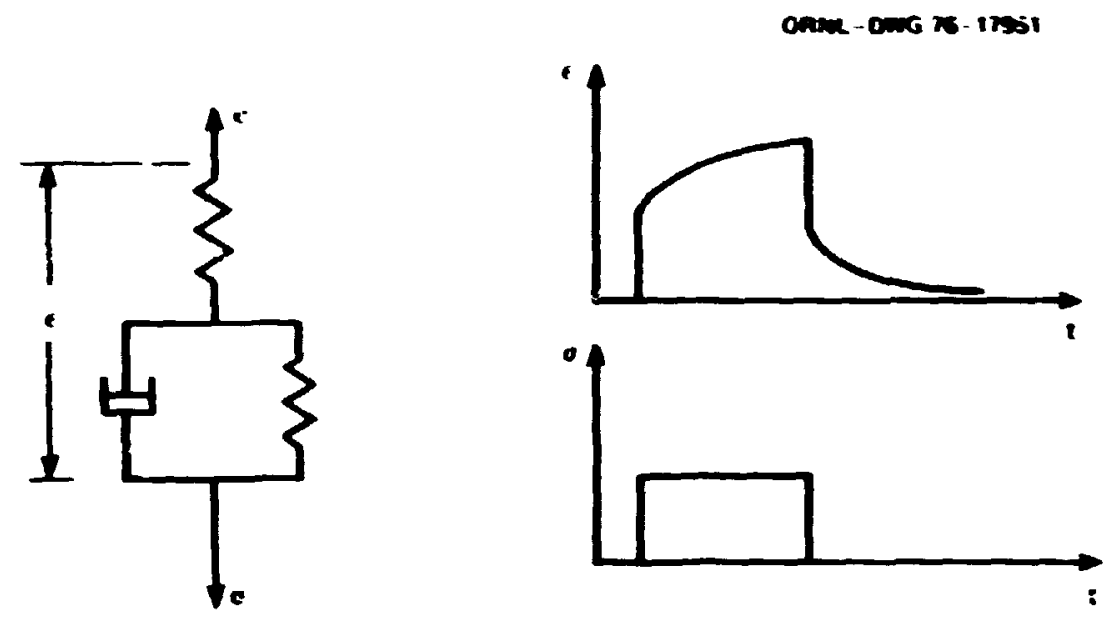

Fig. 19. Typical response of a Kelvin elenent in series with a spring elemerit.

An alternate rate-type form is obtained if relaration functions, rather than creep compliance functions, are expanded in a Dirichlet series. ${ }^{52}$ Matheatically, the relaxation function $E\left(t, t^{\prime}\right)$ is defined by

$$
\sigma(t)=E_{r}\left(t, t^{\prime}\right) \varepsilon,
$$

where $\sigma(t)$ is the stress as a function of tine due to the application of a constant strain $\varepsilon$ at tine $t^{\prime}$. The function $E_{r}\left(t, t^{\prime}\right)$ yields the stress at tine $t$ caused by a constant unit strain applied at tine $t^{\prime}$ (see Fig. 20). By direct substitution, it can be snown that the Dirichlet series

$$
E_{r}\left(t, t^{\prime}\right)=\sum_{i=1}^{n} E_{i}\left(t^{\prime}\right) e^{-\left(t-t^{\prime}\right) / \tau_{1}}
$$

is the solution to the system of differential equations

$$
\begin{aligned}
& \sigma=\sum_{i=1}^{n} \sigma_{1}, \\
& \dot{\varepsilon}=\left[\dot{\sigma}_{1}+\sigma_{1} / \tau_{1}\right] / E_{1}\left(t^{\prime}\right),
\end{aligned}
$$


Onine Ding n-179se
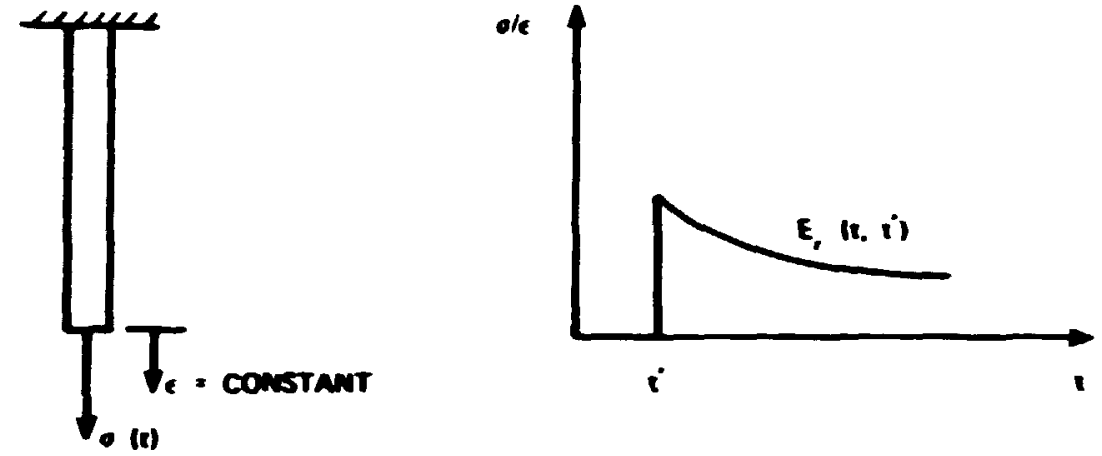

Fig. 20. Relaxation test and the relaxation function.

when a unit strain $c(t)$ is applied at tine $t^{\prime}$. This systen of equations corresponds to the physical systen shown in Fig. 21 and is called the Maxurell chain sodel. The response of a typical elenent of the Maxarell chain in parallel with the spring elenent to a stress pulse is show in Fig. 22. One of the anor differeaces between the flaxwell and Kelvin chain nodels is the part played by the single spring elewent. In the Kelvin chain model, all the instantaneous response occurs in this elewent, whle in the Maxwell wodel, there would be no time-dependent recovery upon unloading without the single spring element.

One difficulty associated with the Maxwell sodel is that the timedependent properties are usually characterized by the creep function $J\left(t, t^{-}\right)$, while the deternination of the parameters requires knovledge of the relaxation function. If the superposition principle is assuned to be valid, the relaxation function is uniquely defined in terms of che creep function as the solution to the integral equation

$$
h\left(t-t^{\prime}\right)=\int_{t^{-}}^{t} J(t, \lambda) \frac{\partial E_{r}\left(\lambda, t^{-}\right)}{\partial \lambda} d \lambda,
$$

where $h\left(t-t^{\prime}\right)$ is the unit step function. The listing of a computer program to numerically deternine the relaxation values correaponding to a general creep function is contained in Ref. 53 along with an algorith for computing the asterial parameters associated with the Maxwell chain adel. 


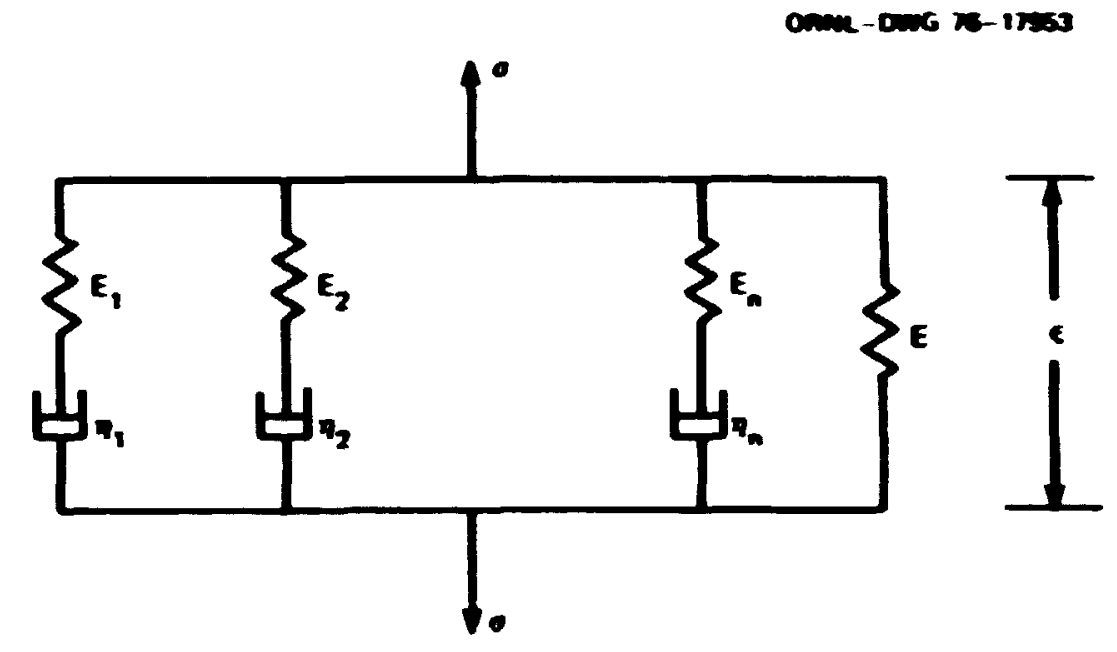

Fig. 21. Maxwell chain odel.
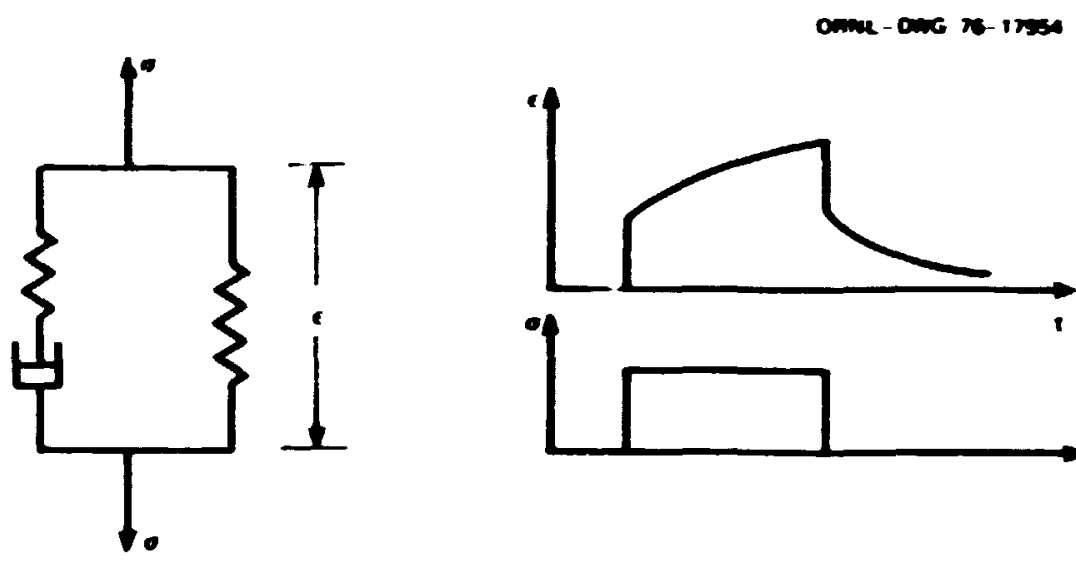

Fig. 22. Response of a Maxwell elenent in parallel with a spring element.

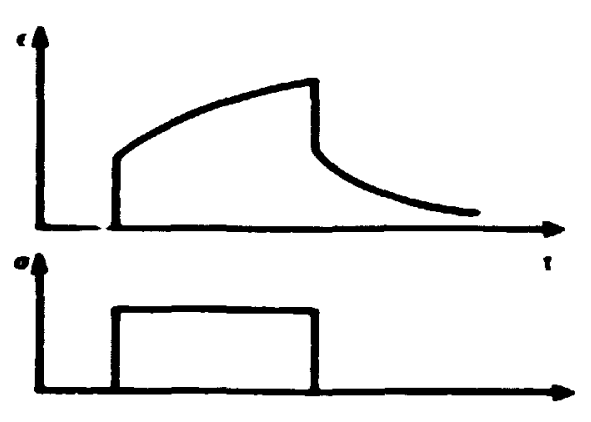

An Increaneatal stress-strain Iaw corresponding to Eq. (24) but based on the Maxwell chain is contained in Ref. 52. As with the Relvin model, the stress history in the increnental $\mathrm{law}$ is defined by a recurrence relation, thus elininating the need to su the complete stress history at each tine step.

It was found that equivalent accuracy was obtaloned for the Maxwell chain with siapler expreastons thas those required for the Kelvin chein. 
Additional advantages arise for the Maxwell wodel when the ef fects of temperature and huidfty changes are fncluded.

\subsection{The Ef fect of Teaperature Changes}

As a structural mterial, concrete has a relatively low degree of chenical stability and consequently its properties are strongly affected jy changes in temperature. The process of cenent hydration that gives rise to aging is a chenical process that fo accelerated by increases in temperature. The aigration of mlecules or fons of solid particles that produces creep deformation is also accelerated by increases in tenperature. Thus, temperature directly influences the defornation rat. and ihe rate of aging of concrete.

A type of temperature dependence that is particularly amenable to analytical description is applicable to the class of materials that are referted to as being thermo-rheologically simple. ${ }^{54}$ With materials of this class, changes in tepperature cause the creep or relaxation functions to undergo a simple horizontal shift when plotted with $\log \left(t-t^{\prime}\right)$ as the abscissa (see F18. 23). Thus, if

$$
C_{T}\left(t, t^{\prime}\right)=J\left(t, t^{\prime}\right)-J\left(t^{\prime}, t^{\prime}\right)
$$

is the specific creep at temperature $T$ and $C_{T_{0}}\left(t, t^{\prime}\right)$ is the creep at ceuperature $T_{0}$, then

$$
C_{T}\left[\ln \left(t-t^{\prime}\right)\right]=C_{T_{0}}\left[\ln \left(t-t^{\prime}\right)+\phi(T)\right]
$$

or

$$
C_{T}\left(t-t^{\prime}\right)=c_{t_{0}}\left[\left(t-t_{0}\right) e^{\phi(T)}\right]
$$

where $\phi(T)$ is called the teaperature-shift sunction.

Using published data, Sackan"s found that concrete behavior could be modeled with sufficient accuracy with this wodel. Mukaddan and Bresler ${ }^{36}$ generalized the nodel to laclude the efiect of tapperature on concrete 


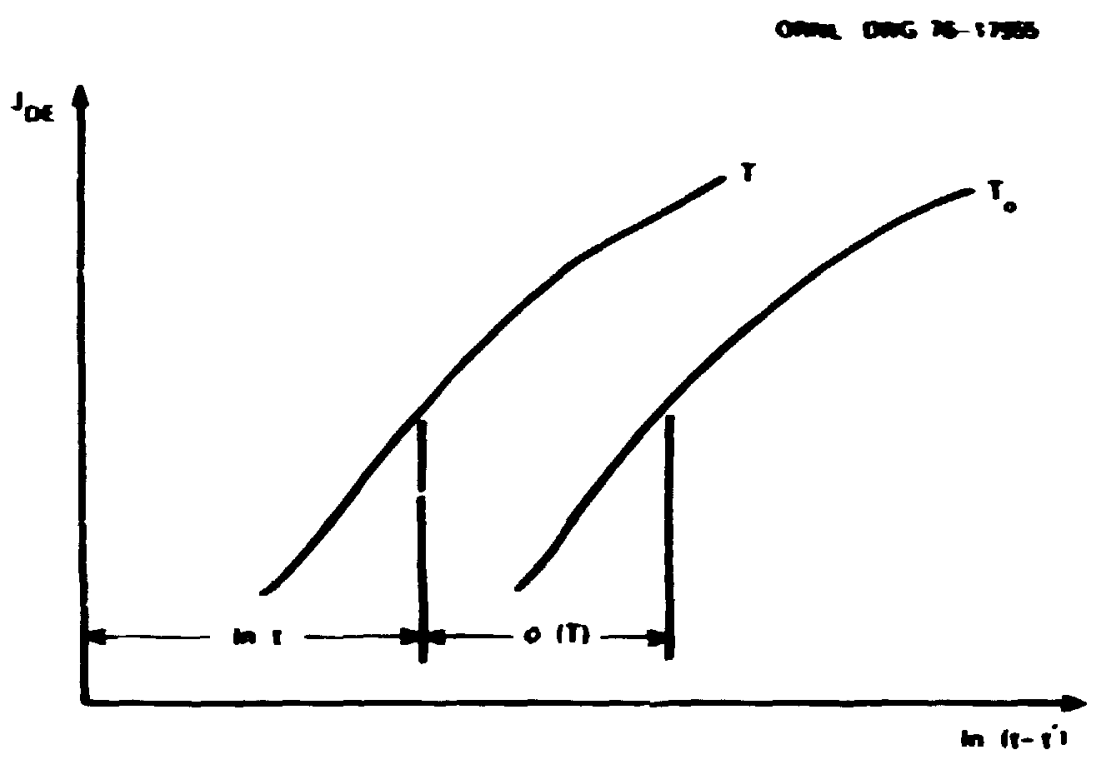

Fig. 23. Tine-temprature shift principle.

aging by introducing a second shift function, $\vec{v}(g)$, where $g$ is an equivalent age as a function of te-perature. This concept was applied to the Kelvin chain wode:'

$$
c_{T}\left(t-t^{\prime}\right)=\sum_{i=1}^{n} c_{i} e^{-\lambda\left(t-t^{\prime}\right) \phi(T ; \phi(g)}
$$

where

$$
\psi(8)=a_{0}+a_{1} e^{-a_{28}}
$$

and

$$
g=\tau_{0}+\sum_{1-1}^{n} \Delta \tau_{1} e^{-A\left(T_{1}-T_{0}\right)}
$$

This form of the law was used to fit the Wylfa reactor tata, 57 and a satisfactory fit was obtained. 
Incorporating the teaperature ef fect into the creep law corresponding to the Maxiell codel is rather siple. Equation (27) is rewritten as

$$
\begin{aligned}
& J=\sum \sigma_{i} \\
& \dot{\varepsilon}=\frac{\dot{\sigma}_{i}}{E_{i}\left(t_{e}\right)}+\frac{\sigma_{i}}{n_{i}\left(t_{e}\right)},
\end{aligned}
$$

where $n_{i}$ is the age-depentent viscosity associated with the ith Maxwell unit, which equals $\tau_{i} E_{i}$ at constant temperature $T$. Since creep is a thermally activated proiess, it is koon from physics that $n_{i}$ should depend on tenperatire according to the Arrhenius equation,

$$
\frac{1}{n_{i}}=\frac{1}{\overline{7}_{0}} \exp \left[\frac{U_{i}}{R}\left(\frac{1}{T_{0}}-\frac{1}{T}\right)\right] .
$$

where $T_{G}$ is the reference teperature, $\eta_{0}$ is the value of $\eta_{\text {at }} T_{0}, R$ is the universal gas constant, and $v_{i}$ is the activation energy of the $i$ ih Maxwell unit. The effect of temprature on aging is represented by making $E_{i}$ and $\eta_{i}$ dependent on $T_{e}$ rather than on $t$, where $\Delta t_{e}$ is an equivalent hydration period that yields the same degree of hydration at temperature $I$ as occurs during a period $\Delta t$ at temperature $T_{0}$. This equivalent time is given by

$$
\Delta t_{e}=B_{T} \Delta T
$$

with

$$
B_{T}=\exp \left[\frac{U_{h}}{R}\left(\frac{1}{T_{0}}-\frac{1}{T}\right)\right],
$$

in which $U_{h}$ equels the activation energy for hydration. The wethod of identifying $U_{i}$ and $U_{h}$ froe test data, given in Ref. 58, is related to a tine-tesperature shift of the relaxation curves. It has been demonstrated that various published data on elevated-temperature creep are properly fitted by the concept. 
Although the creep lars discussed above seen to provide adequate fits of the experinental data, wost have not been validated for states of stress or environeatal coaditions sivlating those existing under PCAV operating conditions. In particular, even if the theories provide adequate fits of isotheral creep daca, it does not necessarily follow that the implied methentical generalization to tefe-varying teperature conditions is valid. In particular, it is ksown that under high rates of change in teqperature, a cemporary acceleration of creep. called transitional theral creep, occurs. Although this effect ay not be of incerest under nomal PCRV operations, It my be significant uader certain accident situations. Sone cest data are avaflable in the literature, and a cheory based upon thermodynanc principles has been developed."2 in the sinplest forn, this effect can be included by replacing $\eta_{i}\left(t_{e}\right)$ in Eq. (35) by

$$
n_{1}\left(t_{e}\right)[1+k \dot{T}]
$$

where $\mathrm{k}$ is a constant to be found from test data. In general, additional research to experinentally validace the coaputational procedures under tine-varying tempratures would be desirable.

\subsection{The Effect of Hoisture Changes}

The behavior of concrete becones nore coeplex then the nofsture content varies within the pores. This wovenent of notsture produces an acceleration of the creep in the zones of changing molsture content. The development of constitutive equations for this condition is enhanced by utilizing the principles of irreveretble thernodyaancs of altiphase systens. Tw kinds of pores in the cenent paste nust be distinguished: the aicropores, wich are less than 10 eolecules thick, and the nacropores, which are larger. The alcropores probably are predoninanty laninar in shape, ax the water nolecules are held by very streng adsorption forces. The acropores contain capillary weer and atr of varyin:, aunce, dependIng on the degree of waturation. Thernodynanic equilibrtu between the adsorbed water (referred to by the subscript d) and capillary water (subscript c) exists when

$$
\mathbf{G}_{\mathbf{d}}=\mathbf{C}_{\mathbf{c}}
$$


where G equals the Gibbs' free energy of wier per unit aass (also called the chenical potential). The free energy $G$ is defined by its total differential

$$
\begin{aligned}
& G_{d}=-S_{d} d T+\Gamma_{w}^{-1} d \pi+p_{d} \Gamma_{v} d \ell_{d} \\
& G_{c}=-S_{c} d T+v_{c} d p_{c} .
\end{aligned}
$$

In which $s$ is the entropy per unit mas, $\Gamma_{w}$ is the mas of witer per unit area of the pore's surface, $\pi$ is the spreading pressure of the water at the surface of the adsorbed layer, $p_{d}$ is the disjoining pressure of water across the layer, $l_{d}$ is the thickness of the water layer, $P_{c}$ is the pressure within the capillary water, and $v_{c}$ is the specific volue of the capillary water. The atcropores are part of the load-cartying aicrostructure, and thus changes of the thickness $t_{d}$ are associated with acroscopic strains.

The conditions of thermodymanic equilibriun require equality of the Gibb's free energies per unit mass of the water within the aicropores and the macrorores and sinilarly for the walls of the solid aicrostructure. The mass flux of the water and solids between the aicropores and the acropores is thus assuned to be proportional to the differences in their respective free energies. Using these basic relations and certain auxiliary ones, it is possible to deduce the form of the constitutive equations for the volumetric deformations:

$$
\begin{aligned}
& \dot{\sigma}_{s_{i}}+\phi_{s_{i}} \sigma_{s_{i}}=E_{s_{i}}\left(\dot{\varepsilon}-\dot{\varepsilon}_{s}-\alpha_{s_{i}} \dot{\mathrm{T}}\right) \\
& \dot{\sigma}_{w_{i}}+\phi_{w_{1}} \sigma_{w_{1}}=E_{w_{i}}\left(\dot{\varepsilon}-\dot{\varepsilon}_{s}-\alpha_{w_{i}} \dot{\mathrm{T}}\right),
\end{aligned}
$$

where $T$ is the temperature, $a_{s}$ and $a_{w_{1}}$ are thermal dilation coefficsents, $\dot{\varepsilon}_{s}$ is the instantaneous shrinkitge strain due to a change in the specific water content, and $\phi_{s}$ and $\phi_{w_{1}}$ are coefficients.

The basic difference between the present equation and the previous rate-type formulation for constant wolsture, Eq. (28), is that in the present equation it is necessary to distingutsh between two types of hidden stresses (those carried by the water in the vicropores, $\sigma_{w_{1}}$, and 
those cartied by the solids, $\sigma_{s_{1}}$ ) and the two associated elastic molu$1 i E_{w_{i}}$ and $E_{s}$. For the case wen $\dot{\varepsilon}_{s}=\dot{T}=0$, the werer becones inoobile and one fay lup the hidden stresses and elastic moduli as follows:

$$
\begin{aligned}
& \sigma_{i}=\sigma_{s_{i}}+\sigma_{w_{i}} \\
& E_{i}=E_{s_{i}}+E_{u_{i}} .
\end{aligned}
$$

and Eq. (45) reduces to Eq. (28). The race roefficients $s_{s_{i}}$ and $\theta_{u}$ are the principal coefficients determining the effect of hidity on creep. These coefficients decrease with decreasing weer content and sharply increase when there is a difference in the Gibbs' free energy potential $\left(G_{d}-G_{c}\right)$, thus correctly edeling the creep of predried concrete ard the acceleration of creep due to induced misture movenent as in drying.

The manerical values of the paraneters involved in Eq. (4j) were identified, and good agreenent with previous test data was demonstrated in Ref. 59. The stable tine-step algorith developed for the Maxwell chain representation, given in Ref. 52, has been extended for Eq. (45); however, the use of independent hidden stresses in the wter and the solid will require twice as wch computer machine tine and storage as required for Eq. (28).

Fur mass concrete structures, the effect of wisture changes has been generally igmred, because the loss of nolsture to the acosphere occurs only to a depth of several feet from the surface. However, this does not preclude the existence of significant wisture movement that might be induced by the sustained temperature gradient across the wall that exists in the PCRV during normal operacions. The significance of the effect of noisture wovewents on the creep occurring in a PCRV under nornel operating conditions has not been evaluated at this tine. A coordinated experinental and analytical progran to ascertain the validity of this constftutive eodel and then proceed to an analytical investigation of the ef fect of molsture migration on a PCRV under various operating conditions would be desirable. Such a study would. provide greater insight into the significance of this effect and basis for either rejecting or accepting the hypothesis that the effect can be ignored. 


\subsection{Effective Madulus Hechod}

When the changes of $O$ from tine $t^{\prime}$ to tine $t$ are very small, as acceptable approximation of the resulting strain is

$$
c(t)=\frac{\sigma(t)}{E_{\text {eff }}\left(t, t^{\prime}\right)}
$$

vith

$$
E_{\text {eff }}=\frac{1}{J\left(t, t^{\prime}\right)}
$$

where $\bar{E}_{\text {eff }}$ is called the effective codules. This equation has the form of a libearly elastic law, and linearly elastic finite-eleneat codes ay be ufed to andyze structures for chese conditions. The primary deffelency In applyins this wethod to the analysis of a Pas is that differences in creep strains within the structure (due to differeaces in temperature and age of the concrete and the presence of steel) produce redistributions of stress with tive. As the approxination is ouly valid for sall changes in stress, this method is oaly applicable for relatively shott tine intervals.

\subsection{Decomstrated Results}

It is difficult to obtain reliable experineatal data on the tinedependent response of a PCAN for eaviromental conditions and loadings representative of sctual operating conditions. As previously discusced, couctete is senofitive to both temperature and nolsture conditions, and each of these mut be carefully controlled. One is also faced with the problen that the experinental instrunentation (in porticular, enbedded strain gagea) is neither very reliable nor very accurate." Decause of these problems and the high cost aseoctaced with tests of this type, there are osly a linfted maber of experinencal validations of the analjtical methode for tine-dependent conditions approximing chose existing in a PCaV under operating condition. In addition, it to not posefble to escablish a consiscent set of factors for model scaling that neets the requirenentes of dineneionsl sinilicude. ${ }^{\circ}$ Thus, the trend has been efther 
to we a full-size vesuel as a direct verification of the ressei respocse or co we a scale oodel to validate a aniftical ecthod an chen use the analytical nethod to extrapolate the molel resalts to the full-siae vesibel.

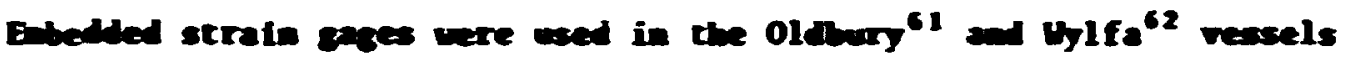

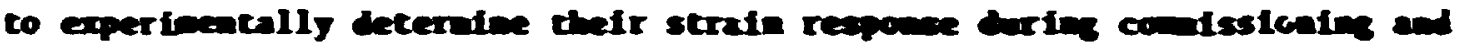
early life. The seateet in the experinental resalte fron the oldbur vessel wos so excessive that general conclosions sre wor justified (see Fig-

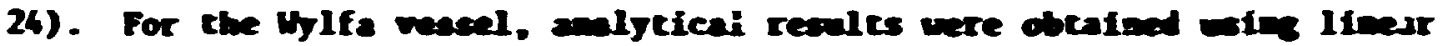
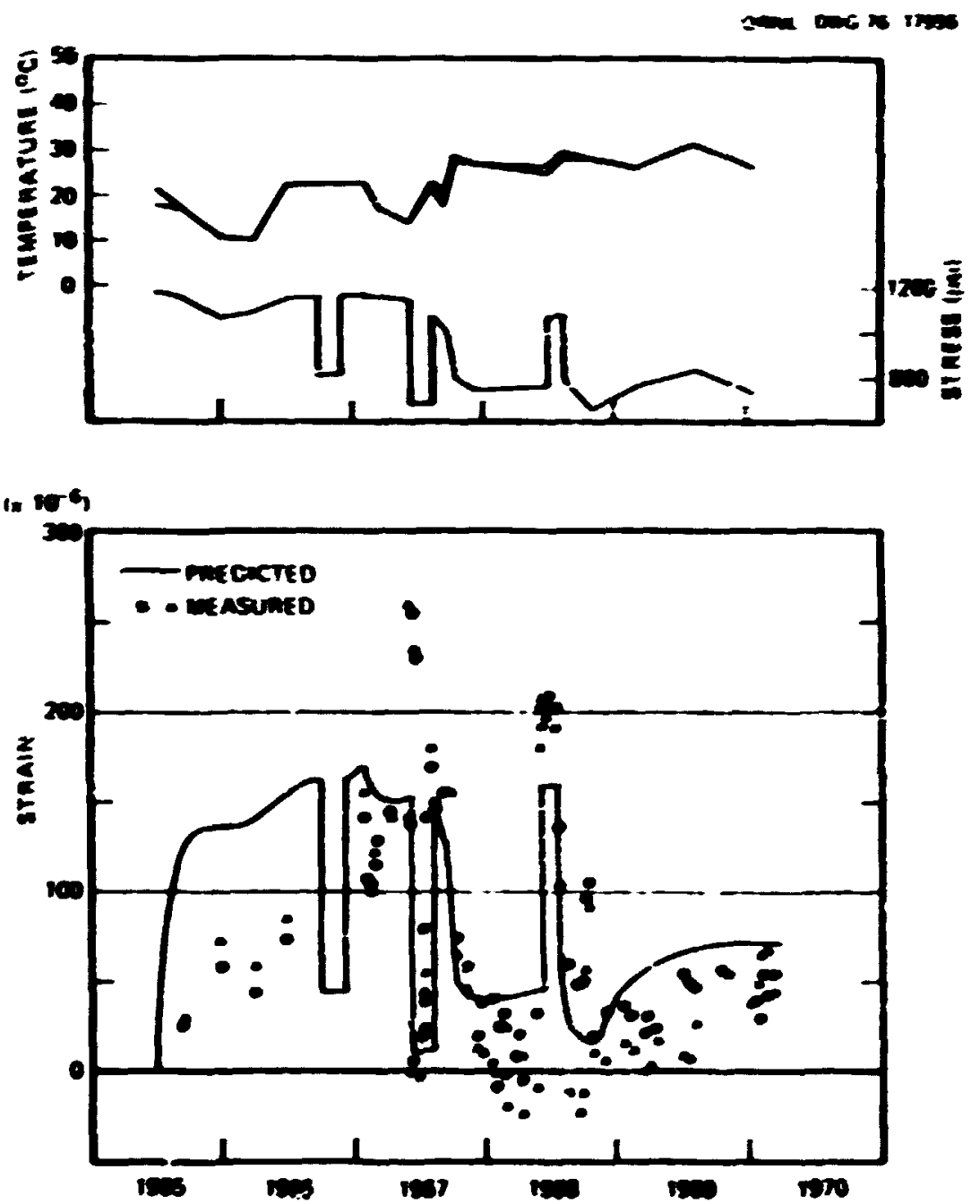

F18. 24. Neasured teperature and strain and calculated hoop streas and strain at eage 41 in 0ldbury reasel (Ref. 61). (1 psi = $6895 \mathrm{~Pa}$ ? 
superpositicn for cilinges in load and temperature and a power-law type of creep law. The agrecment between these results art the experimental results was very good (see Fig. 25).

For the Fort St. Vrain reactor, a scale nodel of tha vessel was used to validate the analytical wethod. Two saparate analyses were published. Ir. whe first, ${ }^{1 ?}$ a logarithaic fors of the creep law was used with the superposition princsple to account for changes in load and teaperature. A nonlinear modification was introduced into the superposition principle in an attempt to correct the tendency of the linear theory to overestinate the straill recovery during unloading. Generally good agreenent was obtained between the analytical and experimental results (see Fig. 26). In a later analysis, ${ }^{57}$ linear superposition was combined with an analysis rhat included a cracking model for the concrete. The tinc-temperature shift algorithm due to Sackman ${ }^{55}$ was used to accouct for the effect of temperature on creep. (The effect of tesperature on aging was not included in the analysis.) The results of both analyses vere essentially the sane.

The latter analysis method was also used to obtain results for the Oak Ridge thermal cylinder experiment. ${ }^{63}$ A sealed, thzck-wall, cylindrical vessel, without restraining heads, was subjected to internal pressure, axial and circumferential prestressing, and a temperature crossfall. Good agreemenc was obtained between the experinental and analytical response throughout the loading history; however, the analysis significantly underestinated the creep strains during the heatup phase of the experiment (see Fig. 27), and the resulting error remained essentially constant throughout the remainder of the test. The source of this error is not fully understood but may be related to transitional thermal creep previously discussed In Sect. 3.6.

These test results seew to indicate that, with the posstble exception of cases involving large thermal transients at high rates, the time-jependent response of a PCRV cai be determined with sufficient accuracy by utilizing a constitutive model based on the linear superposition principle, an appropriate creep law, and constant Polsson's ratios for both elastic and zreep strains. However, the results of the Oak Ridge thermal cylinder test seem to indicate that the creep response during thermal transients may not be accura'sely accounted for if the temperature change is large. 

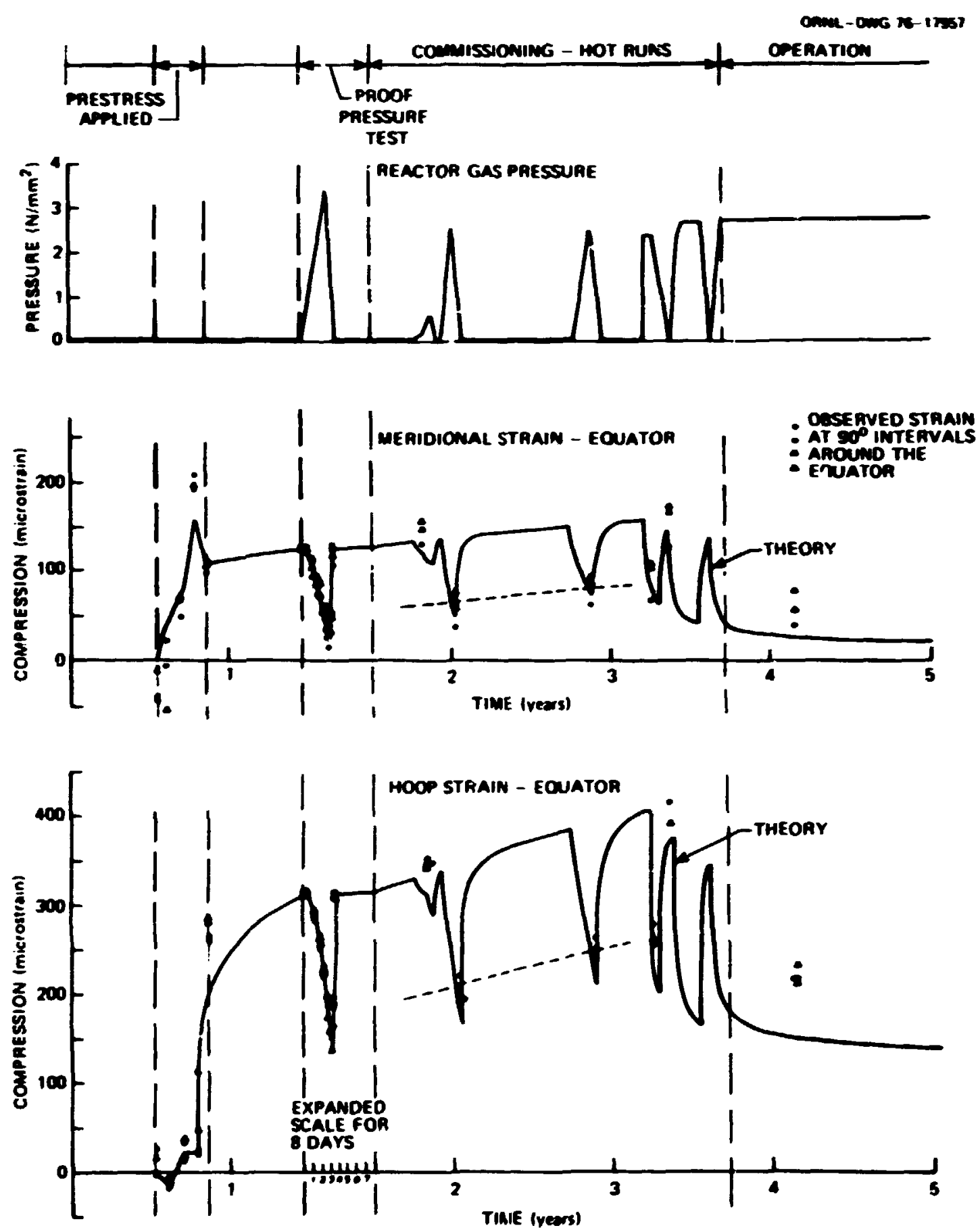

F18. 25. Measured and predicted BLrain changes with time related to operating conditions for the Wylfa reactor vessel. (Gages located at four positions at $90^{\circ}$ intervals around the equator and $300=10.98$ ft) frow the inside face of the vesse: wall (Ref. 62). (1 N/min $1 \mathrm{MPa}=145 \mathrm{psi}$ ) 


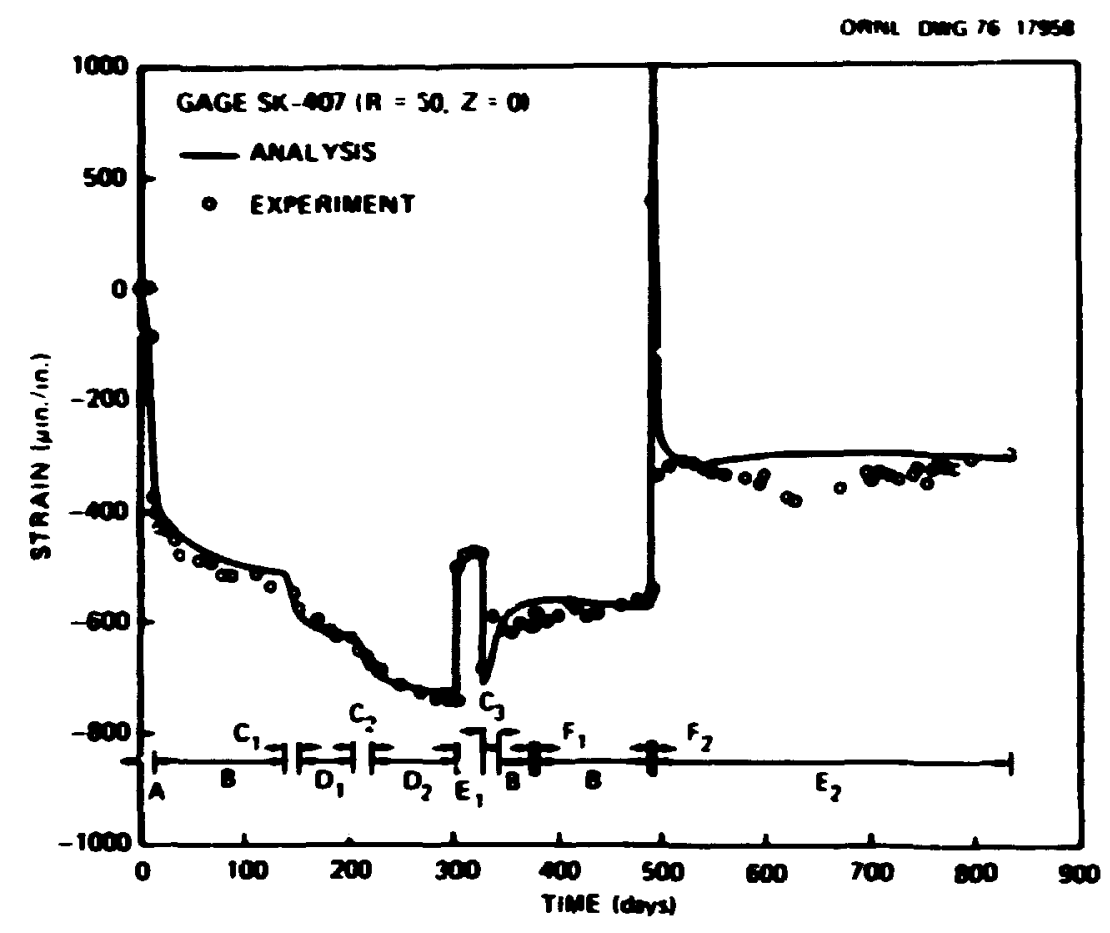

F1g. 26. Circunferentill concrete strain at inner midplane (Ref. 13). Sec Ref. 13 for explanation of test activities. (1 $\mu$ in./in. = $1 \mu / m)$

\section{THE-INDEPEADEST ROILINEAR BEHAVIOR OF CONCRETE}

\subsection{Basic Characteristics}

Perhaps the wost important consideration in the design of a prestressed concrete reactor vessel is the assurance of an adequate margin of safety dgafnst failure by fiternal pressure. If adequate argins are obtained for noral operating conditions by the use of elastic and time-dependent analysis methods, it remains only to validace the vessel performance for overpressures due to potential accident conditions. Because concrete is relatively weak in tension, the basic philosophy in the design of conrsete pressure vessels is to maintain compressive stresses under the action of Internal pressure through the use of prestressing tendons. At a certain level of overpressure, the effect of prestressing is overcome and tensile cracking develops in the concrete. In addition, due to the restraining 


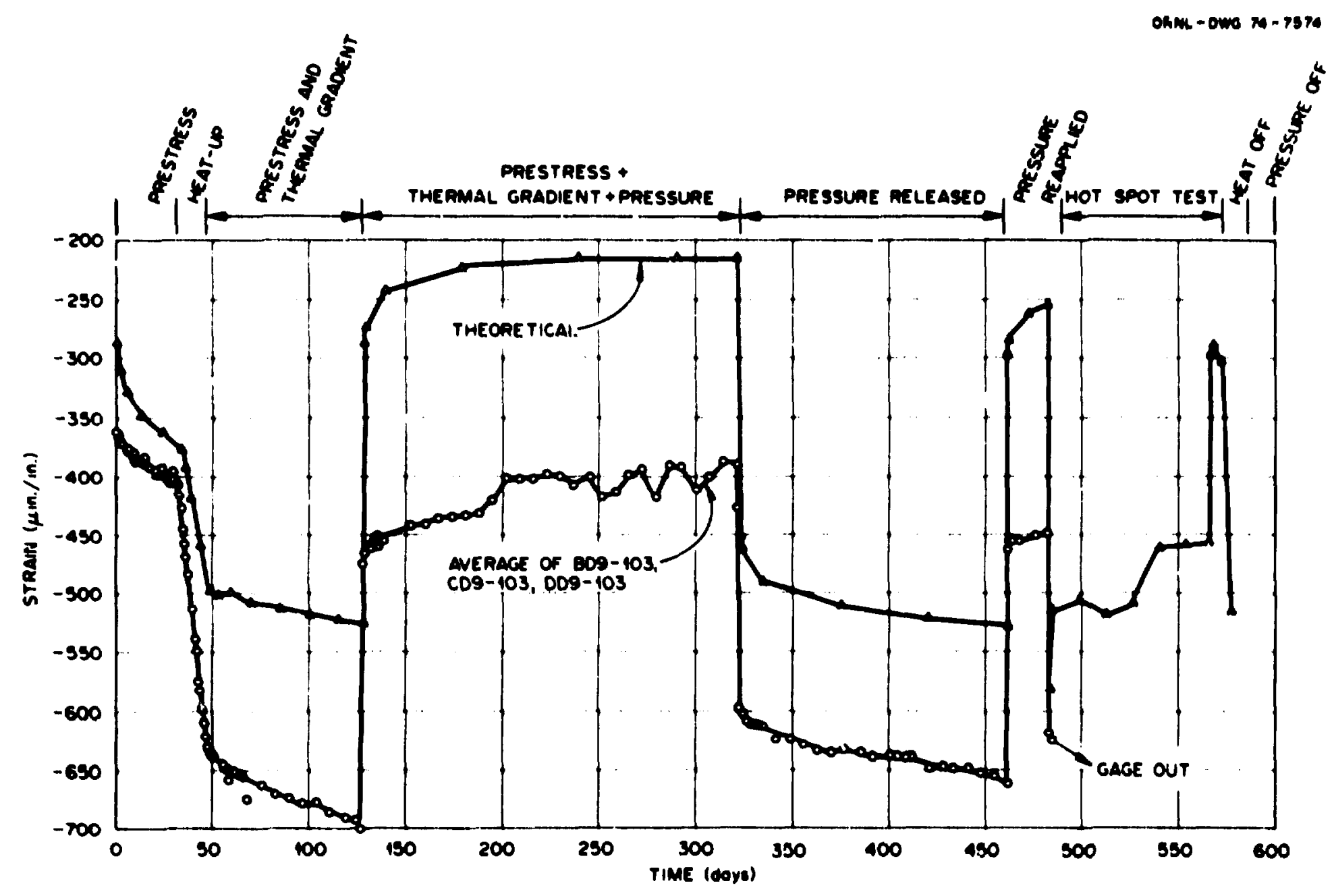

F1g. 27. Theoretical vs experimental straina for average of three circumferential type $A$ vibrating-wire embedment gagea in position closest to Inner liner (Ref. 63). (1 $\mu \mathrm{ln} . / 1 \mathrm{n}$. - $1 \mu \mathrm{m} / \mathrm{m}$ ) 
effect of the head on the will deformations of the vessel, large values of shearing and copreasive streases develop in the head and head-to-vessel intersection. Tr predict the response of the vessel to accidental overpressures, it is aecessary to conduct analyses that include tensile cracking and the noolinent stress-strain response of concrete at high stress levels. Since it is inconceivable that an accident causing high internal pressure would be of lons duration, only short-tine nonlinear behavior is of interest.

It is useful to regard concrete as a structure consisting of large aggregates (gravel) bonded by mrtar, which is a structure of fine azgregates (sand) bonded by cenent paste. The elastic noduli, Poisson's ratios, thermal expansion coefficients, and long-tive deforation properties of the gravel, cortar, and cement paste usually differ, and therefore, any lcading or ceaperature change produces self-equilibrated internal stresses in the acrostructurn. These stresses are further intensifled by any drying shrinkage in the cenent paste.

Under low triaxial confinement pressure, the weakest links in the microstructure are the paste-aggregate Interfaces; therefore, the internal stresses first produce afcrocracking at the interface bonds. This microcracking at the bonds between the wrtar and the large aggregates, show in Fig. 28, is the main source of the non!.Inear stress-strain response at high stresses and subsequent concrete failure. The inelastic strain due to this microcracking is accomanied by volume dilatation, a circunstance that differs significantly from the inelastic response of ductile metals. Failure occurs due to coalescence of bond microcracks by various modes into interconnecting cracks within the mortar.

The behavior of concrete under high triaxial conf ining pressure is completely different. Formation of bond microcracks is prevented and very large shear strains can be achieved withut signiffcant daage to the macerial. Particles of cement paste, subjected to shear, are able to slide relative to each other while continuously breaking and reforning bonds. The same phenowena exist within the bond zone between the wortar and aggregate. Under very high confining pressure, concrete exhibits as wuch ductility as meti.1s do, and, as with metals, no volume change accompanies this type of inelastic strain. 


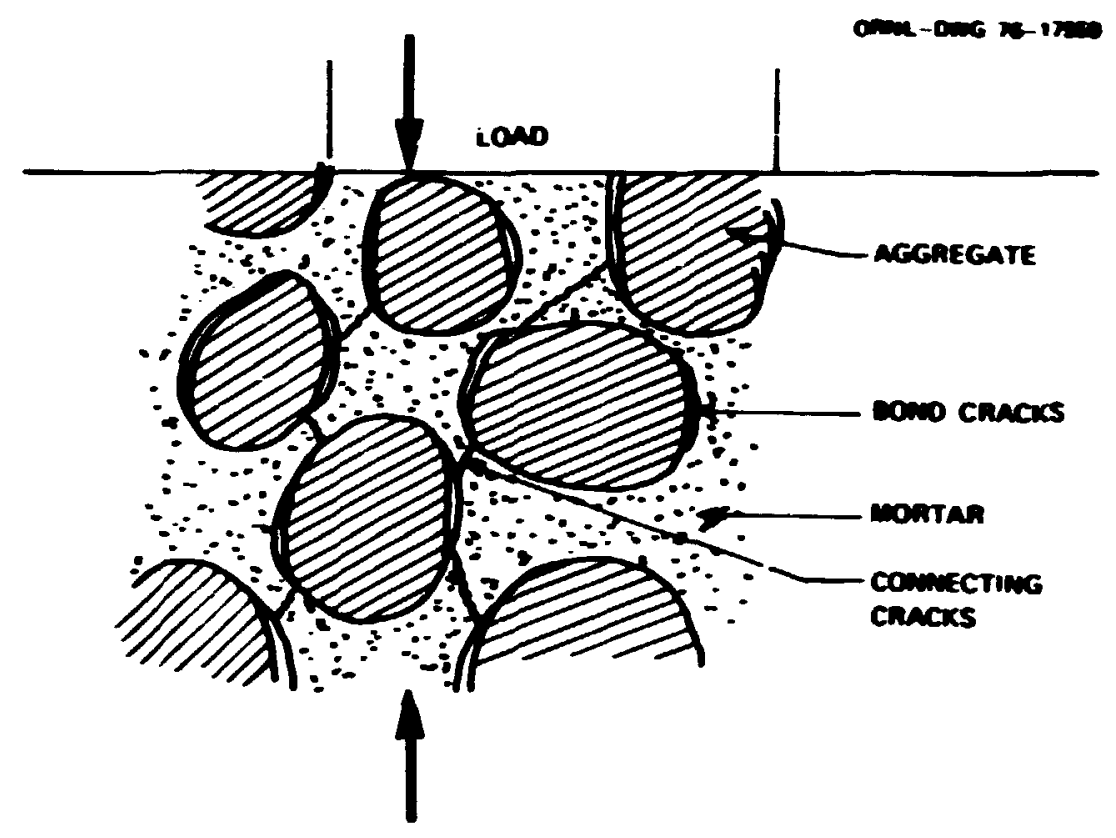

Fig. 28. Schenatic drawing of microcracking in concrete.

There have been a number of efforts directed toward understanding the complex behavfor of concrete through the use of ifealized ncdels. An interesting example of this work is described in Ref. 64. Nine circular disks representing aggregates were esbedded in a mcttar matrix to produce a square array (see Fig. 29). This nodel was tested under bjaxial stress, and the results were compared with those obtained from a finite-element analytical idealization. In the analysis, the material componenc: were assumed to be elastic, and the Mohr-Coulomb shear theory of failure ${ }^{65}$ was used to predict the loss of cohesion at the aggregate interfaces. If the tensile stress in the nortar exceeded its measured tensile strength, a "crack" was introduced by approprtate modification of the material properties. Even with this highly idealized codel, the agreement between the expertmental and analytical stresses at fallure was very good, as seen in Fig. 30, and boch results exhibited the chiracteristic features of the biaxial failure surface of conventional concrete. The stress-strain response of the two models, however, did not agree very well, and neither reproduced the features that characterize conventional concrete (see Figs. 31 and 32 ). 


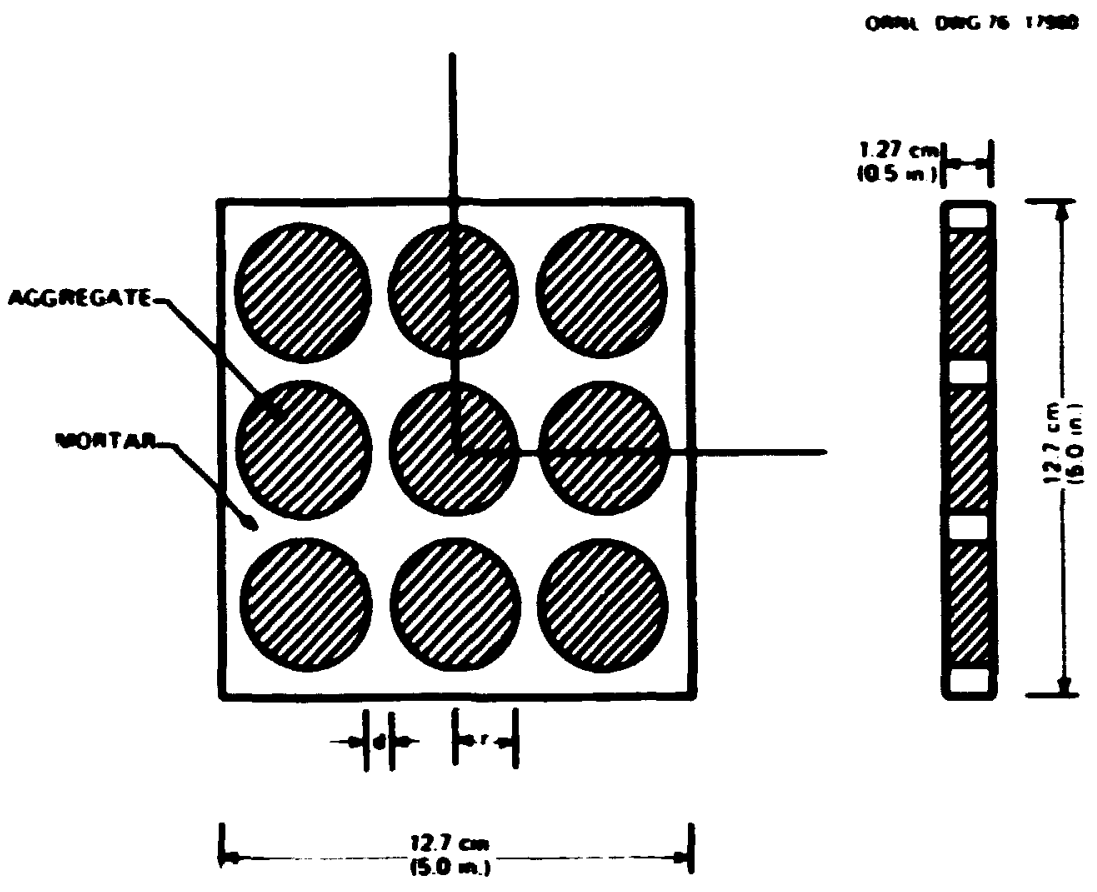

Fig. 29. The concrete model (Ref. 64).

Although idealized wodels provide qualitative descriptions of concrete behavior and confire that the primary mechanisa is initiation and propagation of microcrac's, they do not provide a quantitative description of sufficient accuracy for detalled analysis of concrete structures. Thus, as in the case of time-dependent response, the description of the timeindependent nonlinear response of concrete must be based on an empirical description obtained from detailed testing.

One of the major difficulties encountered in the te;ting of concrete subjected to blaxial and triaxial stresses is the development of loading fixtures capable of producing a well-defined and uniform stress state in the specimen. This is thought to be the prinary reason for the considerable deviation commonly found in biaxial cest data reported by vartous investigators. For example, reported strength values for equal biaxial compression are found to vary from 80 to 3507 of the uniaxial compressive strength, with the higher values obtained winen rigid platens are used and the lower values obtained when well-lubrizated platens are used. Although Poppel" had shown in 1900 that a prismatic specimen may be confined along 


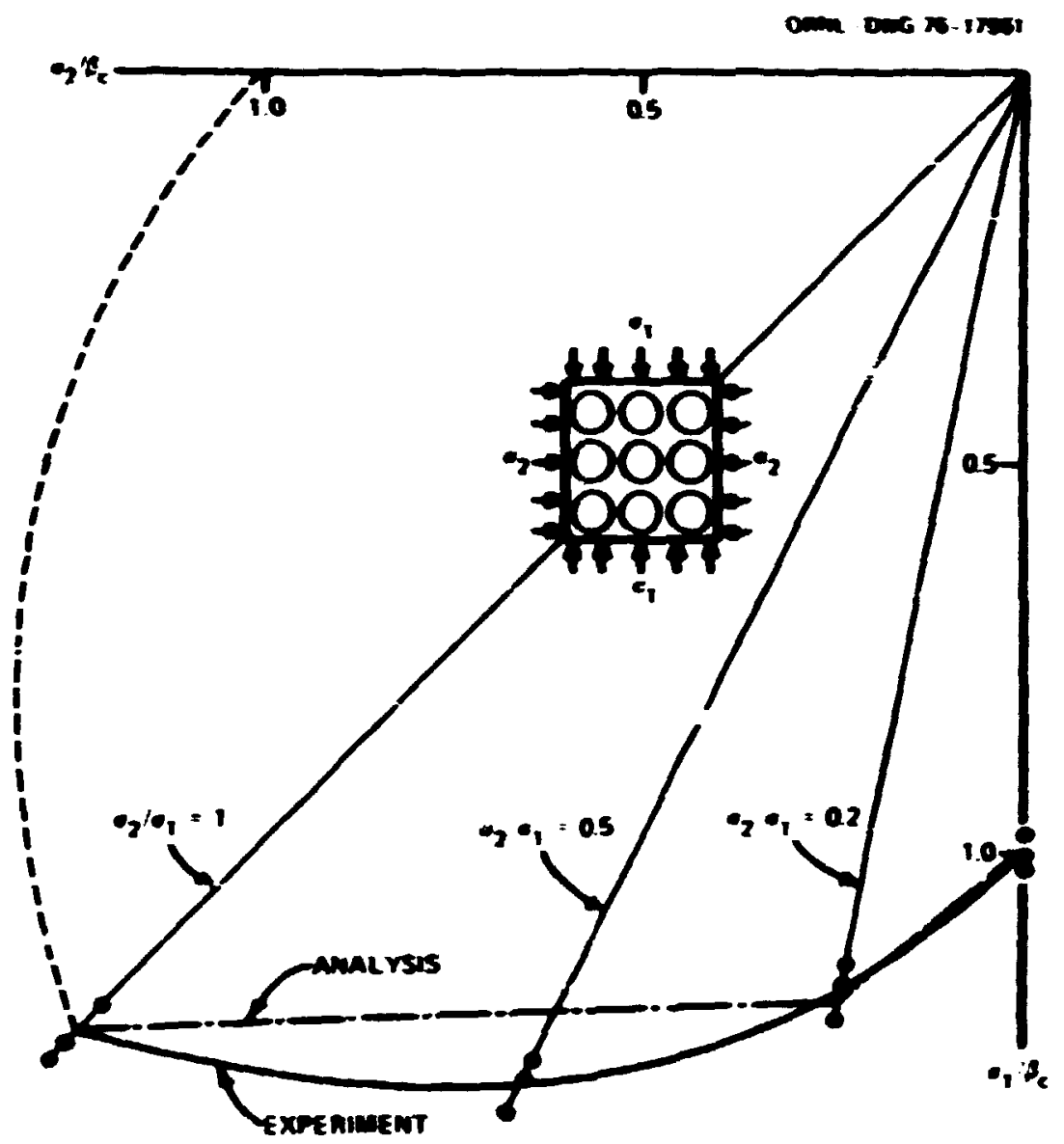

Fig. 30. Shizegeth envelope for model with $d / r=0.5$ (Ref. 64).

its laading surfaces by friction and that such restraint results in an increase in the apparent stizfness and streagth of the specinen, it was not until 1965 that a complete!y satisfactory solution was found.

To overcome the problew of end restraint, Hilsdorf ${ }^{67}$ developed a brush bearing platen consisting of closely spaced sall steel bars that are flextble enough to follow lateral deformations wthout significant restraint but yet have sufficlent buckling stiff ness to transint the required compressive forces (see Fig. 3?). Using the brush platen systen, Xupfer, H1ledorf, and Rusch" conducted a series of biaxial cests of concrete specimens of vartous strengths. The fallure stresses for the various concretes, normaltzed by dividing by the angnitude of compressive strength, are shown in Fig. 34. It can be seen in the figure that the nornalized 


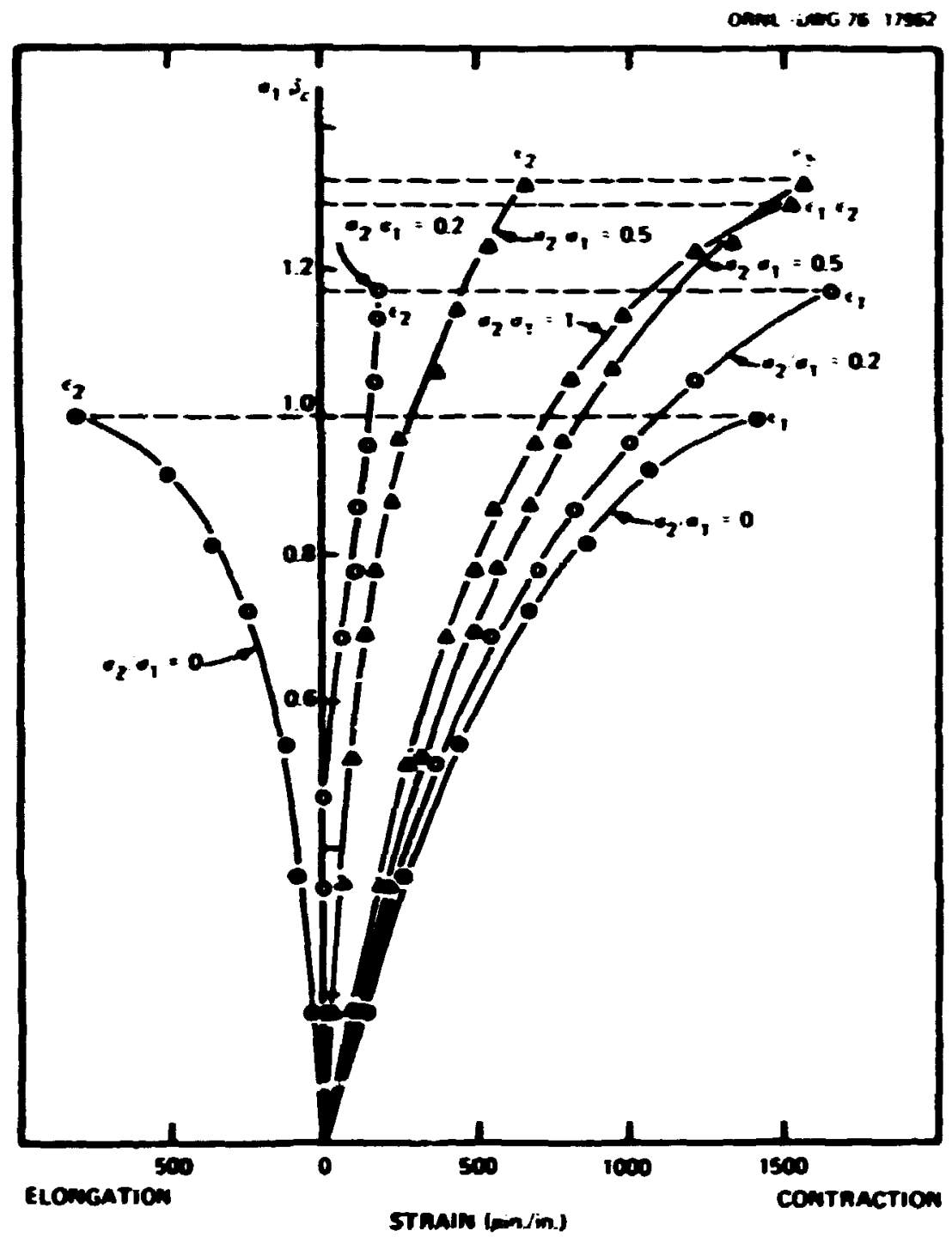

F18. 31. Experimental stress-strain curves for wodels with $d / r=$ 0.5 (Ref. 64). (1 pin./in. = $1 \mathrm{va/s}$ )

strengths for various biaxial stress ratios are only slightly affected by the concrete atx. Also, the strengths under biaxial tension are essentially the sase as those under uniaxial tension.

The stress-strain relations obtained in these tests for biaxial compression, coubined tension and compression, and biaxia! tension loading are shown In Figs. 35, 36, and 37, respectively. As seen in these figures, the stress-strain relations for compressive loading are quite nonlinear, 


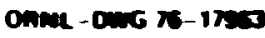

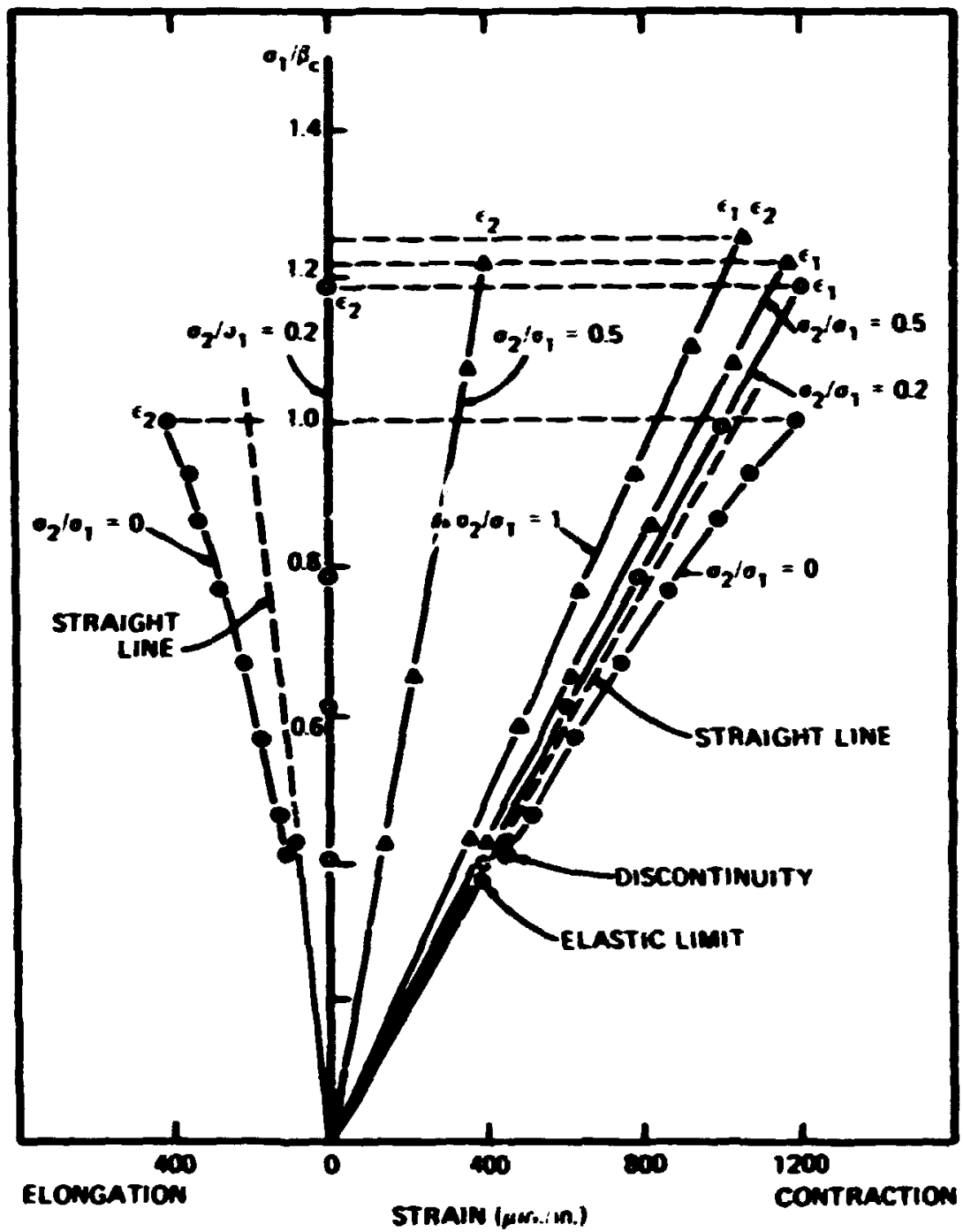

Fig. 32. Stress-strain curves obtalned from finite-elenent analysis

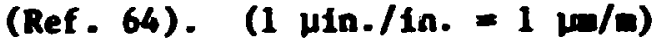

while under tensile loading the relations are essentially linear. Plots of volumetric strains under biaxial compression are show in Fig. 38 . It can be seen in the figure that silght nonlinearity beging at about 407 of the failure stress, while at approxinately $95 \%$ of the failure stress, the minimun volume is obtained and a major inflection exists in the curve. It is generally agreed that this inflection point coincides with the stress 


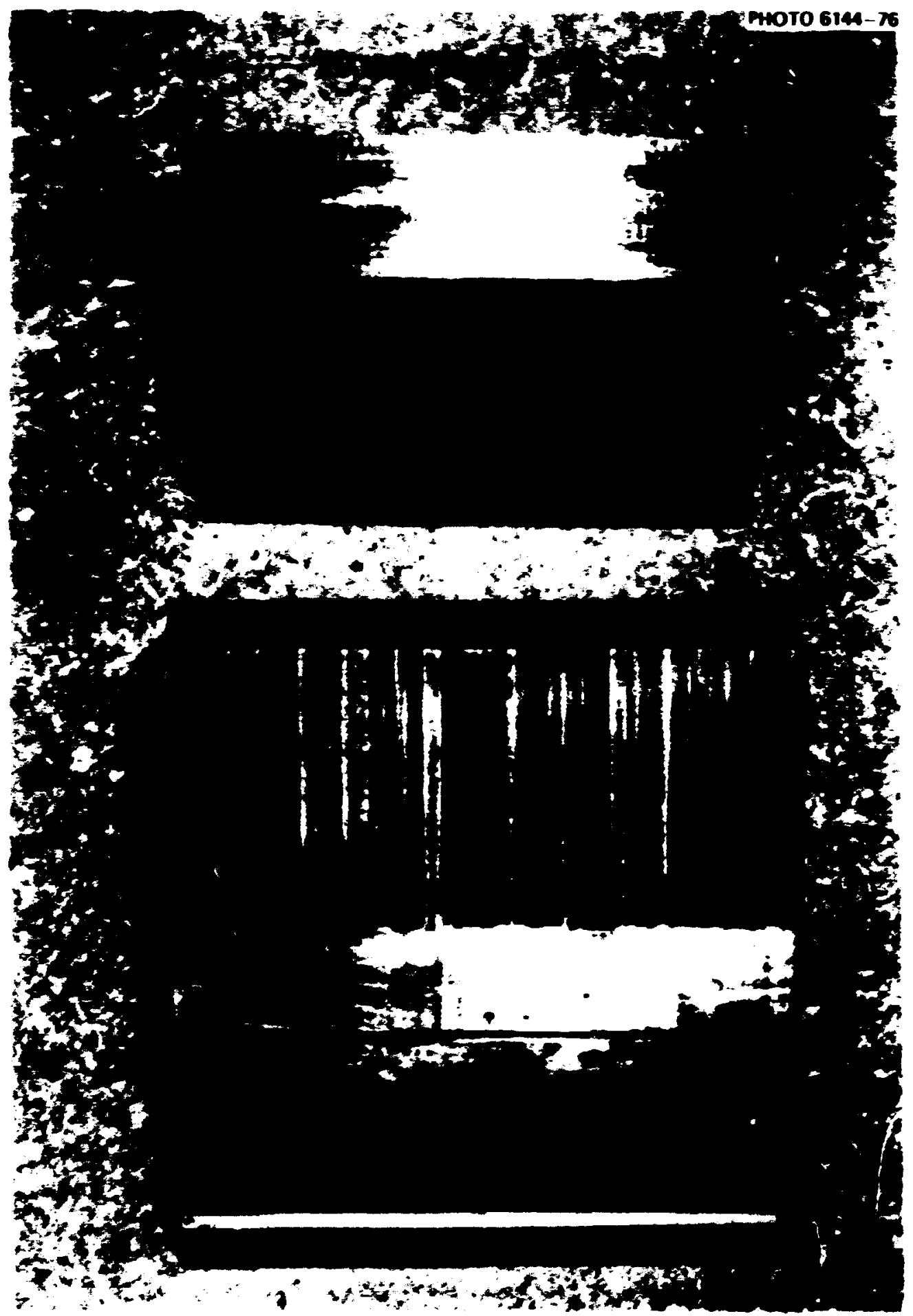

F1g. 33. Brush bearing platens; dimensions of fllaments: $5 \times 3=$ $(0.195 \times 0.118 \mathrm{in.})$; spacing of fllaments: $0.2 \mathrm{~m}(0.0008 \mathrm{in.})($ Ref. 68). 


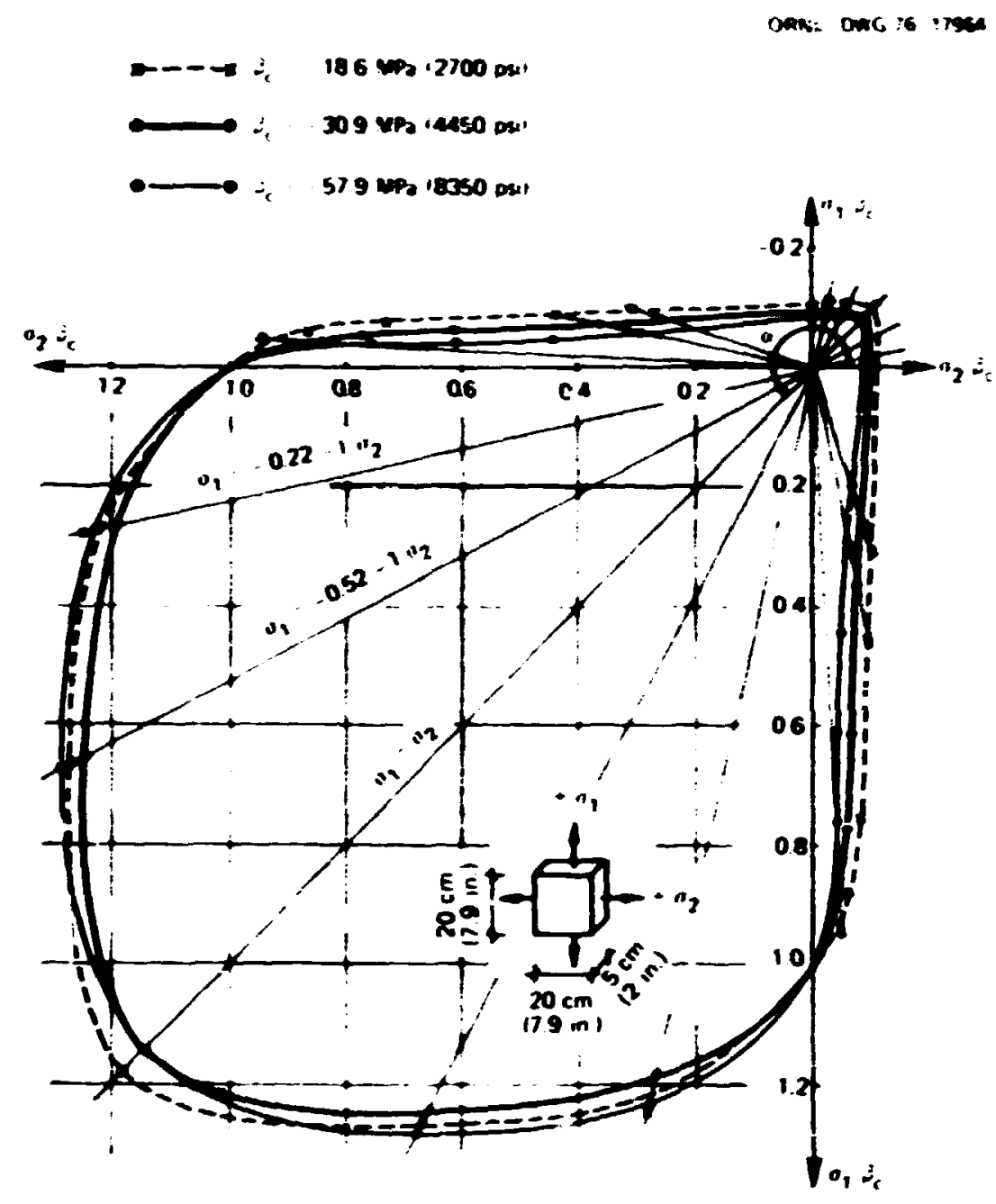

Fig. 34. Biaxial strength of concrete; results of experimental investigation (Ref. 68).

at which major aicrocracking occurs. An important aspect of these test results is that the ratios between the various significant stress levels appear to be essentfally independent of the biasial stress ratio (see fig. 39). This implies that the same functional form can be used to define these various stress levels in strcss space, a fact that is of ten used in modeling concrete response.

Recentiy, there have been a numbar of experfmental investigations into the behavior of crncrete under blaxial and triaxial loadings, with the ajor emphasis placed on establishin"; appropriate failure criteria. ${ }^{6-71}$ 


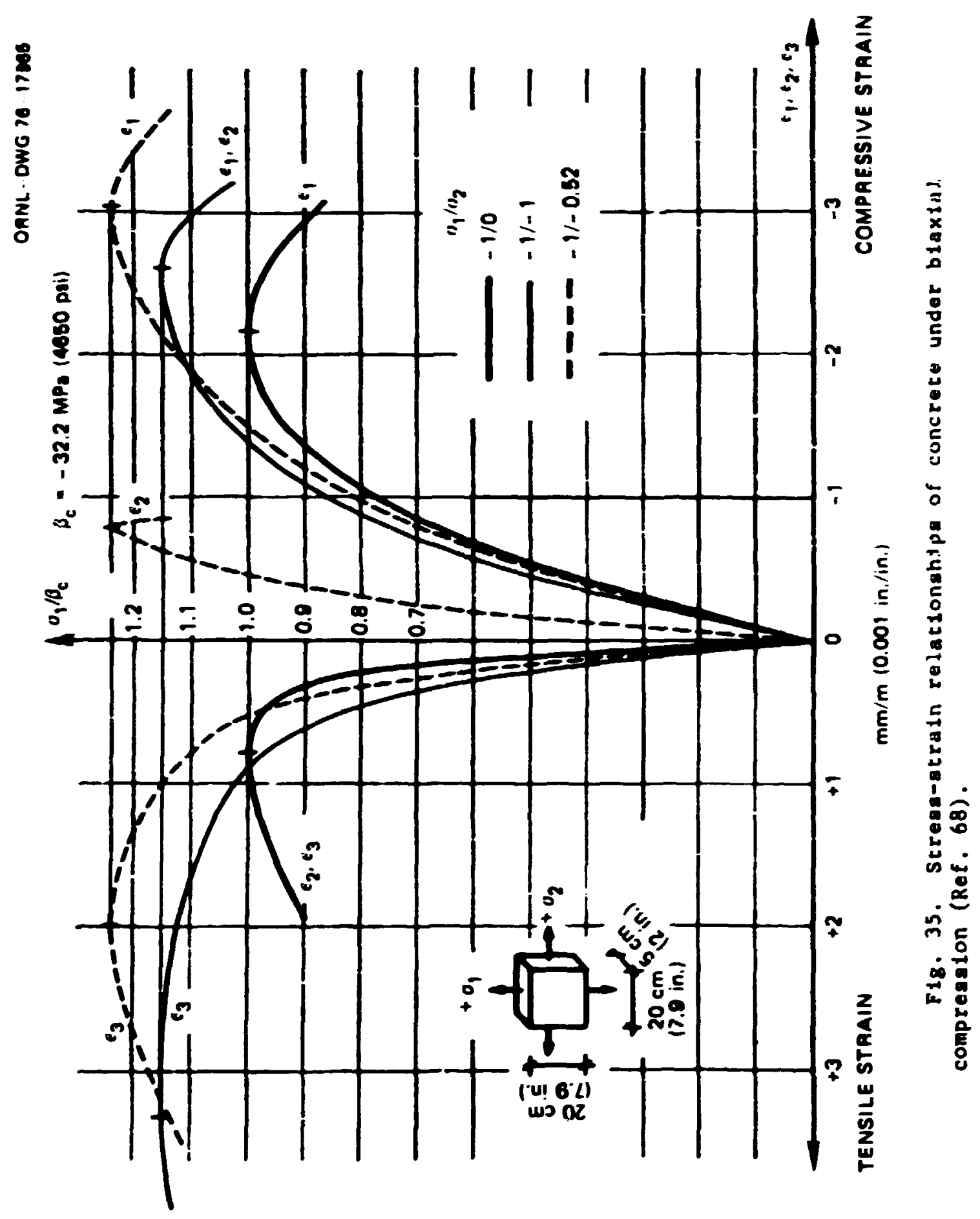




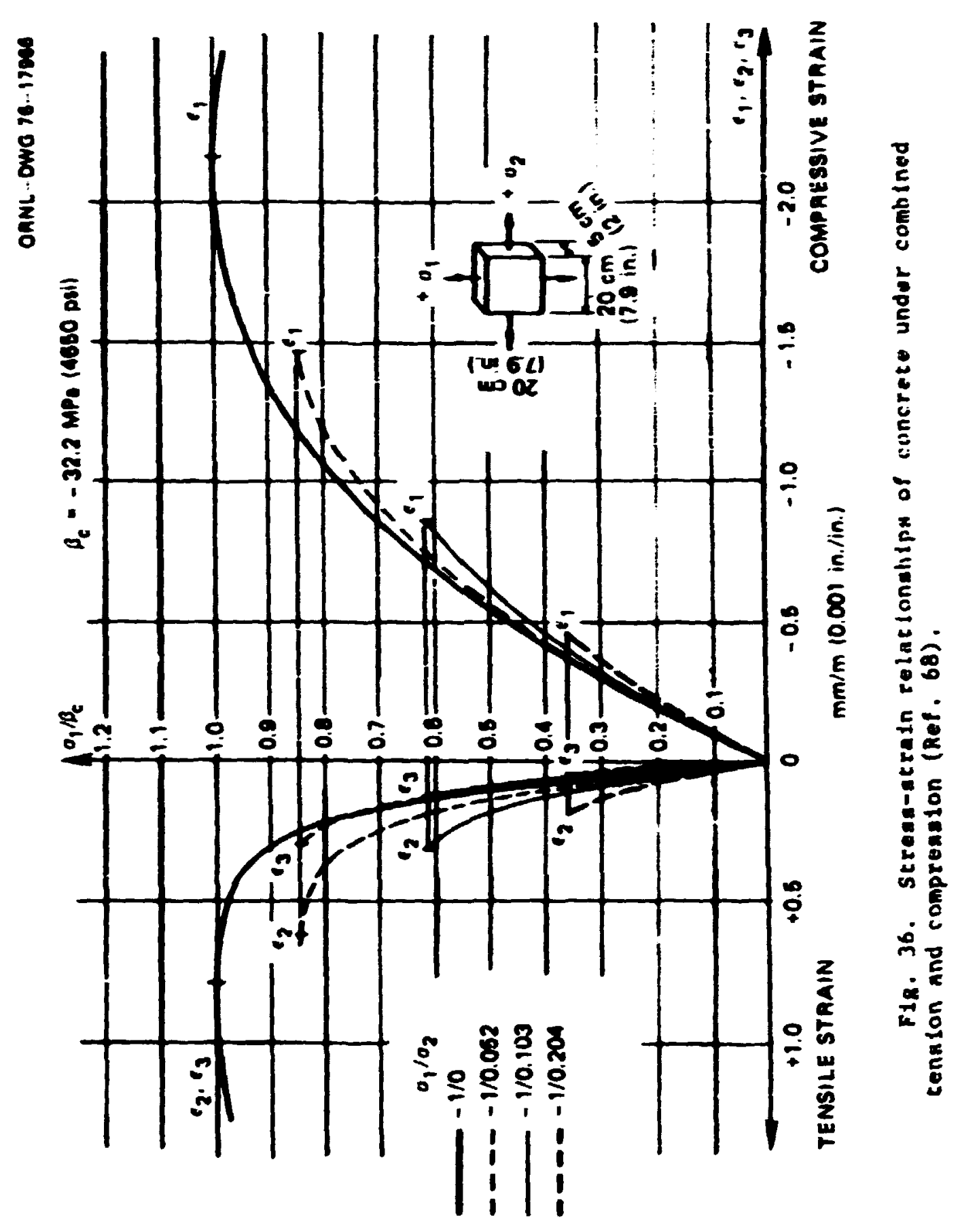




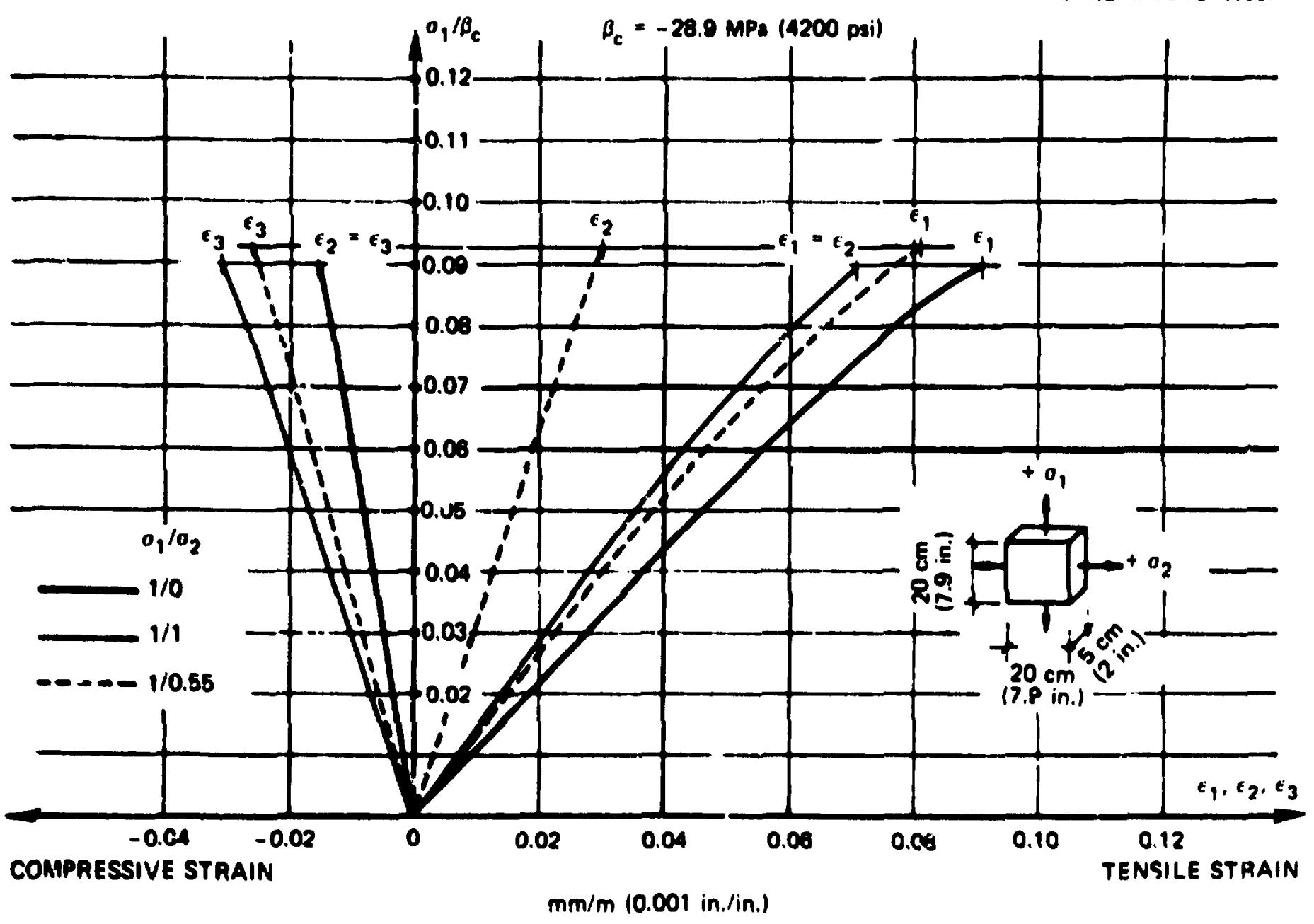

F1g. 37. Stress-straln relattonghipg of concrete under blaxial tension (Ref. 68). 


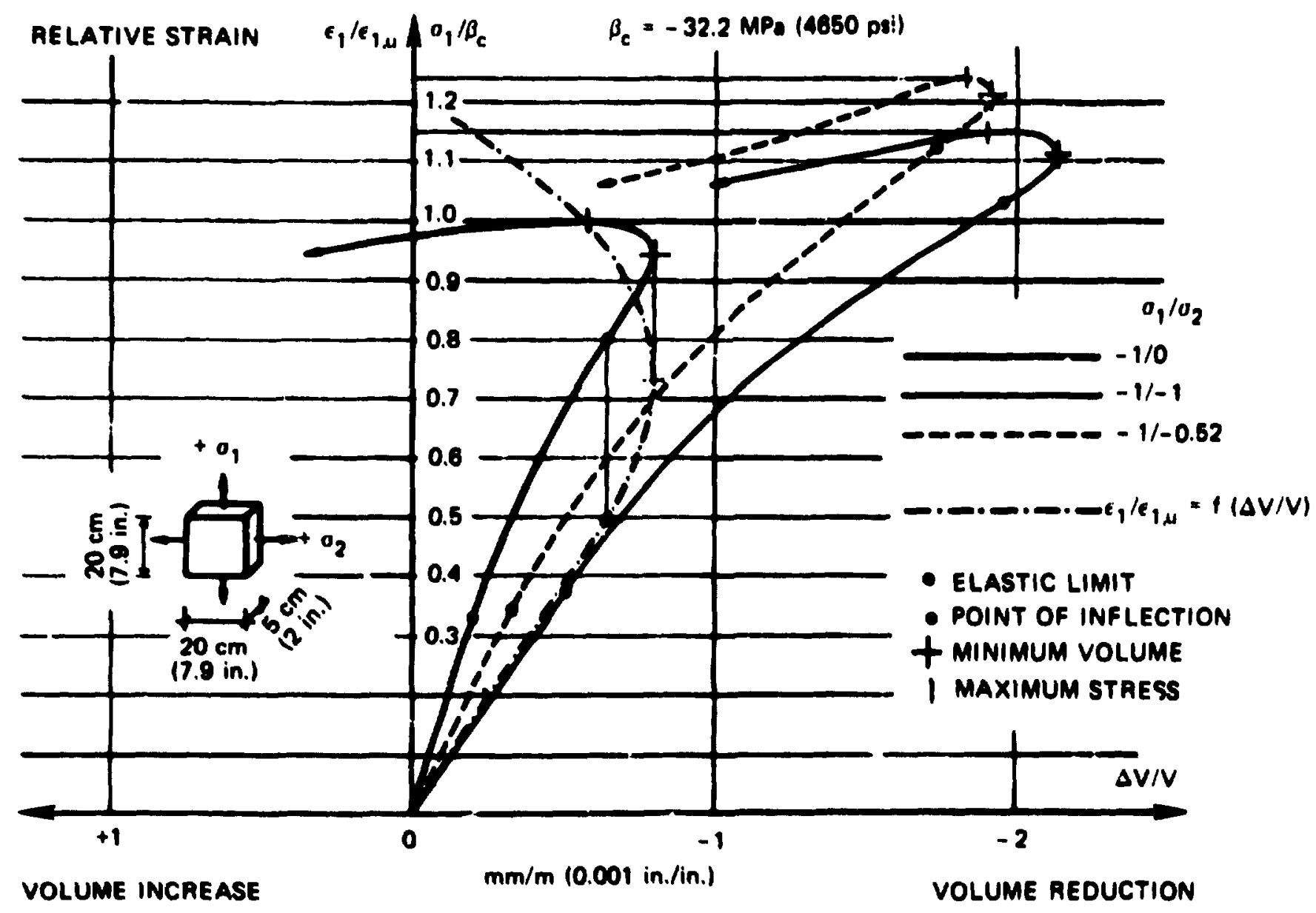

F18. 38. Volumetric atrain of concrete under blaxial compreasion (Ref . 68). 
CLASTIC LINAT

omu Ong 16 iron PONT OF INFIECTiJM OF VOLUME TAIC STAAIN EXTAELE OF VOLUARETAIC - STR XIN

FAILUAE

$3 c=-309 \cos 14050$ pos

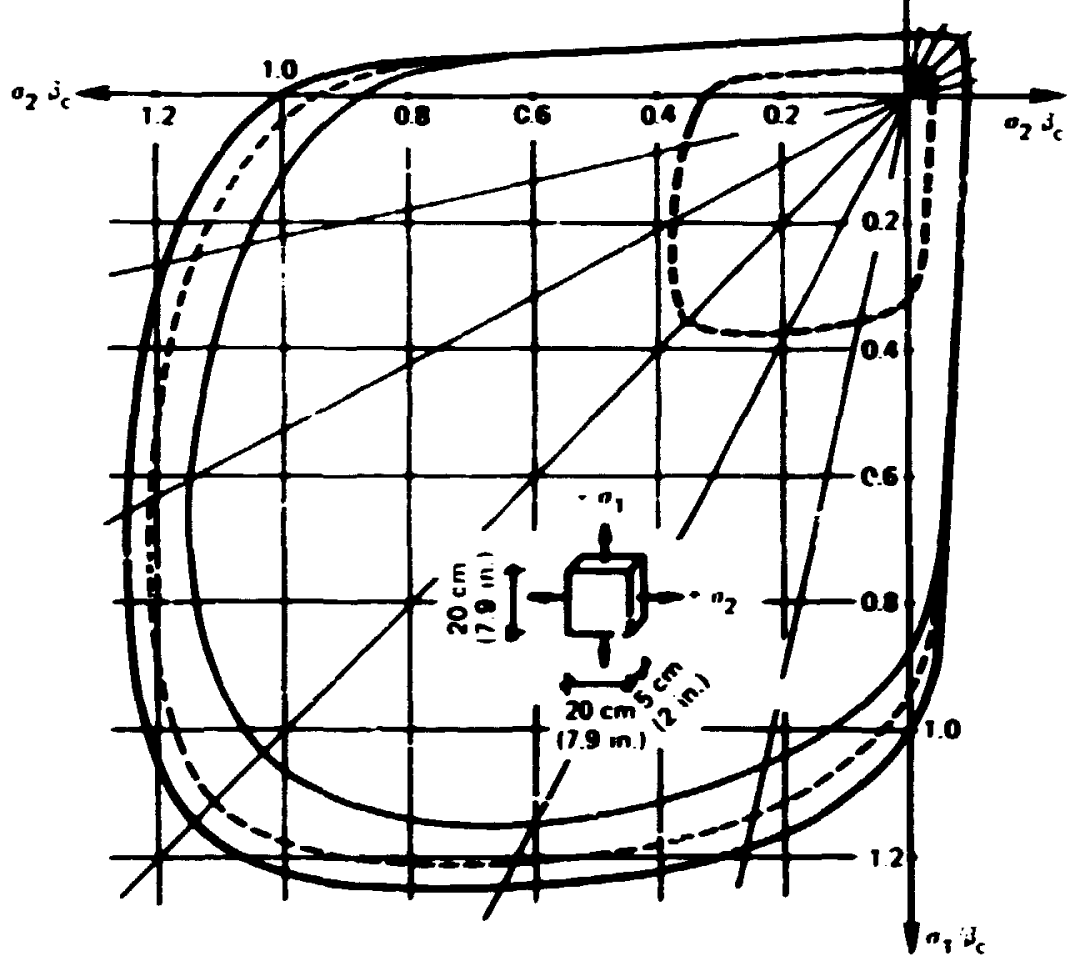

Fig. 39. Stresses at the elastic lint, ginimu volume, and faflure of concrete subjected to biaxial stress states (Ref. 68).

Relatively less ef fort ${ }^{72,73}$ has been devoted to establishing the nonlinear relationship between the stress and strain that exists prior to failure. From an analytical viewpoint, this sparsity of ef fort seens rather shortsighted in that there is little advantage to having accurately defined fallure criteria avallable if one is unable to accurately calculate the stresses in the neighborhood of the failure linit. Also, since fallure of the concrete in a reinforced concreta structure does not necessarily 
imply failure of the structure but only a transfer of load from the concrete to the reinforcing steel, an accurate estimaton of maxim loads requires appropriate nodels for tive postfailure reaponse.

\subsection{Failure Surfaces for Plain Concrete}

Any state of stress is completely defined by its three principal values and their corresponding three orthogonal directions. If the strength of the acerial is independent of direction (an isotropic characteristic), the stace of stress at fallure can be represented as a point In the three-dimensional space whose coordinate ares are the chree principal stresses. The plot of all such points defines a surface in the stress space called the failure sirface for the material.

In recent years a nuber of Investigators have undertaken the development of analytical descriptions of experinentally determined failure surfaces for concrete. Basically, the fallure emvelope is a conical-1ike surface with curved reridfans and noncircular cross sections, augnented by $a$ cutoff in the censile regine (see fig. 40).

One of the sipplest descriptions of the surface is givet by hansson and Schimelpfennig. ${ }^{76}$ The surface is described by a vector $\xi$ on the line of hydrostatic compression,

$$
\xi=\frac{1}{\beta_{c} \sqrt{3}}\left(\sigma_{1}+\sigma_{2}+\sigma_{3}\right) \text {. }
$$

and 3 perpendicular vector,

$$
\zeta=-\frac{1}{\beta_{c}} \sqrt{\frac{1}{3}\left[\left(\sigma_{1}-\sigma_{2}\right)^{2}+\left(\sigma_{2}-\sigma_{3}\right)^{2}+\left(\sigma_{3}-\sigma_{1}\right)^{2}\right\}}
$$

The relationship between $\xi$ and $\zeta, \zeta_{0}(\xi)$, on che weridian $\sigma_{1}=\sigma_{2}>\sigma_{3}$ is approxinated with a quadratic function of the for

$$
\xi=c_{0}+c_{1} \zeta_{0}+c_{2} \zeta_{0}^{2}
$$

and the shape of the other meridians are defined by

$$
\zeta=H(\theta) \zeta_{\theta}(\xi)
$$




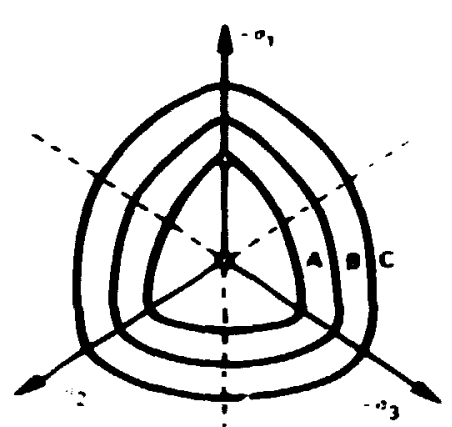

geviaioác section

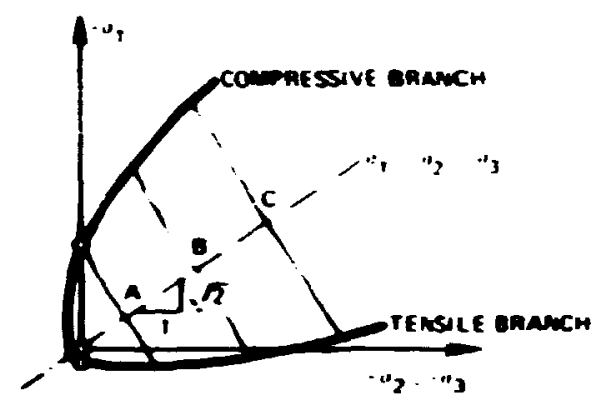

wropostatic section

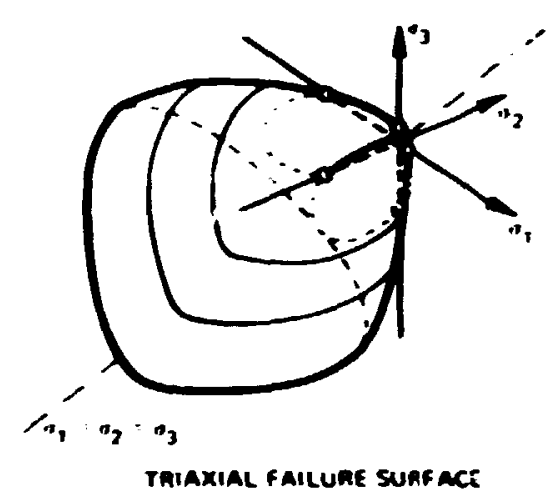

Fig. 40. Failure envelope of plain concrete (Ref. 78).

where

$$
H(\theta)=\frac{\lambda}{1-(1-\lambda)(1-3 / \pi \operatorname{arc} \theta)^{1.9}}
$$

and $\theta$ is the angle perpendicular to the axis of hydrostatic compression, with $\theta=0$ for $c_{1}=\sigma_{2}>\sigma_{3}$ and $\theta=60$ for $\sigma_{1}>\sigma_{2}=\sigma_{3}$.

The four parameters $c_{0}, c_{1}, c_{2}$, and $\lambda$ are deterwined by using the uniaxial tensile and compessive strength, the biaxial conpressive strength, and the requirement that the intersection of $\zeta_{0}(\xi)$ with the $\xi$-axis be deterained by a straight line through the uniaxial and the biaxial compressive strengths. The comparison of the fits with experimental data alcng the meridians $\theta=0$ and $\theta=60$ is show in Fig. 41. The shape of 


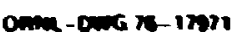

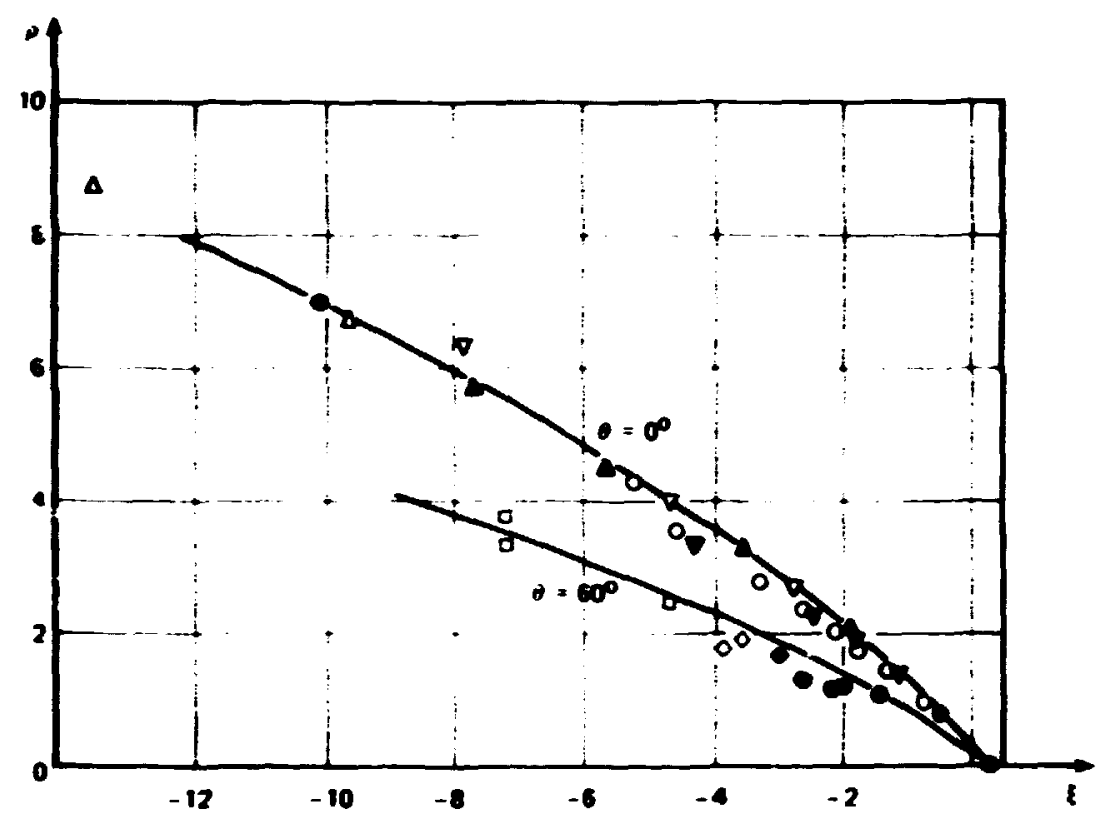

Fig. 41. Comparison of fits with experimental data along meridians $v=0$ and $v=60$ (Ref. 74).

the surface is shown in Fig. 42, and the trace of the surface in the bi3xial plane is shown in Fig. 43.

Willaw and Harnke ${ }^{75}$ also developed an analytical expression for the fallure surface based upon the uniaxial tensile and conpressive strengths and the biaxisl compressive strength. Straight meridians were used in this model, and, hence, it was not possible to obtain an accurate fit at high levels of hydrostatic stress; however, the fallure surface is continuous and has continuous derivacives, a property not exhibited by the previous nodel. This latter proferty ensures that a unique nornal vector existy at each point on the surface for defining the direction of inelastic deformations according to the norality principle of the theory of plastiaty. The functional form of the expression for the fallure surface is rather complex and will not be restated herein; however, the shape of the surface is show in Fig. 44. An even more complicated five-parameter model was developed to obtain a more accurate fit of the exper'mental data at high levels of hydrostatic stress. As can be seen in $x_{2,} .45$, this 



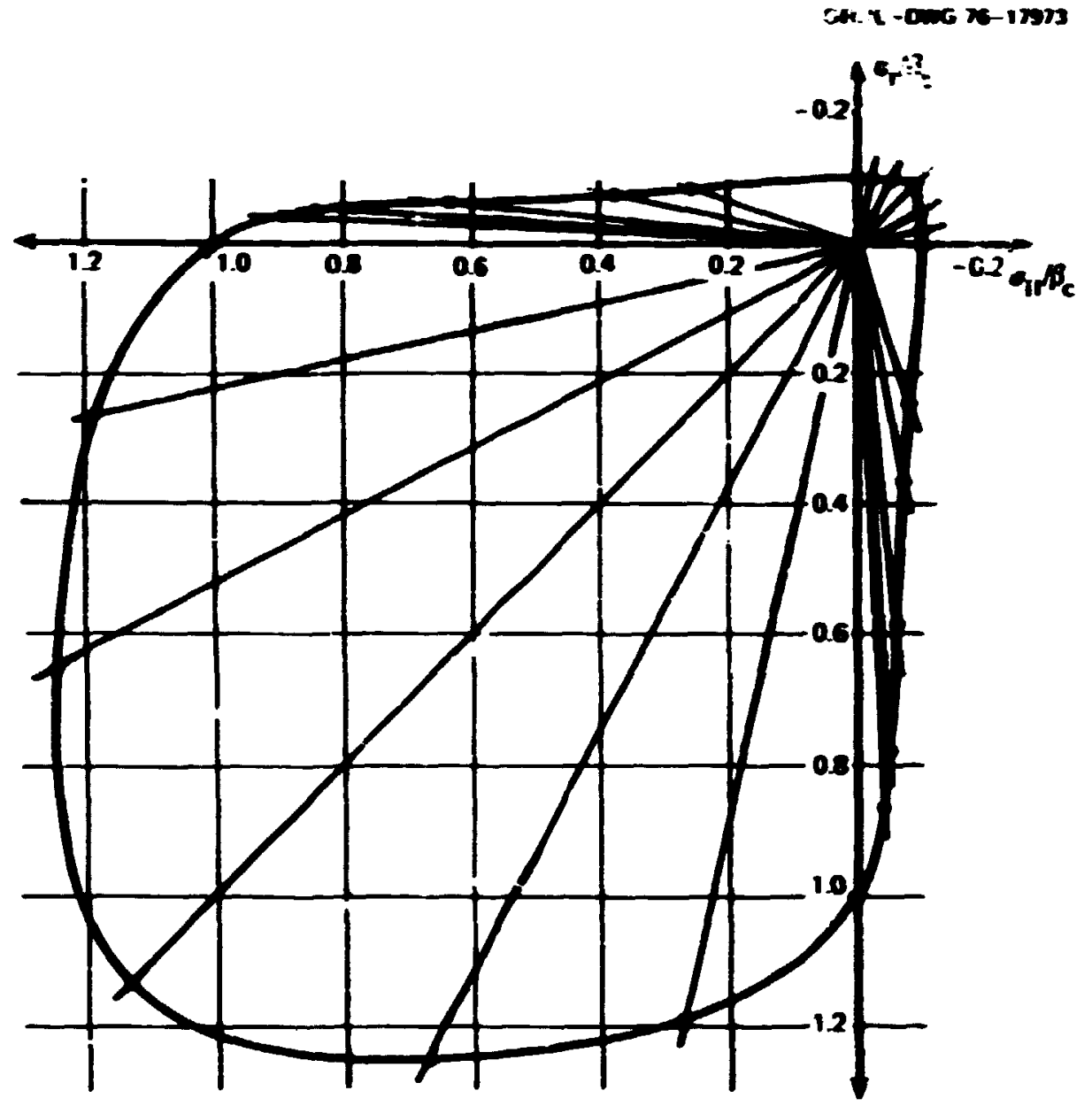
74).

Fig. 43. Biaxizi trace of the fallure surface approximation (Ref.

wodel has curved neridians and produces a better fit with the experfinental results.

The primary advantage of che expressions presented in this work is their applicability to an elastic-plastie computational schene. With this in aind, the authors presented in detall all the required additional relations requited for such a computation. Another interesting feature of the proposed fatlure surface is that it includes, as degenerate cases, the Drucker-Prager criterion, which is a three-diensional approxiantion of the Mohr-Coulomb criterion, and the ron Mises criterion, comonly used to represent aetal behavior. 
66

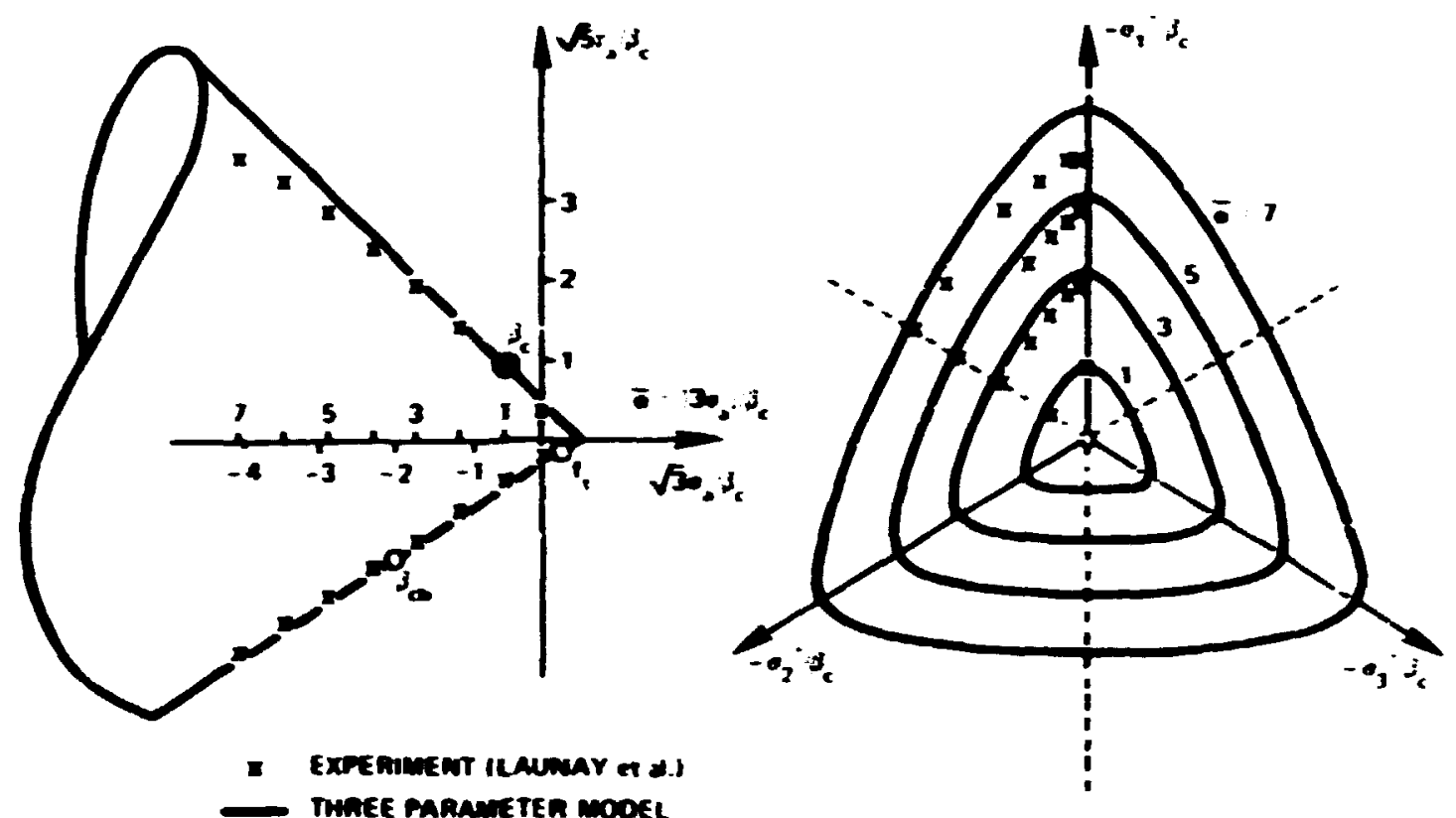

wronostatic SEction $\omega=0$

OEviatonk sections $6 \bar{a}=$ I. 3.5. $n$

Fig. 44. Fitting of triaxial test data - low compression regime (Ref. 75).

other efforts ${ }^{7-81}$ to develop criteria for triaxial failure surfaces have generally either led to wore complicated representations and/or did not provide fits of the experimental data that were as accurate. Some of these 7,79 include attempts to use the Motor-Coulomb criterion that defines the relation between shear stress $\tau$ ind normal stress $\sigma$ at a plane of failuse according to

$$
|\tau|=c-\sigma \tan \phi
$$

where $c$ is the material cohesion and is the angle of internal friction. One of the basic deficiencies of this model is that, contrary to expertmental observations, it predicts failure independently of the intermediate principal stress. 


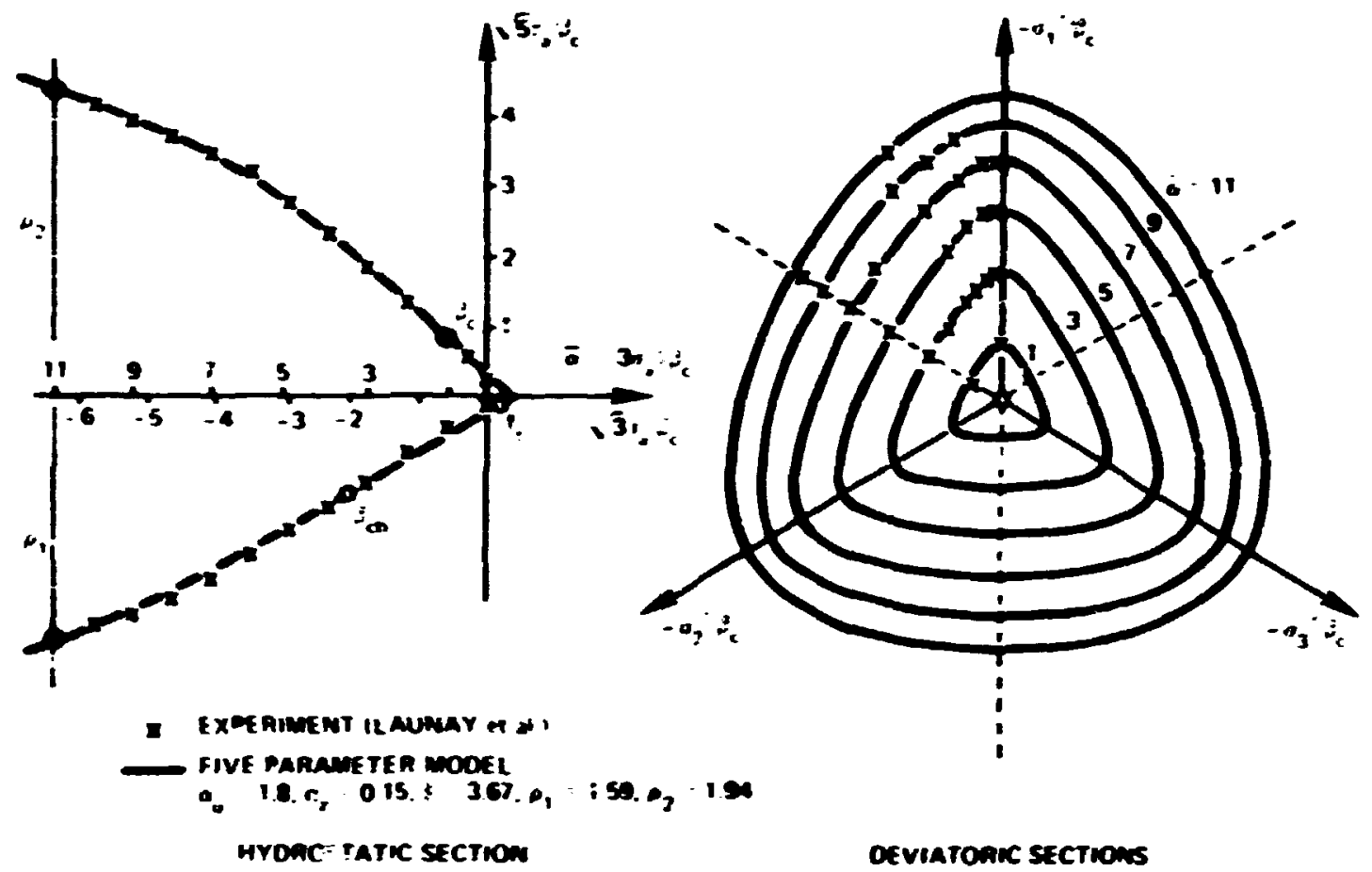

Fig- 45. Five-parameter model - fitcing of triaxial test data (Ref. 75).

\subsection{Postfallure Hodels for Tensile Pallures}

One of the basic difficulties that arises in attempting to establish approprlate nodels for falled concrete is that, for plain concrete, the test is terninated when the specinen fails. One might attent to avoid this problen by testing reinforced concrete specinens, but then complex interantions are introduced between the concrete and the reinforcenent. The comon apprcach is to silply hypothesize the postallure oodel and then justify it by comaring the results obtained using the wodel with results from structural tests. The problem with this approach is that other assuaptions are genarally introduced into the analysis so that the comparison does not necessarily provide a true test of the hypothetical model. Also, a model which is valid for cercain sicuations may not be valtd for others. 
Urder tensile 1 ading, the faflure cf plain concrete is rather conspicuous and takes the forn of cracks in planes transverse to the direction of maximu tensile stress. After failure, the aterial has mo resistance to tensfle stress fn che direction notmal to che rack plane, but it retains its ability to cransinit compressive stresses in this direction. Also, depending on the amount of crack opening, it ay retain some abflity to trangait shearing stresses across the crack due to aggregate incerlock. Except for aggregate incerlock, for which there is mo satisfactory model at this tine, the hrotbetical nodel for a tensile cract is clear, and the win question reatining is bow to achieve the wodel within the context of the analytical procedure.

Even for this racher siple wode of failure, a fuodnental difficulty arises in its inplemeatation in a finite-elenent analysis. In the finiteelement wethod, ccatinuous trial functions are assumed for the displacenent fields within each elewent (see Sect. 2.2), while a crack is characterized by the existence of displacement discontinuities. Thus incerelement cracking cannot be readil; accomodated.

Displaceant discontinuties can, however, be accomodated along elewent boundaries by "disconnecting" the adjacent elements at the nodal points (see Fig. 46). This approach was used by several analysts ${ }^{64,01,02}$ to account for the displacement discontinuities, but it gives rise to problems cf another mature. When adjacent elewents are "disconnected," additional degrees of freedon are introduced into the problem that, in general, abolish the banded nature of the stiffness motix and give rise to difficulties in obtaining a solution to the algebrafc stiffness equations (see Sect. 2.4). This problea can be avoided if the solution algorith is based on an iterative technique. An alternate approach would be to ternimate the analysis when tensile cracking is indicated, redef ine the scructure with due regard paid to the associated bandwidth such that the faces of the crack become boundaries of the body, input che revised information, and continue the calculations.

while the techniques discussed above are useful in theoretical studies of sicple structures, it would be extrenely difficult to develop the required algorithes to automate the procedures for use in an analysis of a 


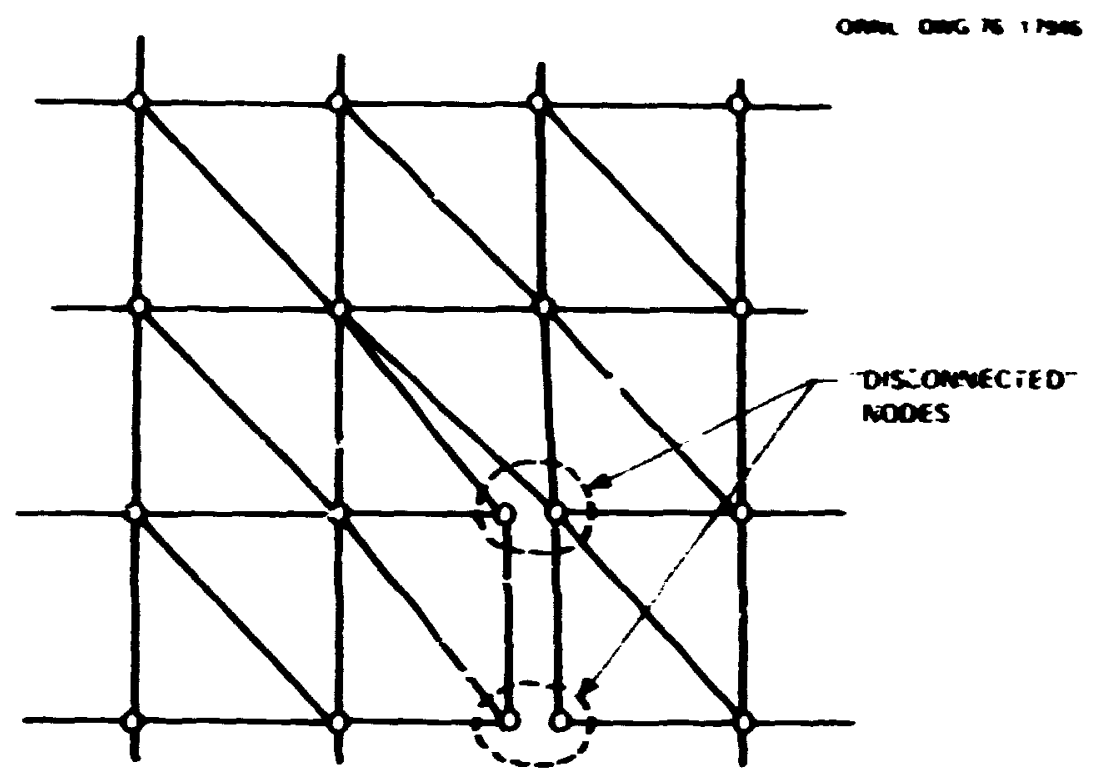

Fiz- 46. Accounting for displacenent disconcinuities at the crack b. "disconnection" of nodes.

complex structure for which. Lie crack planes cannot be predeternined. Because of this, the wore com approach is to ignore the displacenent discontinuities and attempt oily to achieve force-displacement relations for the cracked element that a re consistent with the existence of the crack. When the tensile stress in an element exceeds the failure criteria, the aterial properties of the element are codffied to produce an orthotropic material (see Fig. 47) with zero elastic modulus in the direition nomal to the crack and zero shear codulus for the appropalate orthogonai direcclons.

For the constant-strain elements to which it was first applied, 4, on this procedure can be implemented in a simple axd consistent manner. Incorporating the new waterial properties into the material matrix, $[D]$, and computing the integral (see Sect. 2.3),

$$
\left[k_{i j}\right]=\int\left[B_{i}\right]^{T}[D]\left[B_{j}\right] d v
$$

yields an element stiffuess eatrix that produces consistent force-displacecent relations for the cracked element. 


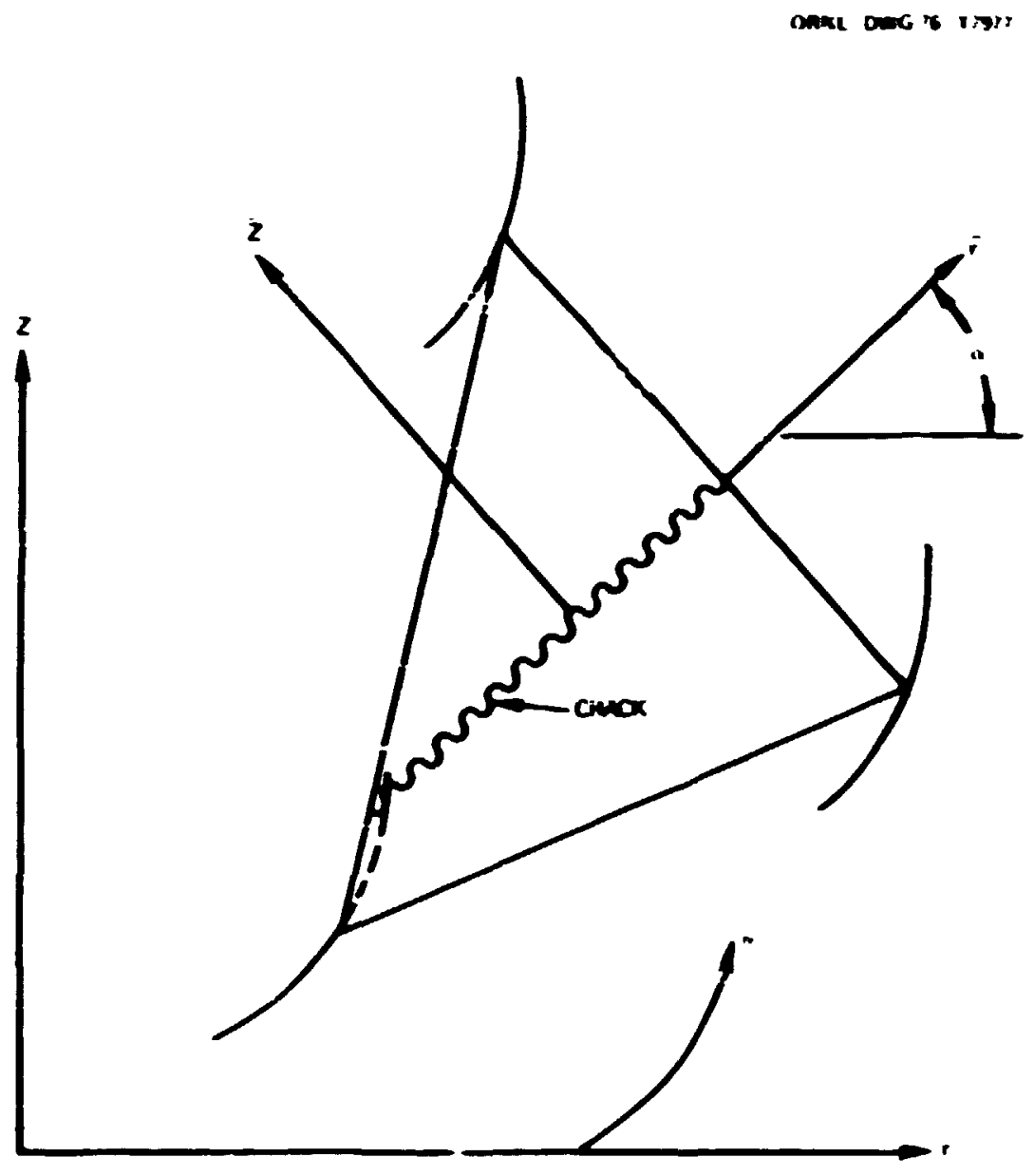

Fig. 47. Cracked constact-strain triangular element (RÉ́. 83).

Certain theoretical difficulties arise when one attemps to ase the material-modificiation technique for wodeling cracks in the high-order iscparametric elements comonly used for amalysis of multicavity PCRVs. $70,05,06$ Por these types of elenents, the elewent stiffness is deternined by numical integration of Eq. (55). The unual procedure is to calrulate the strisses at the integration points and compare thea to the failure criteria. If the failure criteria is exceeded, the material properties at init point are modified in the manner discussed above (see $: 18$ - 48), and the revised element stiffness is determined by suming tne contributions associated with each integration point. The nuber and pusition of the integration pnints depend upon the cype and order of integration used, but, typically, 
onem anc ins

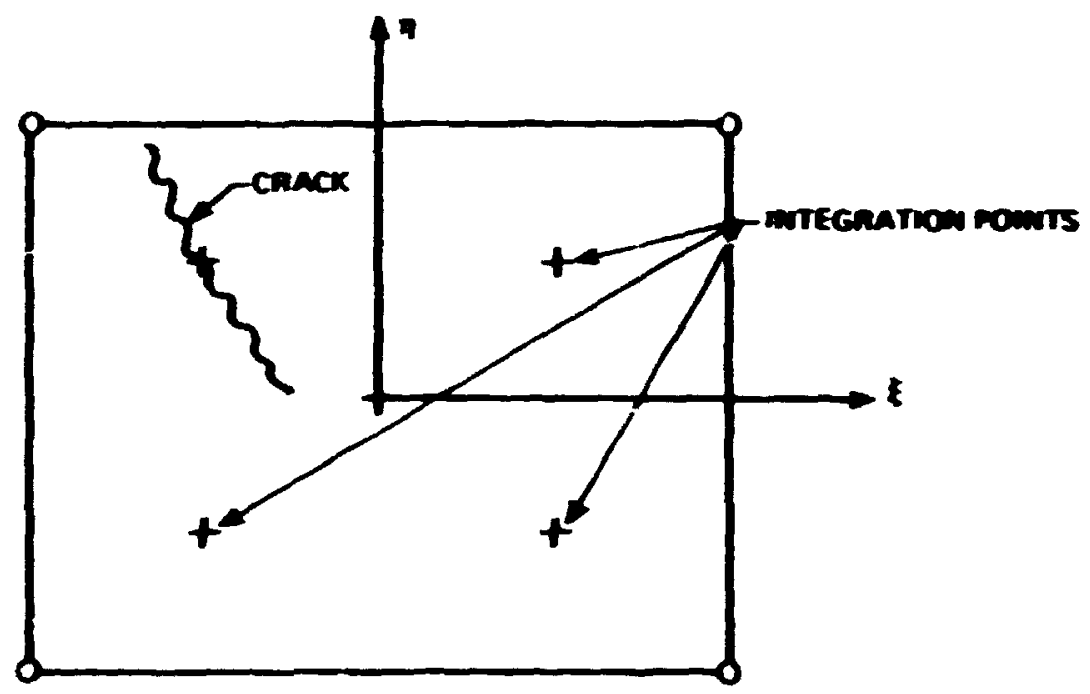

Fig. 48. Cracking in the isoparametric elewent.

second- or chird-order Gussian sacegration is wed. One difficulty with this procedure is that the anowe of eterial odified is affected by the intezration crder used. If a sincle-point fotegration is used, the mierial properties are nodified for the entire element, but as the integration order is fncreased, the volune of aterial affected dininishes until the volune becones zero and the existence of the crack has no effect on the calculaced element seiffass. Austher difficulty is that when the material properties are set to zero at a point, the polyoualal interpolation used in the mberical integratios implies, in geocral, wepative values for the materia: preperties over a fiate adjolatiog resfon. It appears that wefther of these wodesirable characteristics of the wethod hove been recognized by the authors who have utilized this techaique.

A second fundanental difficulty chat arises in the analysts of postcrack behavior is asecciated with the fact that fallure of concrete is accompanied by a declision branch in the stress-strain curve (see figs. 35, 36, and 37). When saflute of this type occurs, the material becomes locally unstable, with the result that the defornations tend to localize into a narrow baod. In such a situstion, the propagation of cracks through the element systea depends on the size of element chosen. If the element 
just ahead of ine crack froat is replaced by severai daller elements, the tensile strain wil! concentrate in the (see F1g. 49). By choosing sufficiently small frontal elements, the stresses in them can be ade arbitrarily large. Thus, the fallure land depends on the chosen size of the elements, which as a theoretical!y incorrect feature. A possible solution is to enhance the criterion of cracking by inposing an additional coudition on the relative displacesenis across the band of cracked eleneats similar to the conditioa oz maximu crack-opening displacenent of fracture aechanics.

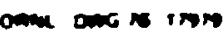

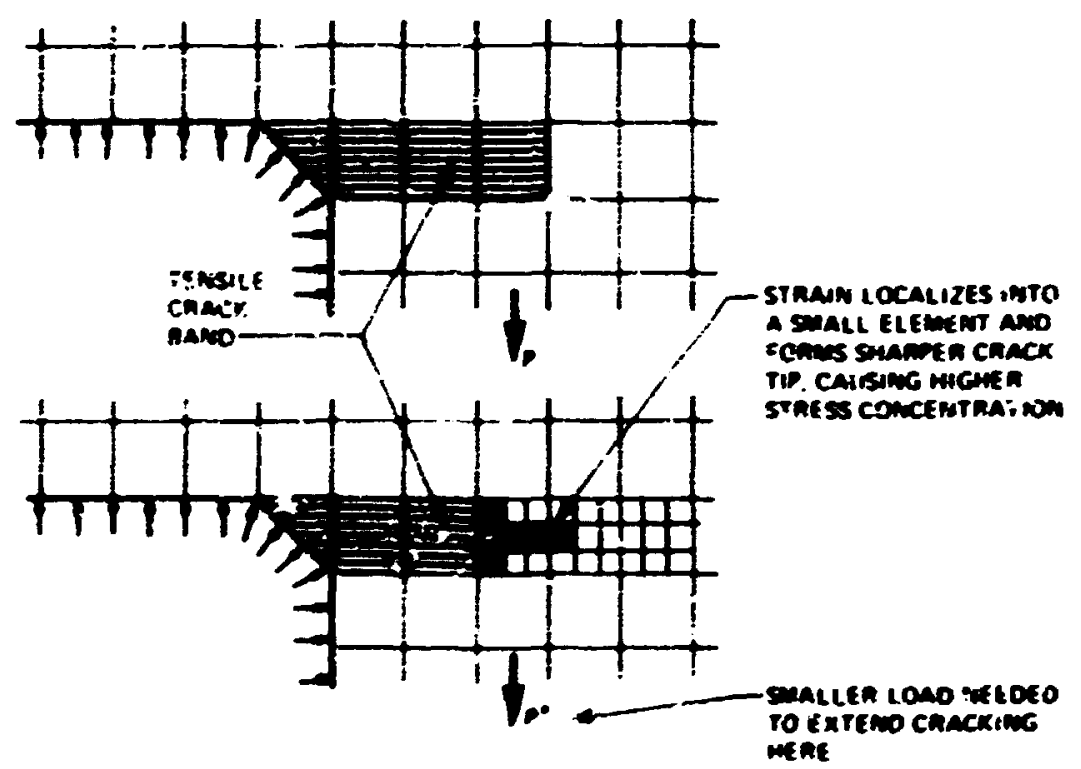

Fis. 49. The spurlous iffect of inice-element size on propagation of a ericik band.

\subsection{Postfailure Hodels In the Cogpressige Rogine}

The fallure of concrete in the compressive regine is more complex than that occurring in the tensile regine. In discussing this problen, Newan and vewas" suggest that und ir unlaxial compressive states of stress. the first afcrocracke develop in the nortar parallel to the direction of the 
compressive stress. As the load lacreases, the crack path extends, dividing and traveling around the hard aggregates until, after final distuption, isolated particles of aggregates are produced to which are adhering sall cones of wortar ailgned in the direction of the principal compressive stress (see Fig. SO). Jnder biaxial compression, the fracture paths extand in the directions of both principal compressive stresses, dividing around the aggregates to produce, at final distuption, isolated particles surrounded by a "halo" of adhering wortar (sce Fig. S1).

The particles that have been isolated by the dividing crack patis exert a wedging influence on the crack that gives rise to the developeent of cleavage planes. The fracture patterns comonly observed at fallure for spectens tested under biaxial stress cunditions are shown In Fig. 52. At low biaxial compression-tensicd stress ratios (zone 1 ), the failure is
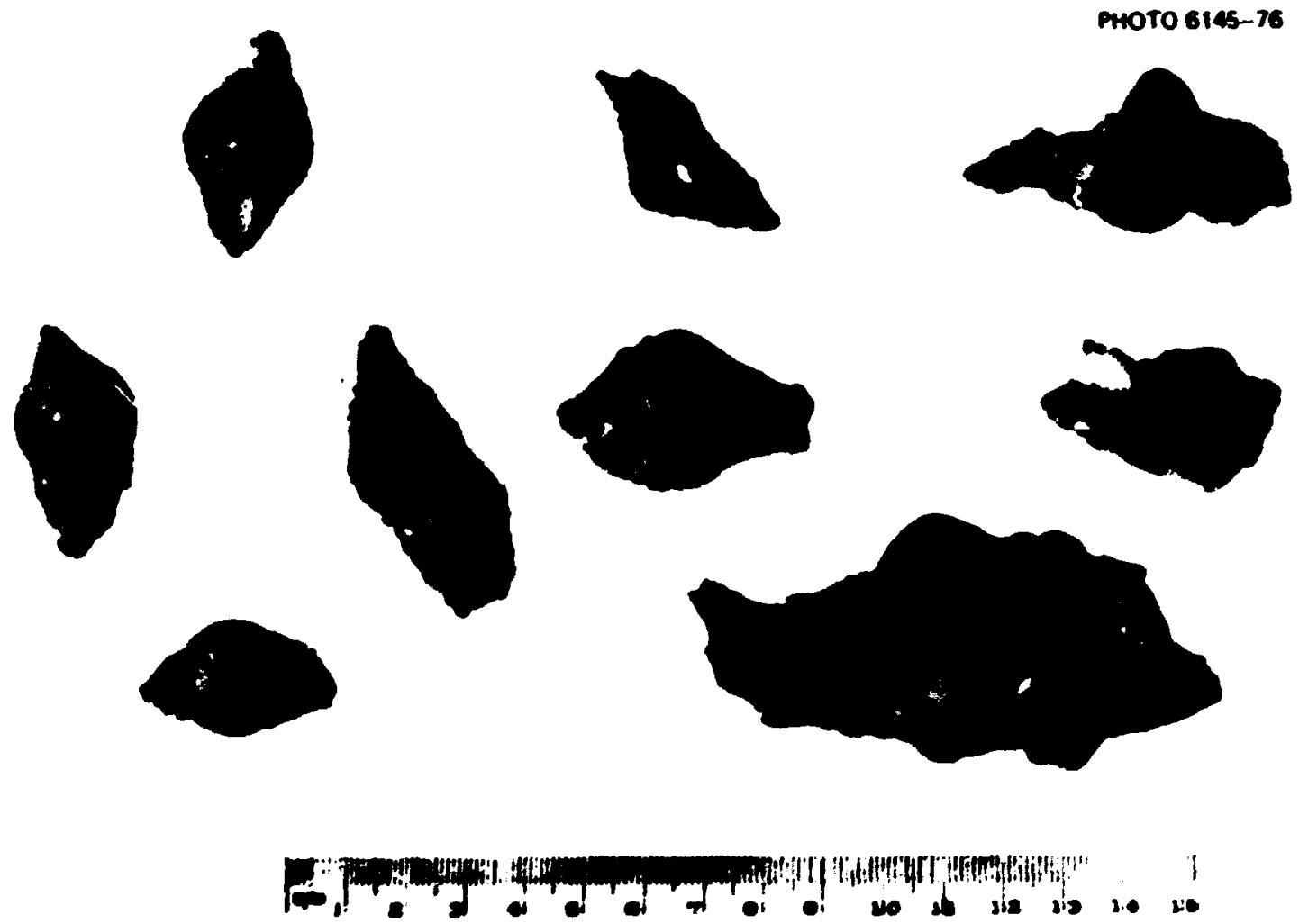

ii.3. 50. Particles of coarse aggregate removed from concrete specimens af cer loading to ultimate fatlure under uniaxial compression showing typical cone formation (Ref. 87). (1 in. $=25.4 \mathrm{~m}$ ) 


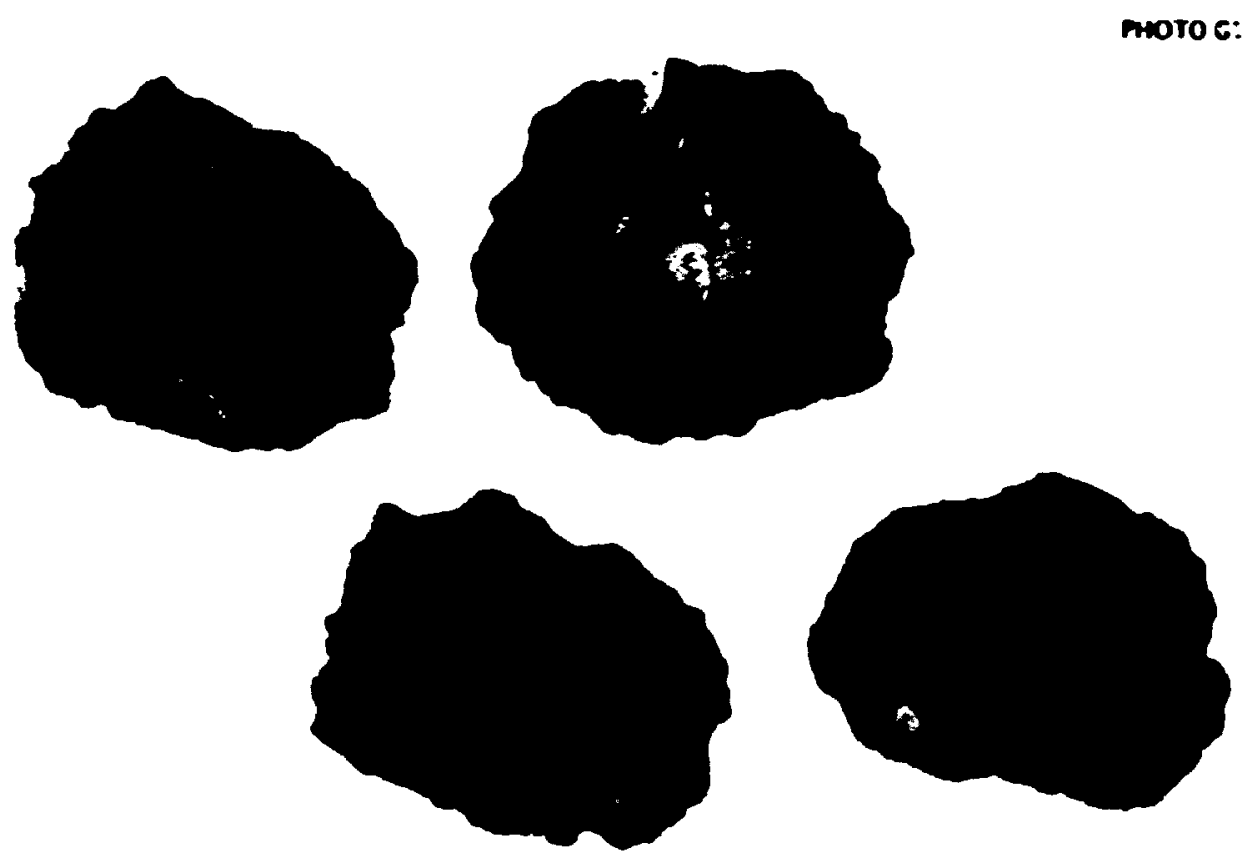

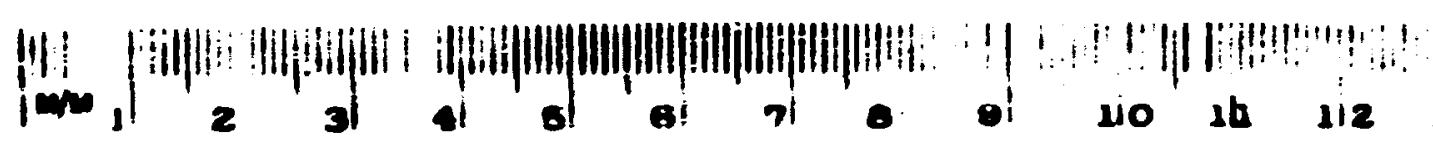

Fig. 51. Particles of coarse aggregate rewo"ed from concrete spec1wens after loading to ultimate fallure under biaxial compression showing typical "halo" formation (Ref. 87). (1 in. = 25.4 m)

characterized by a stagle cleavage crack as discussed in the prevtous section. The tallure is abrup: with an essentially linear stress-strain relation up ti failure. For stress states close to uniaxial compression (zone 2), the crack pattern uodergoes a transition to multicleavage fractures for which the propagation is wore gradual, giving rise to nonlinear stress-strain relations. In the major part of the compression-compression zone (znae 3), the pattern becomes one of several parallel cleavage planes whose propagation is st:ll more gradual, producing a greater nonlinearity in the stress-strain relations prior to fallure.

It is clear from the previous discussion that the single-cleavage model used as the postfailure codel in the censtion regine will not suffice in the compressive regine. The comonly wed nodel for the conpressive 


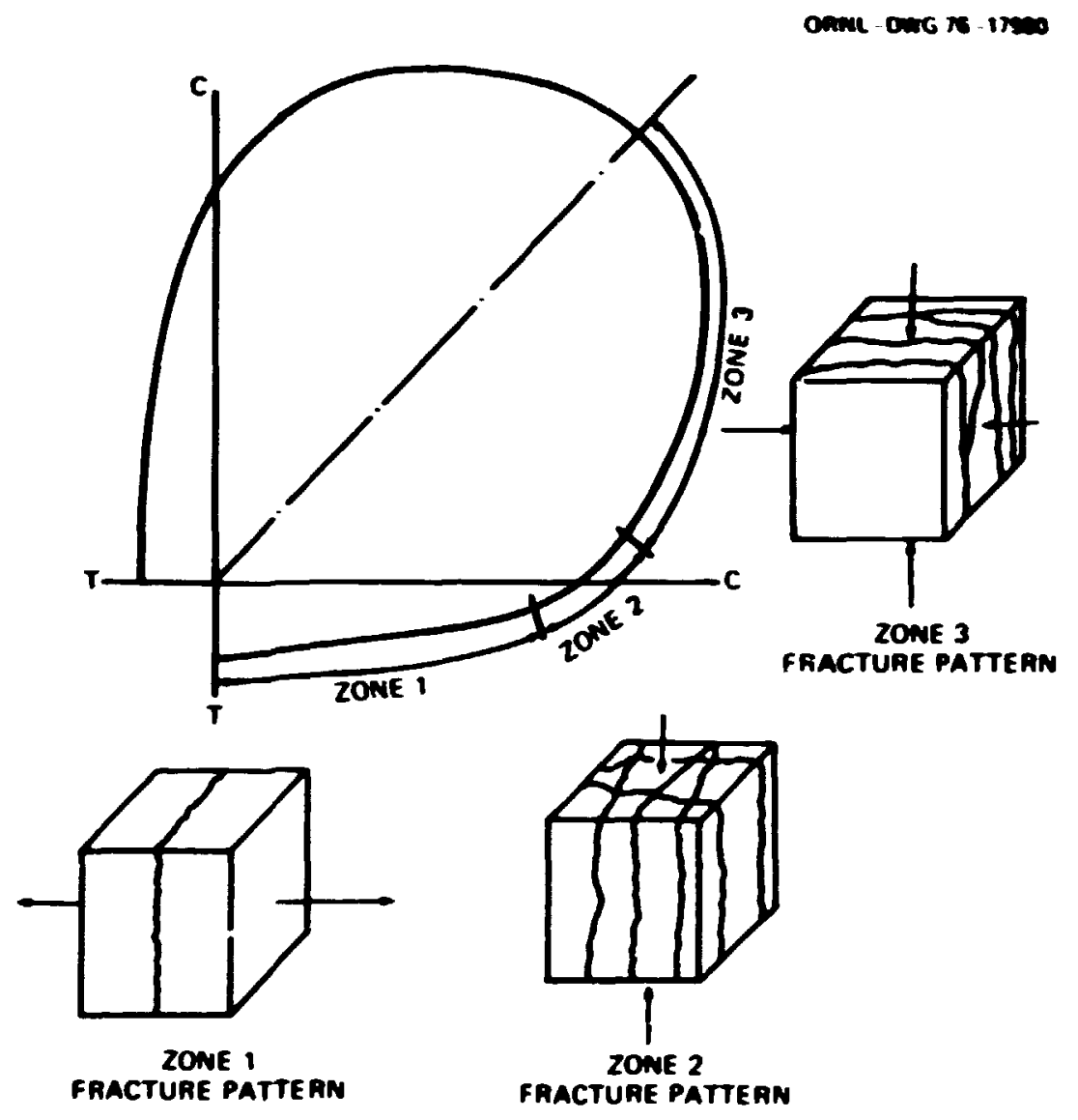

F1g. 52. Idealization of the macroscopic fracture patterns observed at ultimate failure for specimens loaded under biaxial stress states (Ref. 87).

postfailure condition is to assure that the concrece ylelds plastically when the compreasfve failure criteria is satisfied by the stress state.

In a plasticjiy analysis, yielding is assued to occur if the stress state $\{\sigma\}$ satisfies the yield criterion

$$
\mathbf{F}(\{\boldsymbol{\sigma}\}, \kappa)=0
$$

where $K$ is a "hardening" paraneter. This condition can be visualized as a surface in the n-dimenstonal stress space whose postition depends on the parameter $K$ (see Fig. 53). If the state of stress satisfies the yield criterion, then an increaent of strain, $\{d \varepsilon\}$, is diviatble into an elastic 
76

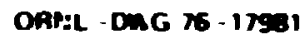

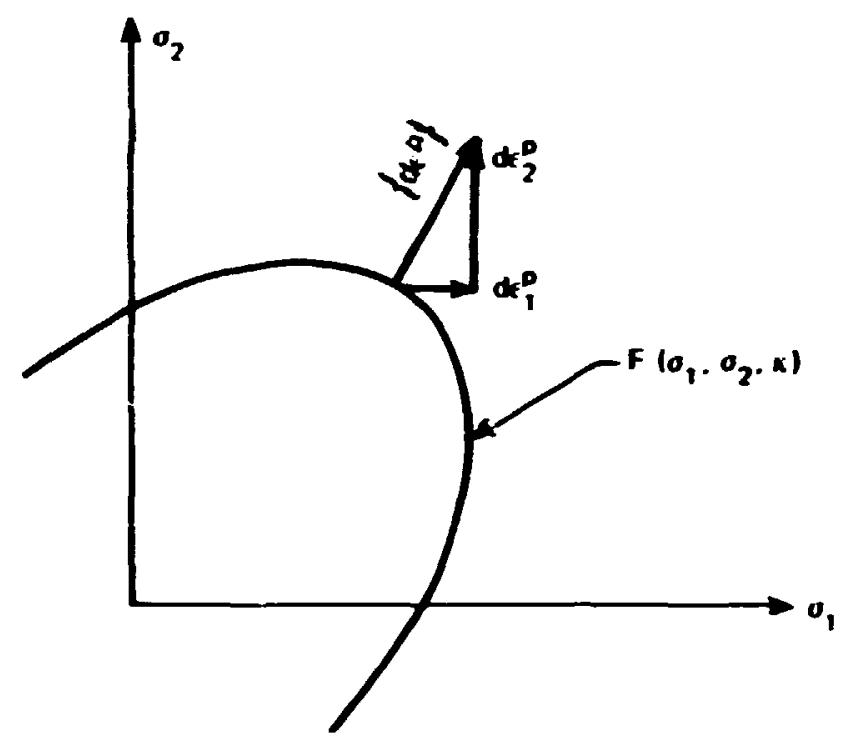

Fig. 53. Yield surface and normality criterion in two-dimensional stress space.

part, $\left\{d \varepsilon_{e}\right\}$, and a plastic part, $\left\{d \varepsilon^{P}\right\}$. Thus

$$
\{d \varepsilon\}=\left\{d \varepsilon^{e}\right\}+\left\{d \varepsilon^{p}\right\},
$$

where $\{d \varepsilon\}$ is the total strain increment. The component of plastic strain is assumed to be normal to the yield surface; hence

$$
\left\{d \varepsilon^{P}\right\}=\lambda \frac{\dot{\sigma} \mathbf{F}}{\partial[\sigma\}},
$$

and the elastic strains are related to the stress by the elastic material matrix, [D], where

$$
\{d \varepsilon\}=[D]^{-1}\{d \sigma\}+\lambda \frac{\partial F}{\partial\{\sigma\}}
$$

During plastic deformation the stress state must remain on the yield surface; thus

$$
\left\{\frac{\partial F}{\partial\{\sigma\}}\right\}^{T} d\{\sigma\}+\frac{\partial F}{\partial K} d K=0 .
$$


Note that for strain-hardening atcrials, $d x \neq 0$ and the yield surface is displaced during plastic deformition, while for perfectly pli-ric aterials, $d x=0$ and the surface remains fixed in stress space. After sone manipulation, the increantal stress-strain relation for plastic deformations becones ${ }^{10,09}$

$$
\{d \sigma\}=[D]_{\text {ep }}\{d \varepsilon\} \text {, }
$$

with

$$
[D]_{e p}=[D]\left\{1.0-\frac{\left\{\frac{\partial F}{\partial\{\sigma]}\right\}\left\{\frac{\partial F}{\partial\{\sigma]}\right\}^{T}[D]}{A+\left\{\frac{\partial F}{\partial\{\sigma !)^{T}}[D]\left\{\frac{\partial F}{\partial\{\sigma !}\right\}\right.}\right\}
$$

and

$$
A=\frac{\partial F}{\partial K}\{\sigma\}^{T} \frac{\partial F}{\partial\{\sigma\}} \text {. }
$$

Several analysts ${ }^{78,90,91}$ have utflized the elastic-perfectly plastic model for the postfallure condition in the compressive regime. In these analyses, the fallure surface is taken as a yield surface.

An objection to the use of this model is that the normality condition of r.q. (58) gives rise to a volumetric dilatancy during plastic straining that exceeds that which occurs in actual concrete. A possible correction to the latter problem is the use of the "constant volume criterion" suggested in Ref. 92. A more fundamental objection to the use of the plasticity theory for concrete is that the existence of a unique yield surface in a principal stress space implies that the material properties are independent of direction, while the damage due to microcracking is known to be directional in nature.

Although there are theoretical objections to the use of the plasticity model for concrete, the effect of these theoretical inconsistencies on the accuracy of the analysis is not known, and reasonable results have been obtained for practical problems. Some of these tesults will be discussed in Sect. 4.9. 


\subsection{Nonlinear Stress-Strain Relations}

One of the difficulties with the elastic-perfectly plastic model discussed in the previous section is that it ignores the nonlinearity of the stress-strain relations for compressive loading. This dericiency can be overcone by using the discontinuity surface as the infitial yield surface and increducing conlinear hardening into the plasticity model. Care must be exerised so that the subsequent yield surfaces are bounded by the faitial discontinuity and faflure surfaces.

Probably the best exaple of such a codel is the one proposed by Chen and Chen." In this work the yield surfaces are defined by the relacion

$$
F(\{\tau\}, K)=\frac{\kappa^{2}}{3} J_{2}-\frac{K^{2}}{36} I_{1} \pm \frac{1}{12} I_{1}^{2}+\frac{1}{3} A_{u} I_{1}-\tau_{u}^{2}
$$

where the positive sign on the third term applies in the conpressive region and the negative sign applies in the compression-tension region. The term $I_{1}$ is the first invartant of the stress censor, and $J_{2}$ is the second invariant of the deviatoric stress tensor. The shipe or the surfaces in principal stress space is shown in Fig. 54. It should be noted that the surface has circular cross sections with curved meridians.

The kinematics of the yield surface involves a translation along the hydrostatic axis and a simultaneous isotropic expansion. The form of the functions describing the strain hardening were obtained by generalizing uniaxial stress-8train data utilizing

$$
\sigma_{e}=\tau+\sqrt{f}
$$

as the definition of the effective stress and

$$
\varepsilon^{P}=\int \sqrt{\left\{d \varepsilon^{P}\right\}^{T}\left\{d \varepsilon^{P}\right\}}
$$

as the definition of che effective plastic strain. Idealized equivalent stress-strain relations obtained from the experimental data given in Ref. 72 are shown in Fig. 55. It was necessary to def ine separate strainhardening functions for the tension-compression and compression regimes. 


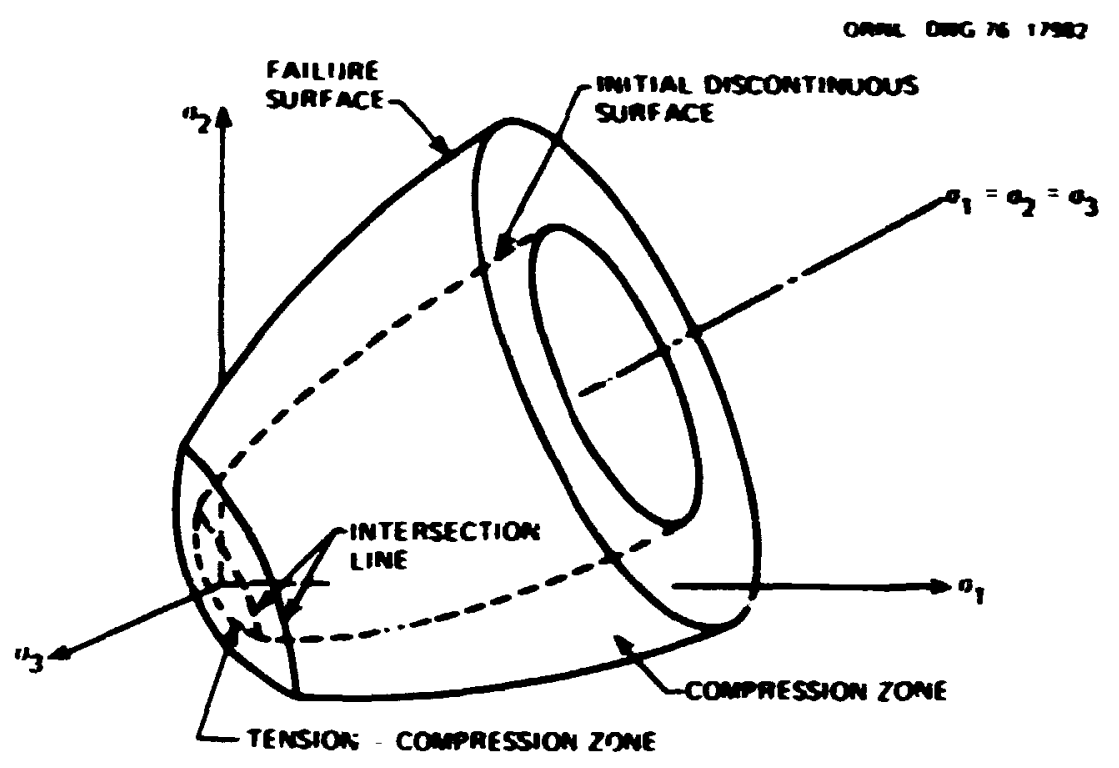

Fig. 54. Failure and inirial discontinuous surfaces in principal stress space (Ref. 80).

A comparison between the experfneutal and idealized stress-strain relations is silown in Figs. 56 and 57 . It can be seen in the figures that thire is good agreement, except for sone deviations in the stress-volunetric strain curves at high stress levels.

An alternative to the use of the strain-hardening plasticity wodel is to utilixe a wodel based upon the theory of hyperelasticity to introduce the nonlinearity in the stress-sirain relations. In this theory the requirement of reversible elastic deformations is dropped, and it is stipulated instead that the stress increnents be linearly dependent on the strain increments, that is,

$$
\{d \sigma\}=\{C(\{\sigma\},\{\varepsilon\})]\{d \varepsilon\},
$$

where the coefficients of the eatrix [C] depend on the components of the stress and strain tensors $\{\sigma\}$ and $\{\varepsilon\}$. This formulation is complicated, and Identification of the aterial parameters from given test data is difficult. The matrix [C] is a fourth-rank tensor which, in general, is a function of two second-rank tensors and must to considered to be anisotropic as a result of the dependence of $\{\sigma\}$ and $\{\varepsilon\}$ (atress-induced anisotropy), even though the anterial is isotropic with regard to the intial 


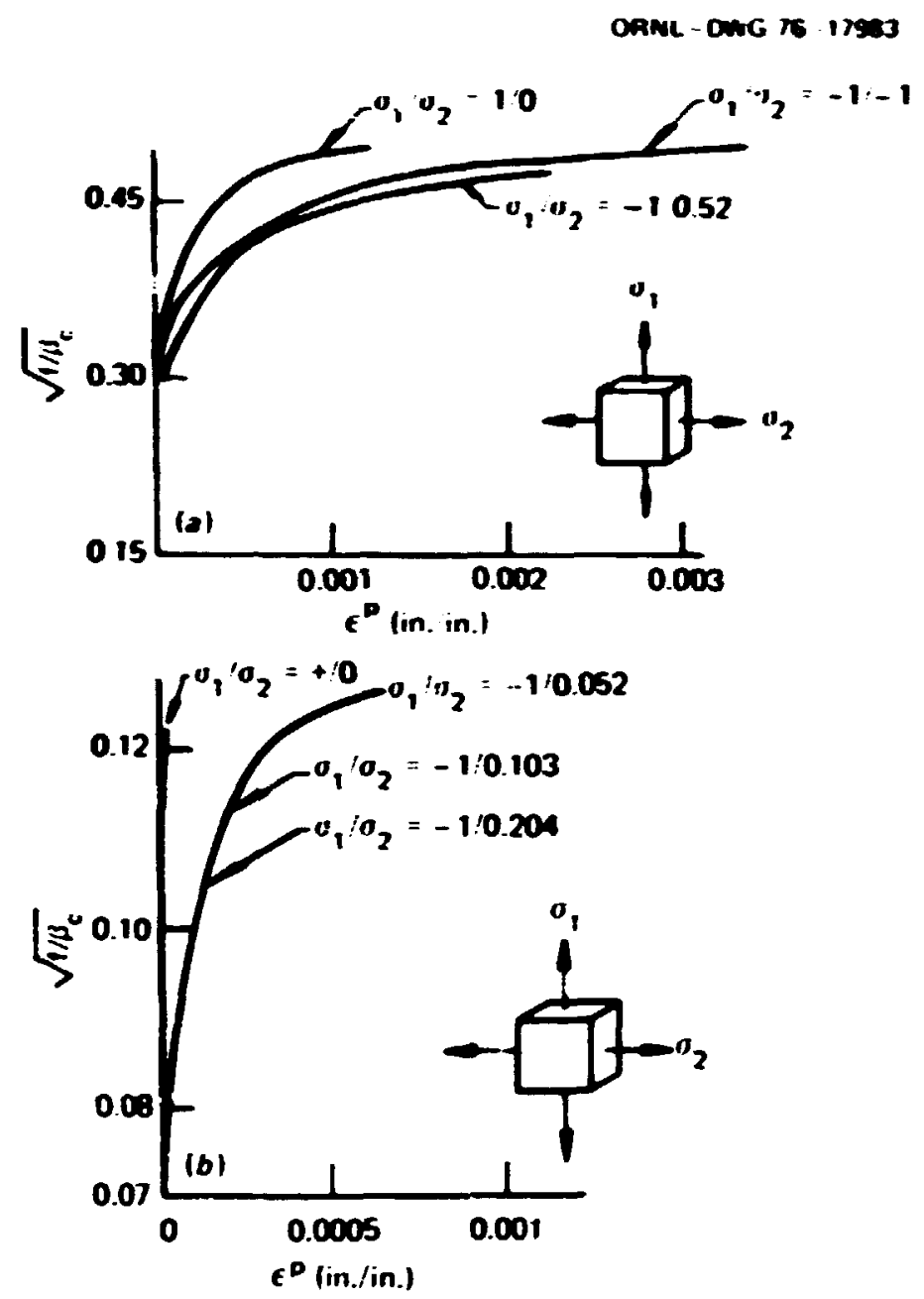

Fig. 55. Equivalent stress-strain relations: (a) compression zone; (b) tension-couprassion zone (Ref. 80).

state. Because of these difficulties, it has not been possible, thus far, to consider wore sophisticated functions for $[C(\{\sigma\},\{\varepsilon\})]$ than a linear tensor polynowizl in terms of $\{\sigma\}$. This has been done by Coon and Evans, 3 who demonstrated acceptable agreement with uniaxial, blaxial, and tridxial stress-strain diagrams up to about 857 of the ultimate strength. However, their formulation toplies infinite strain at peak 3 tress, which is incorrect, and it does not properly represent the inelastic volume dilatancy due to shear. 

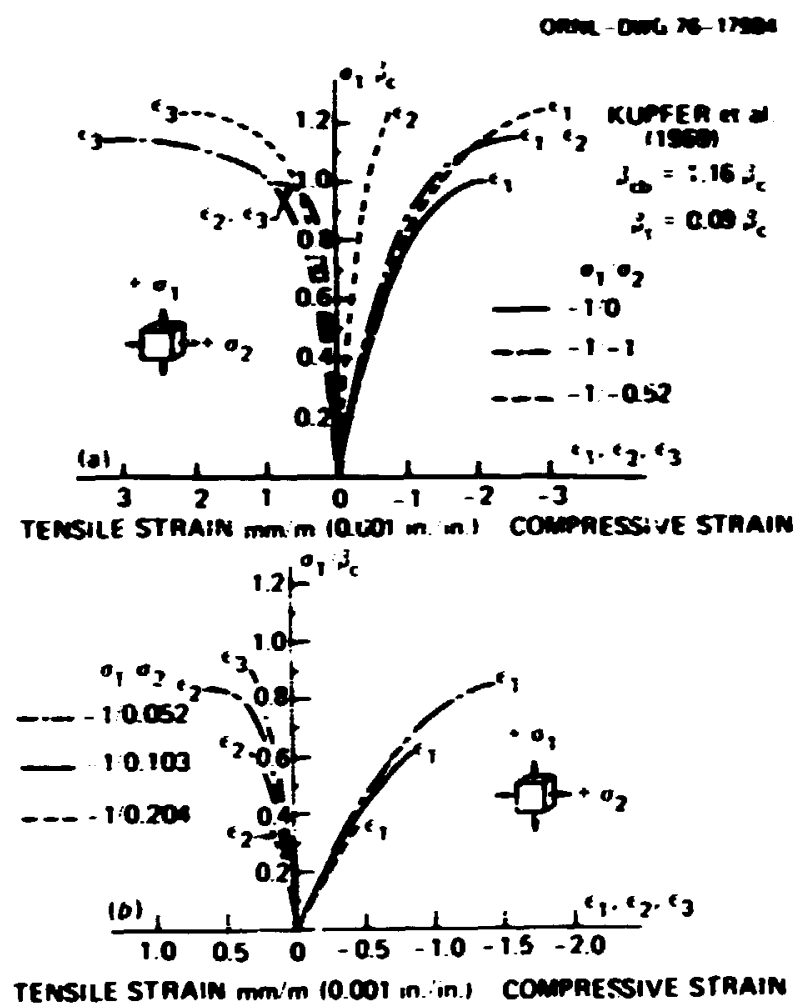

Fig. 56. Stress-strain relationships of concrete: (a) under biaxial compression; (b) under combined tension and compression (Ref. 80).

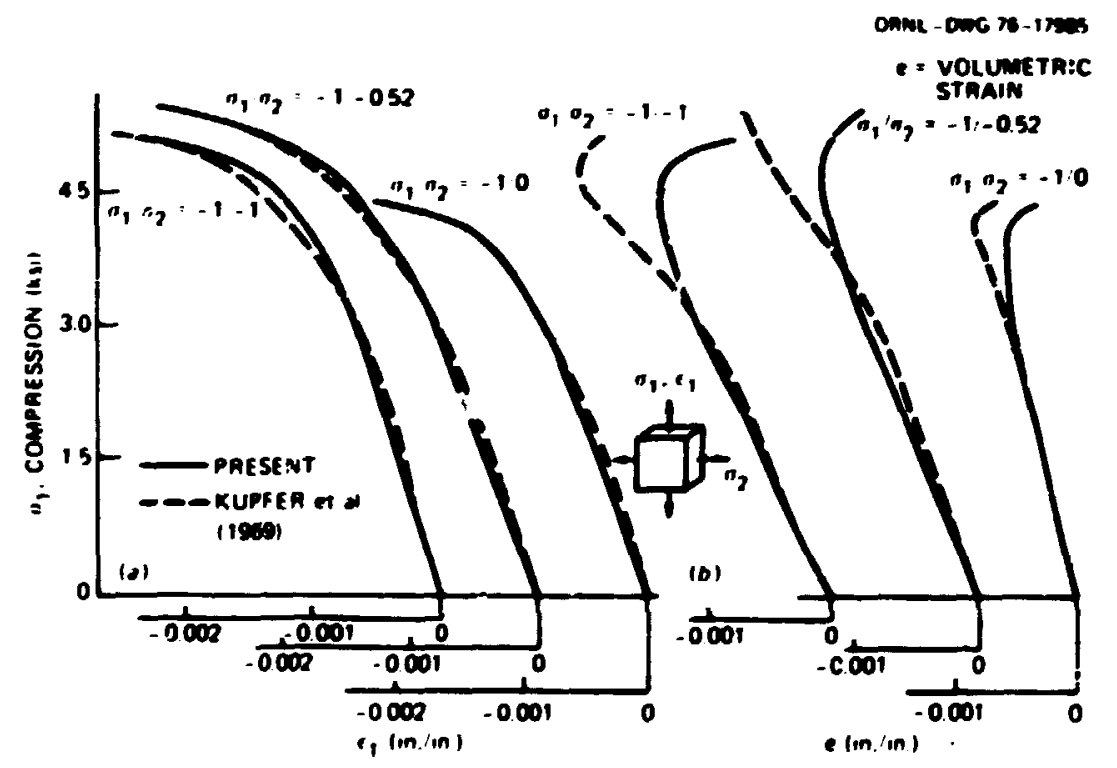

Fig. 57. Stress-strain relatjons in compression zone: (a) stressstrain; (b) stress-volumetric (Ref. 80 ). 
Others have considered the entrix [C] in simpler fors that either neglect the stress-induced anisotropy, ming the components of [C] dependent only upon the invariants of $\{\sigma\}$, or introduce incorrect forms of stress anisotropy in which [C] depends upon certain components of $\{\sigma\}$ but is not an invariant tensorial function. ${ }^{22}$, 94 Such formlations cannot be correct, In geweral, because the material properties are not independent of the choice of direction of coordinate axes. These formlations have served a useful purpose in describing the biaxial stress-strain diagrans of concrete, but they fall for othar types of loading.

\subsection{Endochronic Theory}

A pronisfing wew type of consticutive relation that ay of fer a better description of Eaterial behavior is the endochronic theory. This theory, whose first practical application was to worix-hardening metals, seens to be particularly effective for materials in wich the inelastic strain develops gradually. A prelinimary development of the theory for concrece has been ade by bazant and Bhat.'s The basic concept in the endochronic theury is that of an intrinsic tine 2 which represents a inonotonically increasing variable whose increnent $d z$ depends on the actual tine increment $d t$ as well as the deformation increments $d \varepsilon_{i f}$. Using the conditioa that the intrinsic tine may never decrease, it can be shum that its increment dz wust be defined as

$$
d z=\sqrt{d \zeta^{2}+\left(\frac{d \tau}{\tau_{1}}\right)^{2}}, d \zeta=\sqrt{p_{1 j k 1} d \varepsilon_{1 j} d \varepsilon_{k 1}},
$$

where $p_{1 j k 1}$ and $\tau_{1}$ are coefficients depending on the state of the material variables $\sigma_{1 f}, \varepsilon_{i j}$, and $z$. Further stomplification of the expression is possible using the conditions of 1sotropy and the assumption of an absence of tnelastic strain in purely volumetric deformation.

The presence of dt in Eq. (68) allows simultaneous consideration of strain-rate effects and creep. Coefficients $P_{1 j k l}$ may be selected in a form that reflects the strain hardening as well as the strain softening of concrete and the restraining effect of hydrostatic pressure on the development of inelastic strain. The variable $\zeta$ may be useful as a measure 
of the accumation of danage to the afcrostructure of conctete caused by the deviatoric strain. The damge suffered by concrete as a result of the nicrocracking that accompafes shear strain has long been regarded as the crucial pheaomenon in the inelastic behavior of coacrete.

For tine-indepeadent defurations the stress-strain relations in the endechronic theory are uritten in the form

$$
\begin{aligned}
& d \varepsilon_{i j}^{\prime}=\frac{d s_{i j}}{2 G}+d \varepsilon_{i j}^{\prime \prime}, d \varepsilon_{i j}^{\prime \prime}=\frac{s_{i j}}{2 G} d z \\
& d e=\frac{d \sigma}{3 K}+d \lambda .
\end{aligned}
$$

where $e$ is the volunetric strain, $\sigma$ is the volunetric stress, $\lambda$ is the inelastic dilatancy whose increaent $\mathrm{d} \lambda$ depends on $\mathrm{d} \zeta$. The deviatoric stress-strain relation is analogous to a sinilar relation in the theory of plasticity, and it can be shown that equations of the form of the Prandtl-Reuss equations of plasticity can be obtained as a special case of the endochronic theory. However, in contrast to plasticity, the stressstrain relations of endochronic theory cannot, in general, be reduced to a linear relation between $d \sigma$ and $d \varepsilon$, as in $\varepsilon q$. (61).

The aethod by which the endochronic theory nodels the inelastic strain may be clarified by cousidering the special case of short-time uniaxial deformation, for which, according to Eq. (69) fer $T_{1}=\infty$, one has

$$
d z=k \sqrt{(d \varepsilon)^{2}}=k|d \varepsilon|
$$

and so

$$
d \sigma=E\left(d e-d e^{\prime \prime}\right)=E d e-\sigma k|d e|,
$$

where $E$ is Young's modulus and $k$ is a constant. The stress increment is composed of an elastic increment Ede and an inelastic increment -ok|de| (see Fig. 58). When loading is suddenly reversed to unloading, de is changed from positive to negative, while the inelastic strain does not change its sign. Thin cuuses the unloading branch of the stress-strain diagram to have substantially higher slope than the loading branch. The 


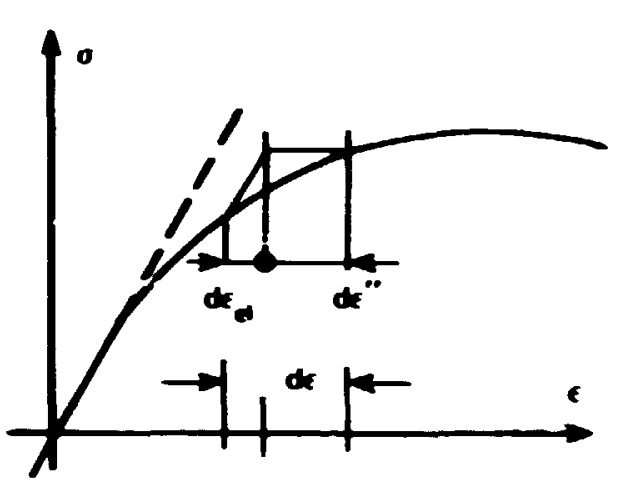

(a)

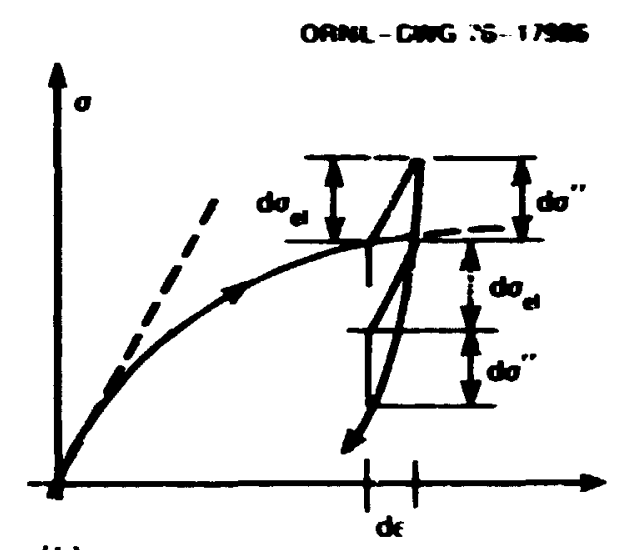

(b)

Fig. 58. (a) Elastic-plastic strain-hardenfng waterial; (b) strain increment in endochronic theory.

irreversibility of loading, which is the salient feature of all inelasticity, is thus embodied in the theory without using any inequality condicions.

Relative to implementation in a finite-element analysis, the endochronic theory has an additional advantage. Due to the absence of inequalities in the constitutive equation, no surfaces of distontinuity in material properties exist within the structure, in constrast to elastic-plastic models for which surfaces of discontinuity separate plasticized regions and elastic regions. The absence of a discontinuity surface is coisistent with the swooth interpoiation polynomials in the finite elements.

\subsection{The Effect of Reinforcement}

The proper creatment of cracking in reinforced concrete structures should take due account of the reinforcenent. Many diffesent paths have been followed in this regard, and they can be grouped under three generai headings: (1) discrete 1dealization, (2) sweered, and (3) embedded.

Discrete idealization. This approach is the most obvious scheme for idealization of reinforced concrete structures and was therefore the first to be employed. In the Hiscrete idealization, different elements are used 
'or the steel and concrete. Additional "special" elenents any be focorporated to reprcsent bond slippage and other phencena. Althorgh the nethod has been used videi; in research studies and has found application in practical analysis, it is gecerally not econouical for large-scale applicacions.

Perhaps the earifest report of discrete idealization of conerete structures is that of ligo and Scordelis, 1 to enloyed rectangular elenents for the coucrete, axial nobers for the steel, and a rero-leagth sprine elecer to represent boud slippage. Subequent studies vere conducted by milson, 12 Mirza and Mufti, 96 Valliappan and Doolan, $97 \mathrm{k}$ and Salnon, 90 and huto et 21. S9 All of these are planar andyses and, wich the exception of the wort by Muto, addressed resench exaninations.

The elenents eqployed in the planar analysis of conctete have been of varied form, depending on the purposes of the investigation. The rectangular eleneats, based on bilinear displacenent fields, found ea: iy use in all types of probles and renin a destrable wode of representaticn when there 15 no bias. Some analysts have used the 8-node planar elenent, wintch is the two-dinenstonal counterpart of the wost popular chree-dimensional element (the 20-node brick element). It should be observed that the quadratic displacement fields on whicin these elenents are based implies the definition of bar elenents that are three-jointed axial mebers. References 85 and 100, anong others, employ this type of axial aeber formulations.

Smeared representation. In the smeared element approach, the efferts of steel and concrete are sssuned to be unfformly distributed over the element, with due account being taken of the directional nature of the steel reinforcement. This approach assues perfect bonding between steel and concrete. In general, the bastc constitutive relationships are expressible in the foliowing form. For concrete alone, which is designated by the subscript "c,"

$$
\left\{\sigma_{c}\right\}=\left\{E_{c}\right\}\left\{\varepsilon_{c}\right\}
$$

and, for a system of $n$ steel bars,

$$
\left\{\sigma_{s}\right\}=\left[E_{s}\right]\left\{\varepsilon_{s}\right\} .
$$


Now, if there is full strain competibility,

$$
\{\varepsilon\}=\left\{\varepsilon_{s}\right\}=\left\{\varepsilon_{c}\right\}
$$

and, with the total stress given by the san of steel and concrete,

$$
\begin{aligned}
\{\sigma\} & =\left\{\sigma_{c}\right\}+\left\{\sigma_{s}\right\} \\
& =\left\{\left[E_{c}\right]+\left[E_{s}\right]\right\}\{\varepsilon\} .
\end{aligned}
$$

As in the case of disirete idealization, wast of the published efforts have been concerned with planar situations. One of the wost notable of these, due to its iplecentation of certafn scherwes for cracking and inelastic behavior, is that of Scanlon and Murray, ${ }^{101}$ but it is concerned exclusively with plate flexural elements. Indeed, way of the developments associated with seared representations involve plate flexure, since this class of problea is not easily treated by discrete idealizations.

Constant-strain triangles have been eployed by a nuber of authors in smeared representations. Colville and Abbasi ${ }^{102}$ use then directly, while Yuzugullu and Schoobrich ${ }^{103}$ contrive a quadrilateral from four triangular elements. Reference 102 gives detalled relationships that account for the arbitrary ortentation of a bar element within the overall element.

Three-dimensional analysis has been undertaken using the aneared approach by Suldan and Schnobrich,"I and again the basic elenent is the 20node brick. The aedian ratios of reinforcenent in the respective coordinate directions comprise the term of a diagonal $\left[E_{s}\right]$ matrix, and th. $\left[E_{c}\right]$ antrix is the conventional representation from isotropic elasticity. The treatment of cracking and of dowel ection in this work should be noted.

One ajor unresolved question of the definition of material stiffress properties in the schese discussed ahove concerns the shear efiects on the crack interface. These effects are due to aggregate interlock, dowel action, and shear refoforcement. Although experimental data show this ef fect to be nonlinear, the conventional approach to its representatjon ${ }^{30 h}$ is in - linear manner through multiplication of the material shear movlulus by $a$ factor $B$, where $B$ ranges between 0 and 1 . The value $B=0.5$ has been used 
5. Stresees and eccuminted plastic etrafne are updated conolatent जth the reault of atep 4.

6. The procese soves to the next load increnest, where exepe 3 to 5 are repented.

The process of load increnentation, repreacented by step 6, is continued until the dealred load aplitude 1 reached or until the etructure is at its ultimate lised capacity.

The tangent stiffoess athod is not often eplojed by itself in the sonlisear analyals of structures. This to true espectally in the analysis of concrete structures, where the method to be deacribed in the next section has been favored. A basic difficulty in cangent stiff peas analysis is that the solution tends to drift fron the correct solution as the lond Intensity Increases. This effect can be reduced by basiog the tangen: properties in an increnent on the estinated conditions in the aiddle of the increant and by usins saller increneats.

Both of the above methods for reducing the errors in a tangent stiffness analysis have disadvantages. It is rather difficult to incorporate in a general-purpose, finite-elenent progran an automatic and reliable schme for the estination of ald-increaent stiffness properties. The reduction of increaent size enharces are basic difficulty of the tangent stiffness wethod - the fact that in each increneat the global stifiness matrix must be reconstructed and solved again.

Initial stress wethod. The objective of the initial strese nethod In nonlinear finite-element analysis is to elininate the difficulty of constructing and solving the zlobal stiffpess atrix in each iterative cycle. This is done by forming a "reference" global stiffness matrix, which is usually the stiffness for linear elastic behavior, and treating departures from linearity as initial forces. The transfornation of departures from linearity intc initial forces is not unique and gives tise to various algorithas. Attention 1s linted in the following discussion to the algo"ithm that has been most widely used in PCRV finite-element analysis - the "Initial stress" approach to formation of initial forces. 
In Chap. 2 of this report [see Eqe. (7) and (8)], It was obeerved that the formula for stiffoes andyote is of the following gemeral form:

$$
\left.\sum \int_{v 01}[B]^{T} d D\right][B] c(v 01)\left[\delta_{j} j-\{R]=0 .\right.
$$

were the matrix [B] compises the transformtion of the joint dioplacenents $\left\{\delta_{j}\right\}$ of a typical $j$ th elenent into strains, and [D] is the matrix of elastic constants. Furthernore, sinct

$$
\left\{\sigma_{j}\right\}=\left[D !\left\{\varepsilon_{j}\right\}=[D][B]\left\{\sigma_{j}\right\}\right.
$$

as a consequence of the streas-atrain and strain-displacenent lass, the stiffness equations can be written as

$$
\sum \int_{v o l}[B]^{T}\left\{\sigma_{j}\right\} d(\text { vol })-\{R\}=0
$$

Wow, If a linear analysis is perforned for an increnent of lond Instead of the correct nonlinear inelastic analysis, the substitution of the calculated stress $\left\{\hat{\sigma}_{j}\right\}$ into the first tern of Eq. (78; results in a residwal on the right side of the equation, rather than zero -

$$
\sum \int_{v 01}[B]^{T}\left\{\hat{\sigma}_{j}\right\} d(v o l)-\{R\}=\{t\} \neq 0
$$

Because the loads (R) are Independent of the displacements, the change in residual $\{d \psi\}$ due to the stresses $\{d \sigma\}$ associated with a change of displaceant $\{d \delta\}$ can be calculated from

$$
\sum \int_{v 01}[B]^{T}\{d \sigma\} d(v 01)=\{d \downarrow\}
$$

Using the residual of Eq. (80) as a load and preserving the initial stiffness $\left[K^{3}\right]$, the correction to the displacenents is

$$
\left\{d \delta^{1}\right\}=-\left[K^{1}\right]^{-1}\left\{\psi^{1}\right\}
$$


The cinares it disolacenent wo calculated perit the calculation of stress changes and the formation of a revised total stress. The revised tutal stress wil, in general, produce changes to the displacenents which will, In turn, cause new residuals, and still furcher corrections are ande until the residuais are negligible.

The foregoing procedure has been described as if the initially inposed load were the desired full intensity of load, although it is generally inpossible to achieve a convergent solution for such cases. The inftial stress procedure can be identified as a for of Newron-Raphson iterative process, which itself is a linear extrapolation schene. The linear extrapolation wight wot succeed when the ifsidual is large. It is therefore customary to divide the load history into a muber of intervals, as in the tangent stiffness wethod. If the stiffness properties pertinent to the start of the interval are used, the first step of tine initial stress wethod is identical to the tangent stiffness procedure. Insertion of the calculated stresses into Eq. (79) gives the residual for the ircrewent, and the correction for this can be ade via Eq. (81).

The procedure to be followed in steps beyond the first is abiguous. It is possible, of course, to construct revised stif fnesses af ter each sycle within a lcad increment. Altermatively, the stiffness that is calculated at the start of the interval can be used throughout all the cycles. Indeed, the linear stiffness atrix obcained from the first load increnent wight be used for this purpose.

Sarne, 106 awong others, presents the results from numerical studies of various alternatives in the definitior. of stiffness properties within an interval. This work dewonstrates that it is suitable to update the stiffness atrix at the start of the load interval and use it in all computational cycles within the interval.

\subsection{Applications in Practice}

The prevalence of numerical analyses of PCRVs using the methods previously discussed is remarkable in view of the high cost of performing such analyses. These studies require hundreds of elesents and solution unknoms and involve repeated solution or tterations in the nonlinear 
regine. Nevercheless, organizations in many countries (Fra:ke, Japan, Ceranny, Denark, Uniced Kingdon, and Italy, to nane a few) have sponsored rather substantial efforts in this respect. It should be noted that chese ef forts pertain ainly to freviously desigred PCRV structures riat ar: of practical proportions or to scale models of existing reactor vessel designs. Few, if any, of these analyses have preceded the design phase. The following review of the analyses teferred to above is limited to the wst recent developments, since the intent of this section is to defire wore realistically the state of the art.

A useful stacting point for this review is work dore in the United Star.es by Sarne." , 106 These efforts involved a 20-node brick isoparaeetric finite elenent to represent the concrete and an 8-node planar element to describe the liner. A schewe of 15 numerical integration points was employed to evaluate the stiffness properties of the brick elesent. The steel reinforcing bars were treaced as axial wemers.

This work accounts for cracking, tine-independent inelasticity, and creep. The treatment of cracking is based on an assessment of the cracking criterion at each numerical integration point; principal stresses are determined, and if the maximu priacipal stress exceeds that which is allowable, the stiffness in the corresponding direction is set equal to zero. The approach taken in dealing with time-independent inelasticity involves assessment of the respective principal stresses in turn, with due account veing taken of the influeace of stresses existing in the other two directions. For creep, a viscoelastic wodel consisting of Kelvin elements in series is adopted. The algorith for creep analysis is a standard initial st-ain formulation. The PCRV analyzed in Ref. 86 is of realistic proportions [approxiantely $27.4 \mathrm{~m}(90 \mathrm{ft}$ ) high and 30.5 - (100 ft) in diameter, with a core cavity 11.3 (37 ft) in diameter and heads $7.6 \mathrm{~m}(25 \mathrm{ft})$ and $9.8 \mathrm{~m}(32 \mathrm{ft})$ thick]. The analyses included dead weight, prestressing load, working pressure, and therwal gradients. The effect of creep was examined for the intended life of the structure. The finite-element idealization, it should be noted, was limited to a $30^{\circ}$ wedge of the complete structure.

Takeda, Yamaguchi, and Imoto 90 have described the inelastic finiteelement analysis of a ulticavity PCRV for which $1 / 20-8 c$ ic test data were 
avallable. ${ }^{107}$ Two independent amalyses, one with axizymetric triangular ring eleaents and the other with 20-node brick elenents, were pe=formed. In the planar case, the analysis eaployed the tangent stiffness approach to the inelastic calculations with the Prager-Drciker yield criterion, ${ }^{16}$ wherein the gield function $f$ is given by

$$
f=a J_{1}+\sqrt{J_{2}} \text {. }
$$

where $J_{1}$ and $J_{2}$ are the first and serond stress ixvariants and $\alpha$ is a nterial-dependent constant. A secant stiffoess appruach zas taken in the three-dinensional analysis.

In these analyses, as in the work by Sarne, 106 the steel Iner is modeled by planar elements and the coodition of cracking is determined by testing the princfpal siresses to see if the maximu value equals or exceeds the allowble. The amalysis test resuits of the paper show, in general, a high degree of correspondeace.

Zienkiewicz, Phillips, and Orea ${ }^{104}$ have described analyses of a prevfously tested reactor vessel ${ }^{109}$ that are noteworthy on account of the use of isoparanetric refaforcing elements enbedded in 20-node brick isoparanetric elements. Cracking is treated by assessing the principal stresses at the anserical integration points in the same nanner as described above fo: other applications, but after cracking, the aggregate-interlock effect on the crack surface is accounted for by using a reduced shear wodulus at the integration point. The nonlinear character of the concrete stressstrain relationship, aside from cracking effects, is accounted for by the initial strain algorith discussed in a previous section using a constitutive law that accounts for both hydrostatic $\left(J_{1}\right)$ and deviatoric $\left(J_{2}\right)$ stress invariant 3.

The wost extensive reports of Applications analyses of PCRVs appear to be those by Saugy et al. ${ }^{.5,110}$ They use 20-node 1soparanetric brick elewents in a general three-disensional analysis. The eaphasfs or this work is upon condticutive relationships for tine-indepeadent plasticfty and creep, with cracking accounted for as described in the prior developments but without consideration of interface shear transfer. Analyses 
huve teea conducted of a bypothetical reactor structure of realistic proportiuns, and wre recently 110 coments have beea ade regarding comparisons with test daca from an actual structure of this type. Results for the latter, bowever, hrve not ret been reported.

Another finite-eleneat PCoN anal-sis conducted along the above general lines was one described by Wade and Hearyood, "11 who bave been concerned with the design of United Kingdon and Gernan reactors. Hexahedroaal elewents with 20 podes were eployed in the finite-element discretization. Analyses were perforned for pressure, teperature, and prestress ioads in -he presence of creep. It appears that neither cracking wor tine-independent inelasticity were taken into account in tis amalysis.

Studies in progress in Desark by ottosen and Axderson'12 and 17 Italy by Ballio, Castellanf, and Fiozi ${ }^{113}$ bear sinilariftas to the work discussed above.

It can be seen, thea, that the 20-node isoparanetric brick element is virtually a standard in large-scale practical analyses of PCWrs. Eightnode planar elements, which are comperible with the brick elenents, are used to wodel the liners. There are significant differences anong the reported analyses in the muber of points used for muerical incegration of the element stiffness properties. Custonarily, the principal stresses are salculated at each rumerical integration point for each load level. If a principal stress is identified as being larger than the tensile strength, a crack is defined in the plane perpendicular to the corresponding priacipal direction. Sone trentments approximate the influence of compressive stresses in the perpendicular direction on the tensile strengih. The represertation of interface shar transfer is conceptually posstble, but few groups have included this effect in anerical analyses because of scarcity of infornation about the shear stiffness properties.

There appears to be no unifornty in adopted yield functions in the analyses reported to date. Generally, these yield functions are chosen to correspond to test datn generated in the past by the group involved in the finte-element analysis. Stullarly, there is a divergence of views on the algorithas for Inelastic analyels, alchough there is a decided preference for Inttial-streas algorithes since these avold the necessity for repeated 
solution of large-scale systes of algebraic equations. Initial-strais algorithes continue to be standard in creep analysis.

As in the case of interface shear stiffaess, the proper treatwent of reinforcement, Inclisding dowel snd bond action, continues to be an open question. Although was different attents at finite-element representation of these phenonean have been ende, ineufficient PCWV experinental data are avallable to define their adequacy.

\section{5. concustons}

Concrete is a cusplex conposite enterial with a relatively low degree of chenical siability whose nicrostructure reacts to changes in temerature, water content, or stress. Fortunately, at low stress levels and quasi-constant temperatures, Its response to stress can be approximated within a reasonable degree of accuracy as a linear-viscoelastic aterial. Berause prestressed concrete pressure vessels are jestgned to operate at low stress levels, the only unresolved question pertaining to their analysis for normal operating conditions is that of resolution and/or validation of an appropriate nodel for thermal transfent conditions. However, the geometric complexity of the PCRV introduces muerical difficulties that require special attention if accurate manerical results are to be obtained.

On the other hand, the proper theoretical nodel for analysis of a PCRV under conditions of accidental overpressurtzation is not clear. All too of ten the sodels comonly used suffer from deficiencies of either a theoretical or a practical nature. The cost critical aspect pertains to wodeling of tensile cracke in plain and reinforced concrete. Of slightly less importance is the oodeling o. nonlinear and postfallure modes under compressive loading conditions. Until these problens are resolved, the results of such analyses wust ie vianed with some skepticisin. 


\section{Rarensices}

1. "The Delnarv. HTGs," Rucl. Bhg. Int. 18, 890-92 (Woveber 1973).

2. Proceedings of the Conference on Model Teohuiques for Prestressed Concrete Pressure Vessels, The British Muclear Inergy Society, London, July 1969.

3. Conference on Prestressed Concrete Pressure Vessels, The Institution of Civil Engineers, London, 1968.

4. A. H. Brown and A. J. Darton, "The Oldbury Vessels," pp. 3-11 in Conference on Prestressed Concrets Pressure Vessels, The Institction of Civil Engineers, Lundon, 1968.

5. P. C. Warnes: "The T.ungeness B Vessels," in Conference on Prestrefsed Concrpte Pressure $V_{t}-e l_{b}$, The Institution of Civil Engineers, London, 1968.

6. I. W. Hornby, G. F. Ve-don, and Y. C. Wons, "Testing the oldbury Vessel Hodel," in Conference on Prestressed Concrete Pressure Vessels, The Institution of Civil Engineers, Loodon, 1968.

i. K. F. Brading and G. Hills, "Use of Structural Hodels in Developing Pressure Vessel Des!gn," in Conference on Prestressed Concrete Pressure Vessets, The Institution of Civil Engineers, Londsn, 1968.

8. G. Lantral et al., "Pressure Veasels for Electricite de France lluclear Power Stations," pp. 29-33 in Conference on Prestressed Concrete Pressure Vesseis, The Institution of Civil Engineers, London, 1968.

9. M. LIda and R. Ausangee, "Scale Hodels for Strength Testing Nuclear Pressure Vessels," in Conference on Prestressed Concrete Pressure Vessels, The Institution of Civil Engineers, London, 1968.

10. A. L. Habush and A. M. Harris, "330-Mu(e) Fort St. Vrain High-Temperacure Gas-Cooled Reactor," Mucl. Eng. Des. 7, 312-21 (1968).

11. R. E. Walker and T. A. Johnston, "Fort Saint Vrain Nuclear Power Station," Mucl. Eng. Int. 14, 1069-73 (1969).

12. T. E. Northup and C. Pelando, "Prestressed Concrete Reactor Pressure Vessel," Mucl. Eny. Int. 14, 1682-85 (1969).

13. Y. R. Rasktd, F. S. Ople, and T. Y. Chang, "Comarison of Experimental Results witt. Response Analysis for a Hodel of a Pressure Vessel," Proc. Inst. Civil Eng. (London), Pp. 147-57 (1969); GA-9309 (Apr. 18, 1969).

14. G. E. Lockett and A. M. Kinkead, "Pressure Vessels for Heliun HighTemperature Reactors," Conference on Prestressed Concreiv Pressure Vesele, The Institution of Civil Engincers, London, 1968.

15. R. E. D. Burrow and A. J. Willians, "Hartlepool AGR Reactor Pressure Vessel," Mucl. Eng. Int. 14, $973-80$ (1969).

16. D. Langan, M. O'Plyan, and A. K. Welch, "The Design of Pod Boiler Pressure Vessels with Particular Reference to Hartlepool Nuclear Purer Station," Proceedings of the First Intermational Conference on Structural Mechanics in Reactor Techology, Vol. 4, Ber11n, 1971. 
17. C. A. Eringen, Mechonics of Continua, Wiley, New York, 1967.

18. D. H. Norrie and G. de Vries, The Finite Element Method, Acadenic Press, New York. 1973.

19. 0. C. 2tenkfericz, The Finite Element Hethod in Engineering Scienne, HeGraw-Hi11, London, 1971.

20. R. H. Gallagher, Finite Element Analysis Prondwinentals, Prentice-Hall, Er ;lewood Cilff8, N.J., 1975.

21. L. Beres, "Relationship or Deformational Processes and Structure Changes in Concrete," pp. 643-51 in Proceedings of International Conference on Structure, Solid Mechanics and Engineering Design in Civil Engineering Materials, Southanton, England, 1959, Vol. 1 HileyInterscience, London, 1971.

22. W. Rockenhauser, "Structural Design Criteria for Primary Containaent Structures," mucl. Eng. De8. 9, 449-66 (1969).

23. H. L. Langhaar, Energy Nethods in Applied Mechanic8, Hiley, Hew York, 1962.

24. S. D. Conte and C. de Boor, Elementary Brmerical Analysis: An Algrrithric Approach, McGraw-H11, New York, 1972.

25. A. D. Tuff and A. Jennings, "An Iterative Method for Large Systems of Linear Structural Equations," Int. J. Mmer. Methods Eng. 7, 175-183 (1973).

26. A. Jezernik and $A$. Leech, "The Comparison of Iterative and Direct Solution Techniques in the Analysis of Time-Dependent Stress Probleas, Including Creep, by the Finite Elewent Method," In The Mathematies of Finite Elements and Applications: Proceedings of the Brunel University Conference of the Institute of Mathematics and Its Applications, April 1972, Acadentc Press, Lcndon, 1973.

27. R. H. Clough, E. L. Wilson, and I. P. King, "Large Capacity Multistory Frane Analysis Prograns," Proc. An. Soc. Civ. Eng., J. Struct. Div. 89(ST4), 179-204 (August 1963).

28. A. M. Cohen, Monerical Analysis, Wiley, New York, 1973.

29. E. L. Wilson, Solid SAP, Structures and Materials Research Report UC SESY 71-19, University of Callfornia at Berkeley (Septenber 1971).

30. B. M. Irons, "A Froncal Solution ILogran for Pinite Elenent Analysis," Int. J. Muner. Methods Eng. 2, 5-32 (1970).

31. C. Meyer, "Solution of Linear Equations - State-of-the-Art," Proc. An. Soc. Civ. Eng., I. Struct. Div. 99(ST7), 1507-26 (1973).

32. C. Meyer, "Special Problea Related to Linear Equation Solvers," Proc. Am. Soc. Civ. Eng., J. Struct. Viv. 101(ST4), $869-90$ (1974).

33. 0. C. Zienkiewicz et al., "Finite Element Methods in the Analysis of Reactor Vesse1s," Mucl. Eng. Des. 20, 507-41 (1972).

34. 0. C. Zienkiewicz et al., "Three Dimensional stress Analysis," International Union of Theoretical and Applied Mechanics Symposiun on High Speed Computing of Elastic Structures, Llege, Belglum, 1970. 
35 J. M. Corus, "Use of Sall Hodels in Design and Analysis of Prestressed-Concrete Reactor Vessels," Mucl, Bug. Des. 16, 301-42 (1971).

36. D. C. Cornell, SAFE-3D. A Computer Progrem for the Three-Dimingional Stress Analysis of Composite Structures. A User's Manual, Report CA-7855, (February 1968).

37. G. D. T. Carnicheel, "The Application of Three-Dinensional rinite Elenents to the Analysis of Podded Boiler Type Prestressed Concrete Pressure Vessels," Mucl. Eng. Des. 16, 35-44 (1971).

38. D. Carlton, J. R. Salch, and G. M. Bellwood, "Prestressing and Proof Pressure Testing of the Whlfa Preatressed Concrete Pressure Vessels and Comparison of Measured Data with Predicted Performance," Proceedings of the First Intermational Conference on Structural Hechanics in Reactor Technology, Berlin, 1971.

39. F. Brener, "Practice with Hodel Techniques," pp. 7-13 in Proceedings 0 - Conference on Model Techriques for Prestressed Concrete Fressure Yessels, The British thuclear Energy Society, Lodon, 1969.

40. J. R. Saith, "Problems in Assessing the Correlation Between the Observed and Predicted Behavior of Models," pp. 81-89 in Eroceedings of Conference on Mode? Techiques for Prestressed Cmorete Pressure Vessels, The British Nuclear Energy Society, London, 1969.

41. T. C. Powers, "The Mature of Concrete," In Significance of Teste and Properties of Concrete and Concrete-Making Materials, ASTH, STP 159-a, 1966.

42. 2. P. Bazant, "Theory of Creep and Shrinkage in Concrete Structures: A Préc1s of Recent Developments," pp. 1-93 in Mechanics Today, Vol. 2, ed. by S. llemat-liasser, Pergaman Press, Elmoford, M.Y., 1975.

43. J. Hanson, A Ten-Year Study of rreep Properties of Concrete, U.S. Bureau of Reclanation, Concrete Laboratory Report SP-38 (July 1953).

44. A. M. Neville, Creep of Concrete: ilain, Reinforced, and Prestressed, North Holland Publishing Cospany, Ansterdan, 1970.

45. J. H. Chuang, T. H. Kennedy, and E. S. Perry, An Approach to Estimating Long-Term Multiaxiul Creep Behavior from Short-Term Uniaxial Creep Results, Department of Civil Engineering, University of Texas at Austin, Report 2864-3 (June 1970).

46. I. J. Jordaan and J. M. IIlston, "The C:eep of Sealed Concrete under Multiaxial Compressive Stresses," Mag. Concr. Res. 21(69), 195-204 (Decenber 19691 .

47. CEB-FIP (Comité Européan de Béton-Pédération Internationale de al Précontrainte), International Recommendations for the Analysis and Construction of Concrete Strustures, 2nd ed., Cenent and concrete Assoc., London, 1970.

48. American Concrete Institute Comitter 209/II, "Prediction of Creep, Shrinkage and Teaperature Effects in Concrete Structures," Designing for Effects of Creep, Shrinkage and Temperature, ACI-SP27, PP. 51-93 (1971). 
49. R. Browne, "Properties of Concrete in Reactor Veasels," Proceedings of Conferenct on Prestresced Concrete Pressure Vesento, The Instivution of Civil Engineers, Loadon, March 1967.

50. 2. P. Bazant and S. P. Wu, Dirichlet Series Creep Punction for Aging Concrete," Proc. An. Sac. Civ. Eng., J. Bng. Mech. Div. 99(E.2), 367Q (1973).

51. 2. P. Bazant and A. Asghari, "Computation of Relvin Chain Recardation Spectra of Aging Concrete," Cen. Comcr. Res. 4, 79?-006 (1976).

52. 2. P. Barant and S. T. Wh, Thate-type Creep Las of Agine concrete sased on Mawell Chain," Mater. Constr. (Paris)/Mater. Struct. 7. 45-60 (1974).

53. 2. P. Dazant and A. Asehari, "Compatation of Age-Dependent Relaxation Spectra," Cen. Concr. Res. 4, 567-70 (1974).

54. R. H. Chriatensen, Theory of Viscollasticity, an Intraduction, scedenic Press, New York, 1971.

55. J. L. Sackan, "Creep in Concrete and Concrete Structures," Proceedings of the Princeton University Conference on Solid Mechanics, Noveaber 1963.

56. M. A. Mukaddan and B. Bresler, "Behnvtor of Concrete under Variable Temperature and Loedins," Concrete for mueleor Reactors, Vol. II, Anerican Concrete Institute, Detrolt, 1972.

57. Y. E. Rashid, Monlibear Analyats of Two-Dinensional Problens in Concrete Creep," Trans. ASIE, SeT. E, J. Appi. Mech. 94, $475-12$ (1972).

58. 2. P. Bazant and S. T. Mu, "Thernoviscoelasticity of Aging Conctete," Proc. Am. Soc. Civ. Eng., J. Eng. Wech. Div. 100(1213), $575-97$ (1974).

59. 2. P. Bazent and S. T. Wu, "Creep and Shrinkage Ixy of Concrete at Variable thuidity," Proc. An. Soc. Civ. Bng., J. Eng. Mech. Div. 100 (घ16), 1183-1209 (1974).

60. H. G. Godden, "Hodel Analysle and the Design of Prestreased Concrete Kuclear Reactor Structurea," mucl. Eng. Des. 9, 400-20 (i969).

61. G. D. T. Carnicheel, I. U. Hornby, and J. Invias, "Strain Behavior of the Oldbury Concrete Prescure Veasel under Operating Pressure and Tennerature," PP. 1567-8h in Concrete for Awelear Reactors, Vol. III, SP-34, American Concrete Institute, Detroit, 1972.

62. R. D. Browne, J. P. Satch, and P. Baforch, The Perfornace of the Wyifa Muclear Pressure Vessels during Conlisetoning in Relation to Design Analysis," "aper n-4/4 in Preprinte - and Intemational Conference on Structural Newharios in Reactor Techology, Bex11n, 1973.

63. J. P. Callahan, J. H. Coru, and G. D. Whituan, "Expertental and Analytical Results for a Preseresed Concrete Renctor Vessel Model under Simulated HTCR Operatias Conditions," paper presented at The 3rd International Conference on Structural mechanics in Reactor Technology, London, 1975.

64. O. Buyukozturk, A. H. Milson, and F. O. Slace, "seress-strain Response and Practure of a Coscrete Hodel in Biaxial Lading," J. Am. Concr. Inst. 68, 590-99 (1971). 
65. M. A. Taylor and B. B. Broms, "Shear Bond Strength Between Coarse Aggregate and Cenent Paste or Mortar," $J$. Am. Concr. Inst. 61(8), 938-58 (August 1964).

66. A. Foppl, Reports from the Laboratory for Engineering Mchanics, Nos. 27 and 28, Techaischen Hochschule, Munchen, 1899 and 1900.

67. Th. von Hilsdorf, "The Experimental Detereination of the Biaxial Str.ngth of Concrete," Heft Deutacher Ausschuss fur Stahibeton, Vol. 173, Berl1a, 1965.

68. H. Kupfer, H. K. Hllsdorf, and H. Rusch, "Behavior of Concrete under Blaxial Stresses," J. Am. Concr. Inst. 66(3), 656-66 (August 1969).

69. P. Launay and H. Gachon, "Strain and Ultinate Strength of Concrete under Triaxial Stress," Paper Hi/3 in Proceedings of the First Interrational Conference on Strucutural Mechanics in Reactor Technnlog!", Berlin, 1971.

70. F. Breaer, "On a Triaxial Strength Criterion for Concrete," Paper SP-34-14, Concrete for Nuclear Reactors, Anerican Concrete Institute, 1972.

71. D. Linse, "Versuchsanlage zur Ernitrlung der Drefachsigen Festigkeit von Beton ait ersten Versuchsergebnissen," Cem. Concr. Res. 3, 445-57 (1973).

72. H. B. Kupfer and K. H. Gerstie, "Rehavior of Concrete under Biaxial Stresses," Proc. An. Soc. Civ. Eng., J. Eng. Mesh. Div. 39(EM4), 853-66 (August 19i3).

73. D. Linse, H. Aschl, and S. Stockl, "Concrete for PCRVs: Strength of Concrete under Triaxial Loading and Creep at Elevated Temperatures," Paper H1/3 in Transactions of the 3rd International Conference on Structural Mechmics in Reactor Techrolony, London 1975.

74. V. Hansson and $K$. Sihimelpfennig, "Concrete Strength in Multiaxial Stress States," pp. 295-311 in Concrete for Huclear Reactors, Vol. I, ACI SP-34 (1972).

75. K. J. Willan and E. P. Warnke, "Constitutive Model for the Triaxial Behavior of Concrete," paper presented at Scminar on Concrete Structures Subjected to Triaxial Stresses, International Association for Bridge and Structural Engineering, Bergawo, Italy, 1974.

76. D. J. Hannant and C. 0. Frederick, "Failure Criteria for Concrete in Compression," Mag. Comer. Res. 20(6'), 137-44 (September 1968).

77. L. Janda, "Triaxial State of Stress of Cuncrete Structures," Froceedings of the First Intermational Conference on structumil Mechaniss in Reactor Techology, Berlin, 1971.

78. J. H. Argyris et al., "Recent Developments in the Finite Element Analysis of Prestressed Concrete Reactor Vessels," Nucl. Eng. Des. 28, 42-75 (1974).

79. M. Fanel11, R. Riccionf, and G. Robute1, "Finfte Element Analysis of Prestressed Concrete Pressure Vesse1," IABSE Seminar on Concrete Stmuctures Subjected to Triaxial stresses, Bergamn, Italy, 1974. 
80. A. C. T. Chen and Wai-Fah Chen, "Constitutive Relations for Concrete," Prac. Am. Soc. Civ. Eng., J. Eng. Mech. Div. 101(Dit), 465-81 (1975).

81. D. Ngo and A. C. Scordelfs, "Tinite Elenent Analyses of Reinforced Concrete Beans," J. An. Concr. Inst. 64, 152-63 (1967).

82. A. H. Milson, Monilnear Analysis of Reinforced Concrete by the Finite Element Method," d. An. Concr. Inst. 65, 757-66 (1968).

83. Y. R. Rashid, "Ultinate Strength Amalyeis of Prestressed Concrete Pressure Versels," muel. Bng. Des. 7, 334-44 (1968).

84. 0. C. Zienkiewicz, S. Valliappan, ad I. P. King, "Stress Amalysis of Rock as a "No-Tension' Material," Ceotechrique 18, S6-66 (1968).

85. B. Saugy, Th. Zi mernama, and M. Huseain. "Three-Dimensionsl Rufture Annlysis of a Prestressed Concrete Pressure Vessel Including Creep Ef fects," hacl. Bng. Des. 28, 97-120 (1974).

86. J. J. Connor and Y. Sarne, Wonlinear Amalysis of Prestressed Concrete Reactor Pressure Vessels," Paper 1:2/2 in Tronsactions of the Thind Intermational Conference on Structural kechamics in Reastor Technology, London, 1975.

87. K. Neiman and J. B. Mewan, "Failure Theories and Design Criteria for Plain Concrete," pp. 963-95 in Proceedings International Conference on Structuare, Solid Mechanics, and Engineering Design in Civil Engineering Naterialo, Vol. 2, Southmpton, England, 1969.

88. Y. Yanada, H. Yoshtmura, ami T. Sakural, "Plastic Stress-Strain Matrix and Its Application for the Solution of Elastic-Plastic Problens by the Finite Elenent Method," Int. J. Mech. Sci. 10, 343-54 (1968).

89. 0. C. Zienkiewicz, S. Valliappan, and I. P. King, "Elasto-plastic Solutions of Engineering Probless. Initial-Stress, Finice Elenent Approach," Int. J. Mamer. Methods Eng. 1, 75-100 (1969).

90. 1. Takeda, Y. Yanaguchi, and K. Inoto, "Inelastic Analysis of a Miltcavity PCRV under Internal Prsesure," Paper H2/5 in Transactions of the Third Intemational Conference on itructural Mechanics in Reactor Tecionology, London, 1975.

91. M. Suldan and U. C. Schnobrich, "Finite Element Analysis of Reinforced Concrete," Prov. Am. Soc. Civ. Eng., d. Struct. Div. 99(ST10), 210922 (1973).

92. E. H. Davis, "Theories of Plasticity and the Fajlure of Soll Masses," Chap. 6 in Soil Mechanics, ed. by I. K. Lee, Butterworths, London, 1968.

93. M. D. Coon and P. J. Evans, "Increnental Constitutive Laws and Their Assoctated Pailure Criteria with Application to Plain Concrete," Int. J. Solide Stmuct. 8, 1169-83 (1972).

94. T. C. Y. Liu, A. H. Mlson, and P. O. Slote, "Biaxial Stress-Strain Relations for Corcrete," Proc. Am. Soc. Civ. Bng., d. Struct. Div. 98(STS), 1025-34, (1972).

95. 2. P. Bazant and P. Bhat, "Endochronic Theory of Inelasticity and Fallure of Concrete," Civil Engineering Dept., Northwestern University, Evanston, I11., 1975. 
96. H. S. Hirza and A. A. Muft, Mionlinenr Finite Elenent Analysis of Reinforced Coocrete Structures," Pp. 403-17 in Finite Stsment Methods in Engineering, The University of New South Wales, 1974.

97. S. Valliappan and I. F. Doolan, Moalinear Streas Analysis of Reinforced Concrete," Proc. An. Soc. Civ. Bng., J. Struct. Jiv. 98(ST4), $885-98$ (1972).

98. C. H. In and C. G. Sainon, "Finite Elenent Analysis cí Concrete Bens," Proc. Ar. Soc. Civ. Bng., J. Struct. Div. 100 (ST12), 2419-30 (Decenber 1974).

99. K. Muto et al., Monlibear Analysis of Reinforced Coscrete BuildIngs," in Theory and Prectioe in Pinite Element Stmuctural Analysis, Y. Tanada and R. Gallagher, Eds., University of Tokyo Press, 1973

100. B. Saugy and Th. 2imenam, "The Finite Elenent Hethod Applied to Massive Heterogeneons Structures," Proceedings of the Conference on Computational Aspects of the Pinite Element Mathods, Stutigart, Germay, Septesber 1971.

101. A. Scanion and D. U. Zurray, "An Analysis to Deternine the Effects of Cracking in Reinforced Concrete Slabs," pp. 841-68 in Proceedings of the Speciality Conference on Pinite Element Method in Civil Bngineering, Engineering Institute of Canade, HeGill Jniversity, June 1972.

102. J. Colville and J. Abbas1, MPlane Stress Reinforced Concrete Finite Elesents," Proc. An. Soc. Civ. Bng., J. Struct. Div., 100(STj), 106782 (May 1974).

103. O. Yuzugullu and U. C. Schnobrich, "A Wuerical Procedure for the Deternination of the Behavior of a Shear Wall Frawe Systen," J. Am. Concr. Inst. 7(70-47), 474-79 (July 1973).

104. O. C. 3ienkiewicz, D. V. Phillips, and D. R. J. Oren, "Finite Element Analysis of Some Concrete Ron-Linearities - Theory and kxamples," Proceedings of Seminar on Concrete Structuares Subjected to Triarial Stresees, Bergano, Italy, May 1974.

105. J. T. Oden, Finite Zlement of Jonlinear Contina, Pp. 279-92, McGrawH111, 1972.

106. Y. Sarne, Material Monlinear Time-Depencient Thnee-Dinensional Pinite Element Analyois of Reinforced and Prestreseed Concrete Structures, Ph.D. thesis, MT, Canbridge, 1974.

107. T. Takeda et a1., "Pressure Tests of PCDV Models," 7th FIP/PCI Intermational Conference, New York, 1974.

108. D. Drucker and W. Prager, "Snil Mechanics and Plastic Analysis on Lfeit Design," Q. AppZ. Math. 10, 157-65 (1952).

109. M. Sozen and S. I. Paul, "Structural Behavior of a Small Prestressed Concrete Reactor Vesse1," Mucl. Fing. Des. 8, 403-14 (1968).

110. Th. Zf heraan, B. Saugy, and E. Rebora, "Yailure Mode Analysis of a PCRV: Influence of Sone Hypotheses," Paper H4/3 in Traneactions of the Third Intermational Conference on Structural Meohanice in Renctor Techology, London, 1975. 
111. M. $\therefore$. Wade and R. R. Hearyood, "Experience in the Application of a Finite Element Systen to the Analysis of Complex Prestressed Concrece Pressure Vessels," Paper $\mathrm{B2} / 3$ in Tronsactions of the Third Iritermational Conference on Structumal Mecharice in Reactor Technology, Loudon, 1975.

112. M. Ottosen and S. Anderson, "Theoretical and Experinental Studies for Optinization of PCRV Top Closures," Paper 13/6 in Tronactions of the Third International Conference on Structual Mecharios in Reactor Technology, Losdon, 1975.

113. G. Ballio, A. Sastellant, and F. Finzi, "On the Design of Massive Structures for thuclear Plants," Proceedings of Seminar on Concrete Structures Sibjected to Triaxial Stress, Bergono, Italy. May 1974. 